A DTHOR'B ABSTRACT OF THIS PAPER ISSUED

BY THE BIBLIOGRAPHIC SERVICE, JANUARY 16

\title{
STUDIES IN THE GROWTH AND DIFFERENTIATION OF THE TELENCEPHALON IN MAN. THE FISSURA HIPPOCAMPI
}

\author{
MARION HINES \\ Hull Laboratory of Anatomy, University of Chicago, and The Carnegie Institution \\ of Washimgton, Laboratory of Embryology, Baltimore \\ FIFTY-ONE FIGURES \\ CON TENTS

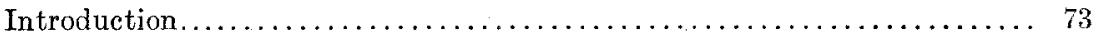

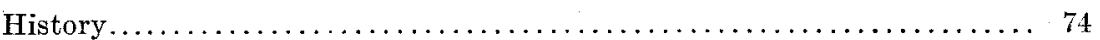 \\ Material and methods........................................ 80 \\ General morphology ....................................... 81 \\ Histological structure .................................. 104

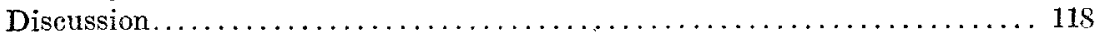 \\ Telencephalon medium................................. 118 \\ Area epithelialis....................................... 126 \\ Fascia dentata..................................... 151 \\ Hippocampus........................................ 155 \\ Fissura hippocampi.................................... 158 \\ The relation of the hippocampus to the neopallium............. 162

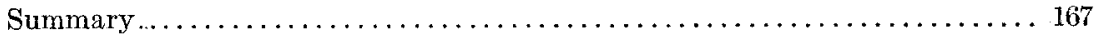 \\ Bibliography........................................ 169
}

\section{INTRODUCTION}

No question in the history of biological science has gripped the imagination of the student of living matter as much as that of growth. To understand the processes of life, the movement of growth must be studied. In the work to be presented this problem may be approached by singling out movement arrested by death and calling the morphology of its expression stages of growth. It is the interpretation of the morphological and histological changes between these so-called stages out of which the student may build a dynamic conception of growth. The first step in such an analysis is the establishment of landmarks or points from which to measure change. It is the purpose of 
this paper to establish landmarks in the growth and differentiation of the telencephalon, such that accurate measurements. of the varied components of the developing cerebral hemispheres may be taken. Such a purpose is the outcome of a consideration of the question, long a mooted one, of early telencephalic fissuration. That history is complicated by a group of uncorrelated and seemingly contradictory facts, which bear the names of the most eminent neurologists and embryologists of the latter part of the nineteenth century. The solution of that problem depends upon a more modern technique and a consideration of histological structure.

The reality of certain fissures which appeared in the medial wall of the cerebral hemispheres of the human embryo between the second and the fourth months was under debate from 1868 to 1904 . These fissures were variously named, the most important being the arched fissure (or the Bogenfurche, the fissura ammonis, the fissura hippocampi) and the fissura prima. The Bogenfurche was divided into an anterior and a posterior limb and sometimes radial folds and an arched accessory fissure were added. Are they real or are they artefacts? If they are real, why do they disappear after four and a half months and seem to play no part in the future fissuration of the medial wall? Previous investigators answered them each in his own manner. Those answers have a peculiar bearing upon the present discussion.

\section{HISTORY}

Meckel (1815) thought that fissures appeared on the medial wall which later "grew into each other, so that the surface of the brain both inside and outside again becomes smooth." Tiedemann (1816) pictured them, but did not consider them to be transitory; rather, he thought them to represent earlier conditions of permanent sulci. The study of the central nervous system remained fifty years where Tiedemann had left it. Bischoff ('68) reported these fissurations as due entirely to alcoholic fixation. However, in the next year, Ecker reported finding them in the fresh brains of mammalian embryos. Schmidt ('92) referred to these fissures as temporary furrows, but failed 
to find them in the sheep, ox, and pig. The maceration artefacts are so great in Marchand's embryos ('91, p. 312) that his description of the hintere Bogenfurche is of little value. But in treating of the vordere Bogenfurche (45-mm. embryo, figs. 1 and 2) he says that the olfactory "bulb. is separated from the substantia perforata by a transverse sulcus, which is continued on to the medial surface as the 'vordere Bogenfurche' (incisura prima)." In 1909, although he had recognized the radial folds as artefacts, Marchand nevertheless described a slight indentation (in the fourth month) which extended from the tip of the temporal pole to the region just anterior to the lamina terminalis.

The following year Cunningham ('92) defined the fissures in question as "a series of furrows which radiate in a stellate manner from the fissura arcuata (Bogenfurche) toward the free border of the hemisphere." He believed that "the influence at work in calling the infolding of the cerebral wall into existence appears to be a purely mechanical one, viz., a restraint placed upon the longitudinal growth of the hemisphere; and this being the case it is easy to understand how the number and depth of the fissures will vary with the degree and kind of restraint which is applied" (p. 14). As to their obliteration, he thought that as the cerebral vesicle thickens and the hemisphere elongates, the stellate fissures become detached one by one from the previous arcuata. "In all cases, however, the posterior hippocampal portion is preserved in situ" (p. 16). The anterior part is obliterated at the time of the disappearance of the radial folds. He suggested, as did Anton ('86), that the disappearance of the transitory fissures has some connection with the appearance of the corpus callosum. He cites several cases of radial fissuration in the brains of Macropus and Halamaturus in which the corpus callosum is rudimentary, and a few instances of congenital absence of the corpus callosum in man. In these brains the radial appearance of fissuration is evident.

In 1898 Hochstetter reported that he could produce the fissuration under discussion by waiting several hours after the death of young fetuses before fixing them. Six years later he challenged His to meet him in Jena. But His could not come. Hochstetter 
demonstrated his preparations without a dissenting voice. Those preparations consisted of three embryos, a $13.6 \mathrm{~mm}$., a three months fetus of $50 \mathrm{~mm}$. C. R., and a model of a $19.4 \mathrm{~mm}$. C. R. There was no fissura arcuata in any of these specimens. However, he noted in well-preserved brains, two to four months old, "a slight trough-like invagination of the medial hemisphere wall" (p. 31), but could not identify an arched fissure. Moreover, in speaking of a sixteen-week embryo (p. 33), he says that he can find no trace of the posterior arched fissure, but that the primordium of the pes hippocampi is visible, not as an infolding of the brain wall, but rather as a thickening at that point.

At this meeting Schaper demonstrated the fissureless condition of the medial wall in the two embryos $10.5 \mathrm{~cm}$. and $4.6 \mathrm{~cm}$. Further, he pointed out an insignificant invagination in the region of His' anterior arched fissure in the Hochstetter fetus of $49 \mathrm{~mm}$. The discussion must have attained some warmth or Fick would not have advised that the term fissure be stricken out of embryological terminology. It is difficult to imagine the necessity of calming a morphologist.

Goldstein ('04) described upon the smooth surface of the medial wall "at the point where the anterior arcuate fissure should be sought, a well defined sulcus which extends approximately vertically from the insertion of the olfactory bulb and which His considers the equivalent of his 'Bogenfurche" (p. 581). This is the fissura prima, and not the true fissura arcuata. For him, the ventricular aspect of the cortex is little disturbed. The broadening and deepening is not an expression of an infolding, but rather a condition of nervous differentiation of the outer level (p. 582). Comparing the posterior arched fissure or the fissura hippocampi with His' figure 86 , he says that the fissure is not as deep as that of His; the outer cortex describes only an arched line so that a slight indentation can be seen (p. 586).

In $1901 \mathrm{~J}$. Symington reported at a meeting of the British Association for the Advancement of Science that the frequency and depth of the temporary fissures had been exaggerated, but that they occurred in well-preserved material. Although the arcuate fissure was not a product of fixation, it could have no 
morphological significance and was in no way related to the hippocampal fissure. In one brain he was able to trace the hippocampal formation from the region of the temporal pole to that of the developing transverse commissures. He further called attention to the fact, formerly supported by comparative anatomy alone, that the gray and white formation above the corpus callosum in the adult human brain is the remains of a hippocampal formation.

Mall ('03) examined some fifty brains in his collection. He found that those fixed in alcohol or in weak formalin showed fissures on the medial wall, while those fixed in strong formalin showed no such structures. He concludes "according to the experience of Hochstetter, Retzius and myself, the transitory fissures are not found in fresh brains. They are therefore artefacts and of no morphological significance."

G. Elliot Smith ('03, p. 217) says: "Two kinds of so-called 'transitory fissures' have been described in the fetal human brain. There is the group of irregular puckerings of the neopallium, which are found in those fetuses of the 3rd and 4th months in which putrefaction changes have begun; and there is a second group which are found in fetuses of the 5th, 6th and 7 th months. It is quite unnecessary to discuss the first group, because their true nature as postmortem wrinklings of the neopallium has been conclusively demonstrated by Hochstetter, and the results of the examination of all known fresh fetuses of the third and fourth months amply confirm the results obtained by Hochstetter's researches."

The heat of the discussion centered around His. But in no instance did he describe the radial folds of Cunningham and the earlier workers. His findings may be compared to those of Retzius ('01), although they share neither the terminology nor the interpretation. In the young embryos (His, '04, fig. 40, embryo C. R. $13.6 \mathrm{~mm}$.) he describes the fissura prima, the anterior and posterior arched fissures and the fissura rhinalis; in later embryos, he adds the fissura arcuata accessoria and the fissura calcarina. The fissura rhinalis and fissura calcarina are permanent and morphologically significant structures. The 
fissura prima is the result of the separation of the olfactory lobe, or the anterior smell brain, on the medial side through a medial continuation of the lateral fissura rhinica (p. 76). This fissure does not extend to the lamina terminalis. It remains in the adult as the fissura parolfactoria posterior of the B. N. A. The posterior arched fissura or the fissura hippocampi is a reality because it contains a characteristic structure in no wise connected with postmortem changes. The fissura arcuata accessoria lies above the hippocampal in His' published models. He fails to state whether or not there is any characteristic histological structure present in its depth.

Retzius ('01, p. 92) says that, although the lateral hemisphere wall is smooth, there is a broad sagittally placed furrow or indenture, in the medial wall forming a hillock, which butts into the ventricle. A year later (p. 66) he says the same in regard to the matter.

Such is the history of the transitory fissuration in the human telencephalic vesicle. But what of lower animals? Only two workers have identified structures similar to the findings of Goldstein, Retzius, and His; they are Martin and Grönberg.

Martin ('94) was able to identify the anterior arched fissure in a transverse series of cat embryos, $1.3 \mathrm{~cm}$. in length (p. 224). It appeared later than the fissura chorioidea $(0.9 \mathrm{~cm}$.). In the cat, the anterior arched fissure resembles the fissure pictured by His (pl. I, fig. 8, '90). The posterior arched fissure appears as a secondary arched fissure $(2.2 \mathrm{~cm} ., \mathrm{p} .226)$. The union (at $5 \mathrm{~cm}$.) of the anterior and posterior fissures with the 'seitlichen Balkenfurche' (i.e., the sulcus fimbrio-dentatus) he considers to be the future fissure of the corpus callosum (p. 242). This fissure maintains the same relationship to the pallial commissure as the sulcus corporis callosi of the rat (Johnston, '13, fig. 59).

The same sequence of fissuration was followed by Grönberg ('01) in the brain of the hedgehog. The choroid fissure appears in the 11-mm. embryo and the arched fissure in the $15-\mathrm{mm}$. In figure 54 the inner wall is evidently thickened and forms a slight bulging into the lumen of the ventricle. 
This is the first primordium of the hippocampus. The thickening of the wall is limited exactly to the middle part of the groove while the wall retains its original thickness at the transition in the choroid fissure and in the outer mantle, the inner edge forms in cross section a stronger band than the outer . . . (p. 280). The fissura ammonis is not the result of a gradual infolding, but rather is to be considered a secondary formation in the outer layer of the thickened wall

(p. 281). If the series is followed through one finds that the fold, if we can give the groove this name, is more accentuated in the posterior portion than in the anterior. A division into two origins, an anterior and a posterior, as His described in the human embryo ('89), I have not been able to confirm (p. 282).

The history of the fissuration on the medial wall of the telencephalon of man, during the second, third, and fourth months, falls naturally into the following subdivisions:

1. Fissuration is an artefact and therefore of no morphological significance.

2. Fissuration is not an artefact. It is accompanied by characteristic histological structure: $a$, without future significance; $b$, with future significance.

If these contradictory statements are true, there is a possible resolution. The solution found rests almost entirely upon a consideration of histological structure and a correlation of development of the tissue in question. To follow the region which lies in the fissura arcuata of His from its earliest differentiation as a tissue distinct from the remainder of the vesicle to its ultimate destiny is the purpose of the present paper. This analysis will give the first point of departure in studying the development of the forebrain as a growing tissue with the hope that at some future time the interrelationship of its various parts may be expressed mathematically.

During the progress of this research I have sought constantly the aid and advice of Dr. G. W. Bartelmez, and depended largely upon the manifold suggestion and the critical judgment of Dr. C. Judson Herrick. Without them it would have been impossible to begin or carry to completion this piece of work. I am happy also to acknowledge the debt I owe Dr. R. R. Bensley, not for aid in this particular problem, but for the scientific training I possess. Further, I wish to acknowledge the use of material 
belonging to the Carnegie Institution, Laboratory of Embryology, Baltimore; the kindly interest of the late Dr. Franklin P. Mall and that of Dr. George L. Streeter. Also thanks are due Mr. A. B. Streedain and Miss Marian Manly, of Chicago, for the drawings, to Miss Phelps, of Baltimore, for the microphotographs of the embryos belonging to the Carnegie Collection, and to Mr. Ralph Witherow, for drawings of models of those embryos. And I cannot neglect to acknowledge the debt I owe M. L. Fyffe for an interest, long sustained, in the outcome of this contribution.

\section{MATERIAL AND METHODS}

This contribution is based upon a study of human material belonging to the Embryological Collections of the Department of Anatomy, University of Chicago, and of the Carnegie Institution, Laboratory of Embryology, Baltimore. Fnr the elaboration of the technique used in handling human embryos, the Department at Chicago is indebted to Dr. G. W. Bartelmez. The details of this technique are given by Bailey ('16). There is no better human material than that belonging to the Carnegie Laboratory. Doctor Mall was able to secure the cooperation of clinicians so that the preservation of the embryos studied was the best our present technique can secure. Wax models of the brains studied at Chicago were made, while those belonging to the Carnegie were plaster casts poured by Mr. Heard. All these models have been checked many times with either the photographs or the outline projection of the brains in question, so that the writer believes them to be as accurate as our present methods allow.

The embryos studied may be grouped as set forth in table 1 .

Besides these embryos the following were examined, although their various olfactory centers were not plotted. In all of them the same areas with the same histological differentiation were found (table 2). 


\section{GENERAL MORPHOLOGY}

The 11.8-mm. embryo, Mall Collection, 1121 (figs. 7, 8, 9, 11)

So far as the nervous system is concerned, this embryo lies between the 6.9-mm. embryo of His (Br.) and his embryo C. R. (13.6 mm. N. L.). It is a thin-walled tube easily divided into

TABLE 1

Embryos described in this contribution

\begin{tabular}{|c|c|c|c|c|c|c|}
\hline NUMBER & $\begin{array}{l}\text { GREAT EST } \\
\text { LENGTH }\end{array}$ & COLLECTION & CONDITION & SOURCE & FIXATION & $\begin{array}{l}\text { THrCK- } \\
\text { NESS }\end{array}$ \\
\hline & $\mathrm{mm}$. & & & & & $\mu$ \\
\hline 1121 & 11.8 & Mall & Good & Abortion & $\begin{array}{l}\text { Corrosive sub- } \\
\text { limate }\end{array}$ & 40 \\
\hline 940 & $\begin{array}{c}14.0 \\
(10.0 \\
\text { in alc. })\end{array}$ & Mall & Excellent & Abortion & Formalin & 40 \\
\hline H173 & 19.1 & Chreagu & Excellent & Abortion & $\begin{array}{l}\text { Formalin- } \\
\text { Zenker }\end{array}$ & 10 \\
\hline 460 & $\begin{array}{l}21.0 \\
(20.0 \\
\text { in alc. })\end{array}$ & Mall & Excellent & Abortion & $\begin{array}{c}\text { Sublimate- } \\
\text { acetic }\end{array}$ & 40 \\
\hline $\mathrm{H} 91$ & $\begin{array}{l}27.8 \\
\text { in for- } \\
\text { malin. }\end{array}$ & Chicago & Fair & Abortion & $\begin{array}{l}10 \text { per cent } \\
\text { formalin }\end{array}$ & 20 \\
\hline $\mathrm{H} 41$ & $\begin{array}{l}32.1 \\
\text { in for- } \\
\text { malin. }\end{array}$ & Chicago & Fair & Abortion & $\begin{array}{l}10 \text { per cent } \\
\text { formalin }\end{array}$ & 20 \\
\hline H163 & 39.1 & Chicago & Excellent & $\begin{array}{l}\text { Operation for } \\
\text { fibroids }\end{array}$ & $\begin{array}{l}\text { Formalin- } \\
\text { Zenker }\end{array}$ & 20 \\
\hline 886 & 43.0 & Mall & Excellent & Operation & $\begin{array}{l}10 \text { per cent for- } \\
\text { malin and } \\
\text { Bowen's } \\
\text { fluid }\end{array}$ & 100 \\
\hline
\end{tabular}

the five brain vesicles of $\mathrm{v}$. Baer. The roof plate is thin in the telencephalon and myelencephalon, but not noticeably so in the diencephalon and mesencephalon. The floor plate is beginning to show its characteristic thickenings. The floor of the fourth ventricle is long, broad, and shallow. The lateral recess is not present. There is no evidence of any increase in thickness of its anterior lip. There is an insignificant groove in the floor 
of the fourth ventricle, continuous with a deeper groove in the wall of the cord and of the mesencephalon. This is the sulcus limitans fig. 8, (Sul. lim.). The part of the mesencephalon which

TABLE 2

Other embryos consulted for this contribution

\begin{tabular}{|c|c|c|c|c|c|}
\hline NUMBER & $\begin{array}{l}\text { GREATEETT } \\
\text { LENGTH }\end{array}$ & COLlection & PLANE OF SECTION & THICKNEss & CONDition \\
\hline & $m m$. & & & $\mu$ & \\
\hline 163 & 9.0 & Mall & Transverse & 20 & Excellent \\
\hline H566 & 11.6 & Chicago & Transverse & $15^{\circ}$ & Excellent \\
\hline H 4 & 13.7. & Chicago & Transverse & 10 & Poor \\
\hline H398 & 14.5 & Chicago & Horizontal & 25 & Excellent \\
\hline 719 & 15.0 & Mall & Transverse & 40 & Fair \\
\hline H 5 & 16.0 & Chicago & Transverse & 15 & Poor \\
\hline $\mathrm{H} 465$ & 16.0 & Chicago & Transverse & 15 & Good \\
\hline 317 & 16.0 & Mall & Coronal & 20 & Grood \\
\hline 406 & 16.0 & Mall & Sagittal & 20 & Good \\
\hline 492 & 16.0 & Mall & Coronal & 40 & Excellent \\
\hline H516 & 17.0 & Chicago & Transverse & 15 & Grood \\
\hline 576 & 17.0 & Mall & Sagittal & 15 and 20 & Excellent \\
\hline 1390 & 18.0 & Mall & Sagittal & 25 & Good \\
\hline 432 & 18.5 & Mall & Sagittal & 20 & Good \\
\hline 431 & 19.0 & Mall & Sagittal & 20 & Good \\
\hline $\mathrm{H} 202$ & 20.2 & Chicago & Horizontal & 25 & Fair \\
\hline H 19 & 20.6 & Chicago & Transverse & 20 & Fair \\
\hline 840 & 24.8 & Mall & 'Transverse & 50 & Good \\
\hline 455 & 24.0 & Mall & Transverse & 20 & Good \\
\hline 632 & 24.0 & Mall & Sagittal & 40 & Fair \\
\hline H 39 & 25.0 & Chicago & Transverse & 25 & Fair \\
\hline 405 & 26.0 & Mall & Sagittal & 40 & Good \\
\hline 1008 & 26.4 & Mall & Sagittal & 40 & Excellent \\
\hline H 50 & 29.2 & Chicago & Transverse & 25 & Fair \\
\hline 878 & 36.0 & Mall & Sagittal & 100 & Good \\
\hline H 98 & 38.4 & Chicago & Horizontal & 25 & Fair \\
\hline 448 & 52.0 & Mall & Sagittal & & Good \\
\hline 267 & 59.0 & Mall & Sagittal & & Good \\
\hline H 44 & 60.0 & Chicago & Transverse & 25 & Fair \\
\hline
\end{tabular}

lies dorsal to this sulcus is thin and expanded. The part which lies ventrally foretells the future thickening of the mesencephalic floor. This ventricular groove passes through the diencephalon and seems to lose itself in the vicinity of the cavity of the optic 
evagination (Rec. op.). Immediately dorsal to this groove in the diencephalon lies another, here termed sulcus dorsalis (fig. 8, Sul. dors.), which to all appearances arises from the sulcus limitans rostral to the meso-diencephalic boundary. Further forward the sulcus limitans and the sulcus dorsalis fade out in the thalamic wall, dorsal and anterior to the optic ventricle.

These two sulci divide the diencephalon into three regions: a large dorsal region, an insignificant central region, here termed the midthalamic region, and a large ventral region, the hypothalamus. The first or epithalamus is bounded rostrally by the velum transversum (fig. 8 , Vel. trans.), dorsally by a thin ependymal roof (fig. 8, Dien. r. pl.), and the epiphyseal evagination (fig. 8,Ep.ev.). The floor of the hypothalamus contains the shallow mammillary recess (fig. 8, Corp. mam.), the broad infundibular area (fig. 8, Inf.), and the bed of the optic chiasma (fig. 8,F.b.op. ch.). The infundibulum can be identified as that area to which the anlage of the anterior lobe of the hypophysis clings (fig. 8, Ant. l. hyp.).

The midline of the telencephalic roof is only a little lower than the two lateral vaults of the hemispheres. Consequently the foramen interventriculare (fig. 8, For. int.) is only a little smaller than the entire cavity of the whole evagination. The only point of constriction lies in the most dorsal part of the ditelencephalic groove, the region of the velum transversum (fig. 8, Vel. trans.).

Following the midline structure forward from the velum transversum, it remains membranous as far as the massive lamina terminalis (fig. 8, Lam. term.), below which a slight constriction marks the preoptic recess (fig. 8, Rec. preop.). Next comes the chiasma ridge (fig. $8, F . b . o p$. ch.) at the di-telencephalic junction. The corpus striatum is barely visible as a slight ventricular eminence in the floor of the interventricular foramen.

The 14-mm. embryo, Mall Collection, 940 (figs. 10, 12, 13, 14)

A difference of only $2.2 \mathrm{~mm}$. between this embryo and no. 1121 has wrought a marked change in the growth of the central 
nervous system. The basal plate of the cord has grown much thicker. The pontile flexure is evident, but not as accentuated as His pictured for the $10.6-\mathrm{mm}$. in his collection; nor is the floor plate of the medulla oblongata as he showed it, The lateral recess has appeared. There is no indication of a cerebellar thickening in the superior lip of that recess. The midbrain is not as prominent a feature of the morphology of this brain, due in part to the acceleration in growth of the diencephalon. The mesencephalon is separated from the rhombencephalon by a marked constriction of the total brain tube, the isthmus. In the 14-mm. embryo the transition from midbrain to the diencephalon is marked off distinctly in the midline by a sudden dip in the vault. The diencephalic portion of the invagination is the posterior limb of the epiphyseal evagination. The basal plate of the midbrain has grown toward the lumen of the rentricles.

The diencephalon is divided into three parts, comparable to those described for the thalamic region of the 11.8-mm. embryo, by the sulcus limitans below and the dorsal sulcus above. The absolute distance between the dorsal sulcus (fig. 14, Sul. dors.) and the sulcus limitans (fig. 14, Sul. lim.) is greater here than in the younger embryo, but the tissue dorsal to this ridge and that ventral to the sulcus limitans has changed little. Above the dorsal sulcus is a well defined ridge which is still more clearly marked in the 19.1-mm. embryo (fig. 15). The diencephalic roof plate is longer, measuring the distance from the velum transversum (fig. 14, Vel. trans.) to the epiphyseal evagination (fig. 14, Ep. ev.). The definitive regions of the floor are already outlined. The wall of the recessus mamillaris is not as shallow as that of the 11.8-mm. embryo. The recessus infundibuli is now a definite well in the floor, dipping down into the solid stalk of the posterior lobe of the hypophysis. The bed of the optic chiașma has increased in breadth and thickness. The preoptic and postoptic recesses are actual cavities in the hypothalamic floor. The sulcus limitans ends blindly dorso-caudal to the optic ventricle. 
The ventricular communication between the diencephalon and the telencephalon has suffered a tremendous change in its contour. Now, for the first time, the future relationships are determined. The dorsal and terminal boundaries of the foramen interventriculare are no longer an arc of a circle, although they are not as yet roof and terminus meeting each other in an angle as described for H173. Instead of the smooth ventricular ditelencephalic union, that junction is marked by a slight eminence, which is continued forward into the floor of the cerebral hemisphere, the corpus striatum (fig. 14, Corp. str.).

The point of entrance of the fila olfactoria (fig. 14, Fil. olf.) into the cerebral hemisphere enables us to locate the region of the future olfactory bulb evagination.

The telencephalic vesicle itself extends far beyond the midline, anteriorly and dorsally. Consequently, the great longitudinal fissure now divides the telencephalon into two parts, the cerebral hemispheres, with a small residual telencephalon medium between.

In the 14-mm. embryo the differentiation of the telencephalon medium and adjacent parts of the cerebral hemisphere has advanced to the point where most of the morphologically significant regions can be delineated. In the following paragraphs these will be described and defined,

The telencephalon medium lying between the velum transversum and the preoptic recess (fig. 14) may be divided into dorsal and ventral moieties, the area chorioidea $(A . c h$.) and the lamina terminalis (Lam. term.), each of which is again subdivided into two parts. The lamina terminalis ventrally is thick and massive (pars crassa, p. c.) and dorsally is a thin epithelium (pars tenuis, $p . t$.). In the course of development the massive part enlarges dorsalward at the expense of the thin part. The area chorioidea consists of two morphologically distinct portions, the tela chorioidea telencephali medii ( Tel. $\mathrm{ch}$. tel. med.) anteriorly and the paraphyseal arch (Par. ar.) posteriorly. In this brain, it is impossible to draw the dividing line between the tela chorioidea telencephali medii and the lamina 
terminalis by the angulus terminalis, as it can be done in the telencephalic roof plate of $\mathrm{H} 173$ (fig. 16, Ang. term). ${ }^{1}$

The peculiar shape of the paraphyseal arch is more clearly delineated in the 19.1-mm. embryo (figs. 15,16). It presents the form of a sharply elevated longitudinal ridge which here forms the floor of the great longitudinal fissure between the two cerebral hemispheres and the roof of the interventricular foramen. Posteriorly it is abruptly terminated by the telencephalic limb of the velum transversum ( $\mathrm{Vel}$. trans). Anteriorly it merges gradually with the tela chorioidea telencephali medii. The lateral border passes over at a sharp angle into the medial wall of the evaginated cerebral hemisphere (see the cross-sections, figs. 24, 25, 27). That portion of the hemisphere wall which lies contiguous to the paraphyseal arch in later stages forms the anterior limb of the lateral choroid plexus (see beyond, p. 87).

The tela chorioidea telencephali medii is of variable length at different ages. It is defined as that portion of the telencephalon medium which lies between the angulus terminalis (fig. 16, Ang. term.) and the paraphyseal arch. The choroid plexus is never developed in the contiguous portion of the medial wall of the cerebral hemisphere.

The structures which have just been considered all belong in the telencephalon medium. In the adjoining part of the cerebral hemisphere there are two structurally distinct regions, ventrally the massive subcortical olfactory centers of the septum, and dorsally a thin area epithelialis. The area epithelialis in the 14-mm. embryo is structurally uniform throughout its extent, but morphologically it comprises two very distinct regions. The portion ventrally of the angulus terminalis and adjacent to the membranous part of the lamina terminalis is part of the septum

1 This term is a modification of His' angulus praethalamicus. Judging from figures 44 and 45 ('04), His refers to a sharp change in the direction of the midline. This angle is probably the same as that described in this paper, although it is not the anterior margin of the midthalamus region. He says that the closing plate of the medial hemisphere wall passes over at a sharp angle into the medial thalamic wall. This point may be called the angulus praethalamicus; beside it begins the margin of transition of the thalamic wall into the hemisphere wall, i.e.. the margo thalamicus of the latter (p. 66), 
(ventro-medial sector of the hemisphere, p. 107) and resembles in form and morphology the septum ependymale of the amphibian brain (fig. 14, Sept. epen.). Almost the whole of this portion ultimately is thickened by intrinsic differentiation of neuroblasts.

The portion of the area epithelialis lying above the angulus terminalis is permanently membranous. Its ventral border is continuous with the septum ependymale, from which at this age it is not structurally distinguishable. Medially it is bounded by the area chorioidea of the telencephalon medium, and dorsally and laterally by the sulcus limitans hippocampi and primordial

TABLE 3

Telencephalic structures in and near the midplane

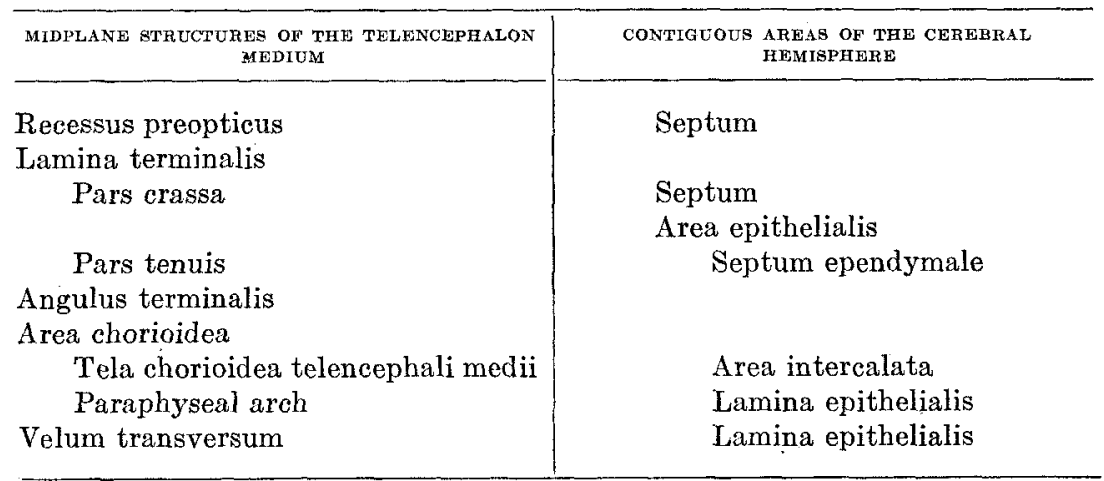

hippocampus. It extends backward beyond the velum transversum toward the occipital part of the hemisphere (figs. 12 and $14, A . e p$.$) , and in later stages it follows the ventral border of$ the hippocampal formation as far as the tip of the temporal lobe (figs. 17, 18, 20).

In the light of future differentiation, the entire area epithelialis may be further subdivided into: 1) the septum ependymale, already referred to; 2 ) the area intercalata (fig. 14, A. int.) lying contiguous with the tela chorioidea telencephali medii (fig. 14, Tel. ch. tel. med.) within which choroid plexus is never developed; 3) the lamina epithelialis (Lam. ep.) lying opposite to the paraphyseal arch and the di-telencephalic junction and in later stages 
extended backward beyond this junction accompanying the differentiation of the hippocampal formation in the temporal lobe (figs. 16, 18). The whole of the lamina epithelialis of these embryos becomes the lamina epithelialis of the adult lateral choroid plexus. The relations above described are expressed in the accompanying table 3 .

The morphological changes noted here in comparison with the $11.8-\mathrm{mm}$. embryo are as follows:

1. The appearance of the pontile flexure and the lateral recess.

2. The marked medial growth of the basal plates in the mesencephalon.

3. Slight advance in the delimitation of hypothalamic structures and more marked increase in the thalamic region lying between the sulcus limitans and the sulcus dorsalis.

4. Change in the angle of the vault above the foramen interventriculare.

5. Marked growth in the telencephalon, i.e., increase in size of the cerebral hemispheres, 1) by dorsal, caudal, and rostral growth, and, 2) by appearance of the corpus striatum as a ridge in the floor of the lateral ventricle.

The 19.1-mm. embryo, University of Chicago, H 173 (figs. 15 and 16)

The whole of this brain was not modeled, but from the sections it is evident that the development of both the basal plate and the ganglia of the cord is precocious. The processes of development, already described in the medulla oblongata, have proceeded with a slight shifting of relative morphology only. The floor plate has maintained a progressive thickening. The depth of the lateral recess has increased. The primordium of the cerebellum has appeared in the dorsal lip of the lateral recess. The midbrain has grown medially by a ventricular extension of the basal plate, while the roof plate and the alar plate have increased in thickness.

In this embryo, as in the 14-mm., the changes in the contour of the thalamus and telencephalon are most marked. The two ventricular markings, namely, the sulcus limitans and the dorsal 
sulcus, separate the thalamic wall into three parts. The distance between the pronounced dorsal sulcus and the sulcus limitans has increased both absolutely and relatively, so that this middle portion of the thalamus is becoming the most extensive of the three divisions. The anterior extension of the sulcus limitans cannot be traced to the neighborhood of the optic evagination. A new ventricular sulcus has made its appearance. It lies between the medial limb of the corpus striatum and hypothalamus, arising in the recessus preopticus (fig. 16, Rec. preop.) and loosing itself in the floor of the foramen interventriculare (fig. 16, For. int.). Immediately dorso-caudal to this sulcus lies the midregion of the thalamus, which now forms the posterior boundary of the foramen (fig. 15). The dorsal boundary of this midthalamic division can be followed rostrally to the region of the velum transversum.

However, in the younger stage, the 14-mm. embryo (fig. 13), the posterior boundary of the foramen is here formed by the velum transversum, whose diencephalic limb is continuous with the epithalamus, and its floor is formed by the corpus striatum.

In the epithalamus the epiphyseal evagination is more constricted. The roof of the whole is a little thicker. In the hypothalamus the infundibular recess is wide and the posterior lobe is not constricted. The floor and the walls have increased in thickness. In the midline the bed for the optic chiasma has increased in volume by growth, not only antero-posteriorly, but also dorso-ventrally. This region is separated from the massive portion (fig. 16, P.c.) of the lamina terminalis by a deep groove, the recess preopticus (fig. 16, Rec. preop.).

In the picture of this model (fig. 16) the most striking aspect of the telencephalon medium lying between this recess and the velum transversum is the sharp angle in the midline. This angle, the angulus terminalis (fig. 16, Ang.term.), was commented upon in the description of the 14-mm. embryo. Here the anterior boundary of the telencephalic midline suddenly changes its direction and becomes the vaulted roof of the foramen interventriculare. Is this angle a landmark? Can it be used as a fixed point from which to measure change? Further, can it be used as a 
fixed point from which to measure the growth of contiguous structures? One thing is certain, it breaks the midline into two divisions, a ventral and a dorsal, whose ultimate outcome in development is characteristic. The ventral limb is thicker than the dorsal limb. It is the lamina terminalis.

In figure $14(14 \mathrm{~mm}$.) the dorsal part, or pars tenuis (p.t.), of the lamina terminalis is much longer than the ventral or massive part (p.c.); but in figure $16(19.1 \mathrm{~mm}$.) these two parts are approximately the same in length. The former subdivision has been called by Johnston ('13) the lamina supraneuroporica. It is a convenient name. The writer would like to use it, but there seems to be no evidence for as complete a separation between the two portions of the terminal plate as Johnston thinks; and, since the last point of closure of the neural tube may lie anywhere, for aught we know, between the recessus preopticus and the velum transversum, it cannot be used to divide the lamina into two morphologically distinct regions. At present the writer thinks there is no fundamental difference in the later stages between the ventral and the dorsal portions of this area, either in development or internal structure.

The dorsal limb of the angulus terminalis (fig. 16, Ang.term.) is divided into two regions, the anterior that of the tela chorioidea telencephali medii (fig. 16, Tel. ch. tel. med.) and the posterior, that of the paraphyseal arch (fig. 16, Par. ar.). Extending lateraily into the two ventricles from this arch are the two lateral choroid plexuses. These plexuses are connected across the midline by the vault (here the paraphyseal arch) of the foramen interventriculare (fig. 16), but are not connected posterior to the velum transversum. Here they form a broad shallow fissure in the medial wall, known as the fissura chorioidea. Bailey ('16a) has called this the posterior limb of the plexus and that adjoining the paraphyseal arch, the anterior limb.

Moreover, dorsal to this fissure in the medial wall of the hemisphere and extending more rostrally is a shallow groove. This groove can be followed as an indentation in the medial wall from a region slightly anterior to the angulus terminalis, caudalward to the tip of the temporal pole. This insignificant furrow 
is the fissura hippocampi (see groove, fig. 15) and coincides in extent with the stippled area in figure 16.

The greatest change in the di-telencephalon relationship is the ventricular growth in the medial limb of the corpus striatum (figs. 15, 29, and 32). Looking into the cavity of the telencephalic vesicle, several typical markings may be seen. In the lateroventral sector lies a depression, which divides the nucleus caudatus into a medial and lateral limb. The lateral hillock is a small and insignificant ventricular ridge; the medial, much larger than the lateral, lies in the ventro-medial part of the ventral sector, just lateral to a deep groove which separates the corpus striatum from the septal region. This medial limb of the corpus striatum is most evident from the ventricular aspect of the di-telencephalic union. The septal region which composes the ventral portion of the medial wall ventral to the angulus terminalis and anterior to the lamina terminalis is separated from this portion of the corpus striatum by a deep groove, called by Herrick ('10) in Amblystoma and other vertebrates the angulus ventralis (fig. 31, Ang. ven.). Further dorsalward in the medial wall of the hemisphere a slight ventricular ridge can be followed, from the base of the beginning olfactory evagination to the caudal pole. This is the hillock made on the ventricular surface by the fissura hippocampi. This ridge is limited ventrally by a sharp turn in the tissue wall, a deep, well-marked sulcus, which will be called the sulcus limitans hippocampi (figs. 16, 29 to 31, Sul. vent.). Ventral to this sulcus and caudal to the anterior limb of the paraphyseal arch lies the massive choroid invagination. Rostral to this portion of the paraphyseal arch, the medial wall ventral to the sulcus limitans hippocampi is very thin epithelial tissue, the area epithelialis (figs. 16, 31, A. ep.).

The outer contour of the telencephalic vesicle is undergoing a change, marked not only by growth rostral to the lamina terminalis region, but also now by a seeming swing of the most dorsal portion of the outer di-telencephalic junction caudo-ventrally. This junction lies ventral to the dorsal thalamic sulcus, which divides the midthalamus from its dorsal region. 'This relationship of the diencephalon to the telencephalon upon the outer 
brain surface is foreshadowed in the structure of embryo no. 940.

The morphological changes found in this embryo as compared with the 14-mm. embryo are as follows:

1. Acceleration of the neopallium and appearance of temporal pole.

2. Appearance of the fissura hippocampi.

3. The invagination of the lamina epithelialis, forming the lateral choroid plexus.

4. Increase in length of the lamina terminalis, and the appearance of the angulus terminalis.

5 . The acceleration of the medial component of the caudate complex.

6. Great growth of the midthalamic region.

The 20-mm. embryo, Mall Collection, 460 (fig. 17)

The development of the central nervous system as a whole is practically identical with that attained by $\mathrm{H} 173$, the $19.1-\mathrm{mm}$. embryo (compare figs. 15 and 16 with 17). In this case also only the telencephalon and part of the diencephalon was modeled. Consequently, the morphological description must be confined especially to the growth of the forebrain vesicle.

The relation of structures in the telencephalon medium are the same as those found in $\mathrm{H} \mathrm{173.} \mathrm{The} \mathrm{angulus} \mathrm{terminalis} \mathrm{is}$ essentially the same. And as noted before, the lamina terminalis is divided into two regions. The diencephalic limb of the velum transversum forms a small elevation which marks the posterior boundary of the foramen interventriculare (fig. 17, For. int.). The anterior extremity of the sulcus limitans coincides with the sulcus which divides the corpus striatal complex from the hypothalamus. This rostral end of the limitans was called sulcus Monroi by His. Milhalkovies, quoting Richert, however, includes in the sulcus Monroi not only the rostral end of the sulcus limitans, but also the sulcus separating the medial limb of the striatal complex from the diencephalon. 
In the telencephalon itself there is little change. The embryonic fissura hippocampi (lying in the stippled area, fig. 17) extends from the region dorsal to the olfactory bulb (fig. 17, olf. $b u l b)$ to the tip of the temporal pole. The greatest difference in the growth between this brain and that of the 19.1-mm. embryo is in the appearance of neopallium on the medial wall of the definitive occipital pole.

In the floor of the lateral ventricle two hillocks lie side by side, separated by a shallow sulcus. The lateral hillock, much larger in this embryo than in $\mathrm{H} 173$, is the lateral limb of the caudate complex. A sulcus separates the medial hillock (figs. 17, 35, and 36, Cor. str. med.) from the thalamus. This groove runs up and over the floor of the foramen interventriculare and ends in the recessus preopticus (fig. 17, Rec. preop.). Rostral to the medial limb of the caudate complex and making up the ventro-medial portion of the cerebral hemisphere is the septum. This area is limited dorsally by the sulcus limitans hippocampi (fig. 17, Sul. vent.) and ventrally. by the angulus ventralis (fig. 35, Ang. vent.). The angulus ventralis is a shallow groove which lies between the septum and the rostral portion of the caudate nucleus. Its rostral end becomes lost in the evaginating olfactory bulb. The septum itself has increased in thickness by a marked ventricular growth.

There are, then, three morphological differences to be noted in this brain as compared with that of $\mathrm{H} 173$ :

1. Increase in the tissue forming the vault of the hemisphere.

2. Growth of the lateral nucleus of the corpus striatum.

3. Dorsal extension of the ventrally thickened portion of the septum.

\section{The 27.8-mm. embryo, University of Chicago, H 91}

The foramen interventriculare is no longer elliptical in outline. It is a dorso-ventral slit lying beneath the paraphyseal arch. It is bounded posteriorly by the midthalamus, ventrally by the medial limb of the caudate complex, dorsally by the area chorioidea, and anteriorly by the lamina terminalis. The sulcus 
which separates the medial limb of the caudate nucleus from the middle thalamus ends in the recessus preopticus and runs along the di-telencephalic ventricular junction into the floor of the lateral ventricle. The rostral end of the sulcus limitans almost reaches it. The dorsal sulcus which marks the dorsal border of the midthalamus region is almost obliterated. There is, however, a little evidence of it at the rostral end of the diencephalon, where a small ventricular ridge lies on the same level in an antero-posterior plane with the lateral limb of the velum transversum. The roof of the diencephalon has become membranous just caudal to the velum transversum.

The angulus terminalis in the telencephalon medium is more obtuse. The thin roof of the telencephalon anterior to the paraphyseal arch has thickened. The dorsal part of the lamina terminalis, the lamina supraneuroporica of Johnston, here called the pars tenuis, has increased in breadth measured from the midplane to the ventricle and in thickness measured dorsoventrally. This same process has caused an enlargement of the lamina terminalis in all directions (fig. 20, Lt., Bailey, '16a).

The seulpturing within the telencephalic cavity is so modified that the medial and lateral limbs of the caudate nucleus closely resemble each other in the extent of their ventricular expansion. The lateral ridge of the caudate nucleus is as prominent a hillock in the floor of the ventricle as that formed by the medial limb of this nucleus. But the greatest change within the ventricle is due to the increase in thickness of the medial wall, which lies ventral to the sulcus limitans hippocampi and cephalad to the massive portion of the lamina terminalis, the septum. This marked growth of the septal region extends rostrally into the base of the evaginating olfactory bulb. The cavity of the ventricle is almost filled by the lateral choroid plexus. Upon the medial wall the developing hippocampus forms a continuous bulging on the ventricular wall, long and low at the rostral end, sharp and high at the temporal pole. Immediately beneath this ventricular ridge is the sulcus limitans hippocampi. The ridge is due to a slight infolding of the medial wall, the groove on the outer surface being the fissura hippocampi. In this brain there 
is no interruption of the fissure. Ventral to this fissure is that of the choroid plexus, whose taeniae lie so near each other that there is no apparent opening.

The caudal pole of the growing hemisphere attached above the telencephalic limit of the di-telencephalic groove is swinging antero-ventrally and carrying with it new tissue, that of the developing neopallium. Consequently the vault is not only increasing in height above the ventral ventricular eminences, but is also increasing in extent simultaneously with the forward and downward growth of the temporal pole.

The 32.1-mm. embryo, University of Chicago, $H$ 41 (figs. 22 and 24, pp. 116 and 117 , Bailey, '16 a)

The most striking aspect of the ventricular surface of the thalamus is the deepening of the rostral end of the sulcus limitans and the progressive fading of the sulcus dorsalis. The region which lies between these two grooves occupies the major portion of the ventricular thalamic surface. Dorsal to the sulcus dorsalis lies a ridge in the midline which is accentuated in the model by the irregular trimming of the diencephalic roof plate. This ridge was described by His as containing the stria medullaris and the habenula. It is interesting to note that its anterior end reaches the lateral limb of the velum transversum, while its ventral border (the sulcus dorsalis) gradually fades out anteriorly in the same region. Consequently, the foramen interventriculare is closed posteriorly by the great midthalamus. The hypothalamus remains almost unchanged. Optic fibers are present in the chiasma ridge. The recesses which lie anterior and posterior to the chiasma ridge are deepened. The infundibulum opens into the cavity of the posterior lobe of the hypophysis. The tuber cinereum is thin. The mammillary recess is very shallow.

The rostral end of the sulcus limitans joins the sulcus which separates the hypothalamus from the medial limb of the corpus striatum, and runs over the floor of the foramen interventriculare into the basal portion of the lateral ventricular surface of the diencephalon. This portion of the corpus striatum together with the dorsal part of the lamina terminalis forms the anterior 
wall of the foramen. The vault is sealed by the tela chorioidea telencephali medii and the paraphyseal arch. The angulus terminalis has become still more obtuse. The dorsal portion of the lamina terminalis is no longer slender and ependymal; but, rather, growth in all directions so characteristic of this region in its ventral area has involved the whole of the terminal plate from the recessus preopticus to the angulus terminalis. The pars tenuis becomes less in extent as the pars crassa of the lamina terminalis increases in length.

Looking into the ventricle, the lateral and medial limbs of the caudate complex are separated from each other by a shallow sulcus. The lateral component of this complex has increased in growth relatively more than the medial. The ventricular eminence formed by the fissura hippocampi upon the medial wall is broken in the region dorsal to paraphyseal arch, so that there is now an anterior and a posterior segment. The sulcus limitans hippocampi, lying ventral to this eminence, is continuous from the tip of the temporal pole to a region rostral of the lamina terminalis. The septal region lying between this sulcus and the angulus ventralis has grown in length and width, epecially in the ventral portion near its point of continuity with the diencephalon.

The outer contour of the cerebral hemisphere is such that superficially the various poles of the adult hemisphere are recognized. The growth which has given this change in the surface is the result of increase in the tissue which is attached medially to the dorsal border of the hippocampus and laterally to the lateral limb of the caudate complex, namely, the neopallium. The most noticeable result of the growth of this tissue has been the swinging of the primitive caudal extremity, posteriorly, ventrally, and anteriorly. Thus the primordium of the temporal lobe is laid down.

The fissura hippocampi is a shallow groove rostral to the lamina terminalis, while in the region above the paraphyseal arch it is barely visible. However, caudal to the velum transversum this fissure is deeper. Moreover, it follows the new direction of growth of the temporal lobe ventrally and anteriorly, so that its shape upon the free surface of the medial wall becomes a semicircle. 
The changes which characterize the two embryos last described are:

1. Closure of the choroid fissure.

2. Actual evagination of the olfactory bulb.

3. Plexus formation in the anterior portion of the diencephalic roof plate.

4. Great increase in growth of the midthalamic region.

5. Reversal of relative size of the two limbs of the caudate nucleus.

6. Further thickening of the dorsal portion of the lamina terminalis, i.e., the encroachment of the pars crassa upon the pars tenuis.

7. The incipience of the temporal lobe in the cerebral hemisphere.

8. The fissura hippocampi is not so deep above the area chorioidea in the $27.8 \mathrm{~mm}$. embryo as in the $19.1 \mathrm{~mm}$. or the $20 \mathrm{~mm}$. Anterior to the angulus terminalis and posterior to the velum transversum the fissura resembles that found in the embryos previously described. The formation, however, is continuous throughout. In the $32.1-\mathrm{mm}$. the fissura hippocampi is very shallow anterior to the velum transversum, posteriorly it is relatively a deep groove.

The 39.1-mm. embryo, University of Chicago, H 163 (fig. 18)

The changes in the medulla oblongata and the midbrain may be seen at a glance. The cerebellum (Cer.) appears as a medially growing thickening of the dorsal lip of the lateral recess, but as yet no fusion has taken place in the midline. The floor plate in both the medulla oblongata (Myel.) and the midbrain (Mes.) has thickened. The floor plate of the latter does not show any of the subdivisions characteristic of the adult mesencephalon. The sulcus limitans (Sul. lim.) can be easily followed from the cord through the myelencephalon and mesencephalon into the posterior part of the diencephalon.

The greatest change as compared with $\mathrm{H} 41(32.1 \mathrm{~mm}$.) is found in the development of the prosencephalon, especially in the telencephalic portion. In the diencephalon the sulcus divid- 
ing the medial limb of the caudate nucleus from the hypothalamus runs over the floor of the foramen and ends in the recessus preopticus (Rec. preop.) as described before. This sulcus is joined at its dorsal end by the anterior portion of the sulcus limitans. The hypothalamus is the same as described for $\mathrm{H} 41$. Within its floor are found the recessus mamillaris, the infundibulum, its recessus, the bed of the optic chiasma and the preoptic recess. It is not possible to identify the sulcus upon the medial surface of this thalamus, comparable to the sulcus dorsalis found in the embryos previously described. In the epithalamus the habenula $(H a b$.$) , the superior commissure (Hab.com.), and the epiphysis$ $(E p . e v$.$) are easily identified. Immediately anterior to the$ habenula the diencepbalic roof plate is non-membranous. Its anterior end, however, extends forward over the paraphysis ir the form of membranous pockets, the postvelar tubules of Warrer. (P. vel. t.). These ependymal tubules (Warren, '17, fig. 18, pl. II, p. 125), invaded by vascular connective tissue, seem comparable to the dorsal sac of amphibians and reptiles.

The telencephalon medium joins the rostral limb of the plexus chorioideus ventriculi tertii at the most anterior attachment of the postvelar tubules (fig. 18, P. vel.t.). From this point in the telencephalic midline to the preoptic recess the region which shows the greatest growth in length and breadth is the massive portion of the lamina terminalis (fig. 18, Lam.term.). Only a small region immediately ventral to the angulus terminalis has remained thin and tenuous. The antero-posterior measurement of the area chorioidea is almost the same as that of the two embryos, $27.8 \mathrm{~mm}$. and $36.1 \mathrm{~mm}$. in length. Of this, the tela chorioidea telencephali medii (fig. 18, Tel. ch. tel. med.) occupies its anterior half and the paraphyseal arch its posterior (fig. 18, Par. p.). The pouch itself extends over the area chorioidea a real evagination of midline tissue continuous with the velum transversum. In the series this is the only embryo which has the typical circular constriction of the stem of the paraphysis. Although the figure delineates but one sac, there are two small lateral pouches which open directly into the central evagination. These relationships are similar to the one which Warren ('17 fig. 14, p. 121) has described for a 25-mm. human embryo. 
In the medial wall contiguous to these structures lie the typical subcortical tissues. The most cephalad of these, the septum (fig. 18, Sept.), bulges into the cavity of the lateral ventricle. Dorsal to the septum, lying between the sulcus limitans hippocampi and the pars tenuis of the lamina terminalis, is the thin septum ependymale (fig. 18, Sept. epen.). Morphologically it differs in no respect, except in position, from the area intercalata (fig. 18, A. int.) adjoining the tela chorioidea telencephali medii. The anterior limbs of the lateral choroid plexuses are continuous with the paraphyseal arch a short distance cephalad to the anterior limb of the paraphysis.

The foramen interventriculare is barely visible from the medial surface. The growth of the midthalamic region, forward and medialward, has restricted its caudal boundary. Its floor is filled with the medial limb of the caudate nucleus. Its anterior boundary is limited by the dorsal region of the terminal plate. Its vault contains the paraphysis and the tela chorioidea telencephali medii. Hence the boundaries of the foramen have not changed, although its diameter is narrower than that found in $\mathrm{H}$ 41. The surrounding structures have increased in size, growing toward the center of the foramen in all directions.

Looking down toward the ventricular floor in the rostral pole of the hemisphere, at the level of the lamina terminalis, the anterior and the medial limbs of the caudate nucleus are seen. The medial nucleus increases in width gradually as far as the level of the anterior limb of the paraphyseal arch. From that point posteriorly it becomes narrower. The lateral nucleus of this complex springs from the side wall at the level of the root of the olfactory bulb. It attains its greatest width at the level of the dorsal portion of the lamina terminalis. Caudally it terminates in the region of the posterior extremity of the hippocampus. The angulus ventralis lies between the medial limb of the caudate complex and the lateral extension of the septal region. It extends from the base of the olfactory evagination into the floor of the foramen interventriculare. The two ventral sectors of the hemisphere wall have grown in length, so that the telencephalic evagination projects beyond the lamina terminalis much farther 
than in the stage previously described. On the medial wall, the hippocampus does not bulge into the hemisphere except posterior to the region of the tela chorioidea telencephali medii. However the sulcus limitans hippocampi lying ventral to the hippocampus extends from the tip of the temporal pole over the foramen and becomes lost just caudal to the olfactory bulb evagination. The original caudal pocket of the ventricle has swung ventro-anteriorly and carried with it the lateral complex of the nucleus caudatus. The neopallial arch which bridges the lateral division of the corpus striatum and the medial olfactory area is much higher than before. The plexus chorioideus ventriculi lateralis almost fills the cavity. The chorioidal fissure is filled with mesenchyme and blood vessels.

The outer contour of the telencephalon begins to resemble that of the adult. In the center of the lateral surface an area of retarded growth is present, the future island of Reil. Dorsal, caudal, caudo-ventral, and rostral to this point of slow growth, the telencephalon swings out, growing as it were between its points of attachment to the diencephalon. Upon the medial surface the line of separation of the cerebral hemisphere from the evaginating olfactory bulb is carried up on the wall as a small indentation, which terminates rostral to the lamina terminalis. This is the fissura prima of His. Caudal to the velumtransversum the fissura hippocampi can be traced to the tip of the temporal pole. Rostral to this point this fissura no longer can be identified on the medial surface of the hemisphere. The changes which have taken place in growth between the two embryos $H 41$ $(32.1 \mathrm{~mm}$.) and $\mathrm{H} 163(39.1 \mathrm{~mm}$.) are as follows:

1. Marked evagination of the olfactory bulb, which accentuates the fissura prima of His.

2. Great growth of the lamina terminalis, together with a lateral extension of the septal region into the ventricle.

3. The fissura hippocampi is restricted to the medial wall caudal to the velum transversum.

4. Constriction of the foramen Monroi by the growth of the midthalamic region. 
5. No sulcus dorsalis thalami can be identified upon the ventricular surface.

6. Appearance of the island of Reil.

7. Great growth of the neopallium.

The 43-mm. embryo, Mall Collection, 886 (figs. 19 and 20)

This embryo measured $39.9 \mathrm{~mm}$. greatest length in alcohol, only $0.8 \mathrm{~mm}$. longer than $\mathrm{H} 163$. It is not strange that the forebrains of these two embryos are very similar. The development of the cord and the medulla oblongata is the same. The cerebellum appears as a medial outgrowth from the dorsal lip of the lateral recess. The floor plate is very thick. The midbrain is divided into alar and basal plates by the sulcus limitans. The basal plate is increasing in depth. There is no hint of a division into colliculi upon the roof of the mesencephalon. The ventricular markings in the thalamus are the same. The sulcus limitans ends blindly in the hypothalamus. It is joined for a short distance by the sulcus which delimits the ventral boundary of the midthalamus, the sulcus Monroi. Dorsal to this sulcus is the great midthalamic mass. Here as in the $39.1 \mathrm{~mm}$. embryo there is no visible separation between this part of the thalamus and the epithalamus. The epithalamus contains the characteristic structures, the epiphyseal evagination, the habenula, the habenular commissure, and the choroid plexus of the third ventricle. The hypothalamus contains the corpus mamillare, the thin tuber cinereum, the posterior lobe of the hypophysis, the recessus infundibuli. The last recess is deeper in this embryo than in $H 163$ (39.1 mm.). The recess preopticus lying between the chiasma ridge and the inferior limb of the lamina terminalis is longer and more shallow than that of the 39.1-mm. embryo.

The structures of the telencephalon medium are similar in relation and development to those found in the 39.1-mm. embryo. The lamina terminalis is slightly longer, but not broader. The angulus terminalis is not as well delineated. The length of the area chorioidea is practieally the same as that of $\mathrm{H} 163$. Its anterior division, the tela chorioidea telencephali medii is like the 39.1-mm. but its posterior, the paraphyseal arch, is not the same. 
Taking for its anterior limit that part of the midline where the two lateral choroid plexuses are continuous over the telencephalic roof and the velum transversum as its posterior boundary, its length is approximately that of the $39.1 \mathrm{~mm}$. However, it was impossible to identify a dorsal outpouching in the region of the paraphyseal arch. This may be due in part to the fact that the embryo was sectioned at $100 \mu$, coronal to the cerebral hemisphere. A thinner section in the transverse plane is more advantageous for the study of this region. In the $39.1-\mathrm{mm}$. this structure was present for about $175 \mu$.

The septum continues its growth into the ventricle. The area of the septum ependymale measures approximately the same and cannot be distinguished morphologically from the area intercalata. The exfent of the lamina epithelialis resembles that of the $39.1-\mathrm{mm}$. embryo.

Within the telencephalon the ventricular ridges have the same relationship to each other as that described for the $39.1-\mathrm{mm}$. embryo, $\mathrm{H} \mathrm{163.}$. The lateral limb of the caudate nucleus is large and ends in the ventromedial horn of the lateral ventricle. The medial limb of the same complex terminates at the base of the olfactory bulb. The angulus ventralis separates this medial limb from the septal region. The hippocampus forms a rounded hillock upon the medial wall which tends to flatten out anterior to the angulus terminalis. The sulcus limitans hippocampi lies beneath it, extending from the tip of the temporal pole to a region slightly anterior to the rostral limit of the fascia dentata. The fissure of the choroid plexus is completely closed. The vault of the hemisphere is higher in the region of the paraphysis than in the $39.1-\mathrm{mm}$. The anterior and ventro-posterior extension is not greater than that of the last brain described.

The outer contour is not materially changed. The island of Reil is visible on the lateral surface, so that the hemisphere may be divided into various regions indicative of its future lobulation. The olfactory bulb is large and its cavity opens into the ventricle. Along its medial boundary of constriction, extending dorsally anterior to the lamina terminalis lies the fissura prima of His. Posterior to the terminal plate, the fissura hippocampi can be 
followed from the region of the paraphysis to the end of the hippocampal formation.

The most marked difference between this embryo and $\mathrm{H}$ $163(39.1 \mathrm{~mm}$.) is the relative growth of different portions of the telencephalon medium. They are as follows:

1. Increase in length of the lamina terminalis.

2. No discernible paraphyseal arch.

3. Increase in the height of the neopallial vault, especially in the central region of the hemisphere.

In the first two brains described, no. $1121(11.8 \mathrm{~mm}$.) and no. $940(14 \mathrm{~mm}$.), no fissure or sulcus on the medial wall was visible. But in the description of nos. $\mathrm{H} 173$ and 460, 19.1. mm. and $29 \mathrm{~mm}$., respectively, a shallow groove extended on the medial wall of the hemisphere from the region of the future olfactory bulb evagination to the most caudal and ventral extremity of the lateral area of di-telencephalic fusion.' This fissure was also noted in much the same position in $H 91$ and $H 41$ (27.8 and 31.1 $\mathrm{mm}$.), although its depth was not as great rostral to the terminal plate. Immediately dorsal to the paraphysis this groove is very shallow, the wall being almost smooth. But caudal to the paraphysis the fissure follows the curved contour of the temporal lobe of the hemisphere, lying in the medial wall, describing an arc of a circle. In the oldest brains here considered $(39.1 \mathrm{~mm}$. and $43 \mathrm{~mm}$.), the rostral division of the medial wall is very smooth. However, just posterior to the region of the paraphyseal arch lies the rostral end of an indentation, the fissura hippocanpi. This fissure may be traced as a shallow depression in the hippocampus to the caudal end of the primitive temporal pole.

Besides this fissure another was described, the fissura prima of His. It is found only in the older embryos of the series (32.1 $\mathrm{mm}$., $39.1 \mathrm{~mm}$, and $43 \mathrm{~mm}$.), or in those embryos in which the olfactory evagination is prominent. It seems to delimit the tissue basal to the attachment of the olfactory bulb from the cortex dorsal to its point of evagination. It is the former groove or fissure hippocampi which has claimed the writer's consideration for a number of years. And you, the reader, are you ques- 
tioning its reality? You may well do so, when its history is remembered. Certain it is that the question of fixation was adequately controlled. The embryos studied were carefully preserved, their further handling as good as our present technique allows, and yet such treatment did not banish from the medial wall of the early telencephalon the fissura arcuata of His (the fissura hippocampi of "others). Nevertheless the description of this fissure seems to indicate that its preterminal limb is transient. If this groove is real, there must be some explanation, first for its appearance and second for its partial obliteration. Further, if it is real, a histological differentiation would be expected and processes of growth differences may account, in part at least, for its appearance and later its disappearance in the prevelar region. It is not a question of fixation. A very meager experience with this material gives an unerring criterion to the investigator for the determination of artefacts. The explanation is to be found, rather, in the development not only of the tissue involved in the fissure itself, but also in the histological differentiation of tissue in more remote parts of the developing hemisphere wall.

\section{HISTOLOGICAL STRUCTURE}

The 11.8-mm. embryo, Mall Collection, 1121 (figs. 21 to 25)

The telencephalic vesicle of the brain of this embryo is little more than a single evagination, which has expanded slightly beyond its initial attachment to the diencephalon. The lateral expansion of this vesicle is greater in the region midway between its anterior and posterior poles. The midline extending from the region of the velum transversum rostrally is interrupted by an infinitesimal elevation, the paraphyseal arch. Figures 21 to 25 are line drawings of sections of the vesicle cut at right angles to the chord joining the velum transversum and the preoptic recess. The levels are indicated in figures 8 and 11. The midline, beginning in the region of the bed of the optic chiasma, may be divided morphologically into the following regions (figs. 7 and 8 and p. 85 supra):

Region of the optic chiasma (fig. 21, F. b. op. ch.).

The lamina terminalis pars crassa (fig. 22, Lam. term.). 
The pars tenuis of the lamina terminalis and the septum ependymale (fig. 23, Sept. epen.).

Region of the paraphyseal arch (figs. 24 and 25, Tel. r. pl.).

Velum transversum (figs. 7 and 8, Vel.trans.).

In the region of the bed of the optic chiasma (fig. 21, F. b.op. ch.) the evaginating vesicles form two arcs of a circle, their intersection being marked by a small depression in the midline. Following this arc of the telencephalic brain wall around to its point of union with the diencephalon, it appears fairly uniform in histological structure. In figure 22 the vault of the brain wall is more extensive. Within its outer margin a barely discernible clear zone appears, the Randschicht of His, or the marginal velum (Man. l). This zone is more clearly defined a few millimeters (measured on the figure itself) lateral of the midline. The wall at this point shows a very slight local thickening. In figure 23 the lateral expanse of the vesicle is greater and the marginal velum more sharply defined. The union of the two vesicles is made by a thin epithelial plate of cells. In this figure, approximately $6 \mathrm{~mm}$. on either side of this thin line, no mantle zone can be identified in the brain wall (figs. 9 and 11, Sept.epen.). But beyond this region, for $10 \mathrm{~mm}$. on either side, the marginal velum reaches its maximum definition.

Figure 24 is a section through the caudal portion of the telencephalic roof plate, at the level of what appears to be the paraphyseal arch (figs. 8 and 24, Tel. r. pl.). This small arch in the midline is one feature of a remarkable histological differentiation in the telencephalon. Joining the lateral limbs of this arch is a slender, homogeneous epithelial tissue. Immediately lateral to this tissue is an area in which the marginal velum is clearer and wider than any other portion of the vesicle. Again lateral to this area is a region of the brain wall which forms the telencephalic evagination (Tel. evag.) or incipient cerebral hemisphere, extending backward to the point of junction with the thalamus at the di-telencephalic groove. Upon the ventricular surface the first and second areas are separated by a shallow sulcus, which will be referred to as the sulcus limitans hippocampi (fig. 24, Sul. vent.). 
In figure 25 also on the right side reading from the midline lateralward, the following histologically distinct areas are found: 1) the telencephalic roof plate, i.e., the paraphyseal arch ( $\mathrm{Tel}$. $r . p l$.$) ; 2) region of the future lamina epithelialis (not labeled);$ 3 ) an area which will contain the fornix and the fascia dentata (compare the older embryo, fig. 14);4) separated from the lamina epithelialis by a ventricular sulcus (Sul. vent.), the sulcus limitans hippocampi, is the primordium of the future hippocampus (Prim. hip). The sulcus limitans hippocampi can be traced from the caudal level of the paraphyseal arch (fig. 11, Reg. par. ar.) to a region immediately anterior to the most rostral extent of the arch. This ventricular marking delimits areas at this stage of development already histologically distinet. This sulcus, together with the clear marginal velum lateral to it, enables the writer to bound accurately the anlage of the hippocampus. These slight early differentiations are of great importance, because they can be used as landmarks from which to measure the further growth and differentiation in the telencephalon.

The 14-mm. embryo, Mall Collection, 940 (figs. 26 to 28)

The counterpart of the distinct histological structures, dorsally placed in the telencephalon of the $11.8-\mathrm{mm}$. embryo, are found either in the unevaginated midline little changed or in the medial wall of the hemisphere of the 14- $\mathrm{mm}$. The hemispheres of this brain extend for an appreciable distance anterior to the lamina terminalis and posterior to the velum transversum. In order to facilitate the description of the shifting position of histologically distinct areas, especially anterior to the lamina terminalis, within the developing hemisphere, they may be divided into quadrants (following the morphological terminology of Herrick, '10). In that paper Herrick suggested a subdivision of the amphibian cerebral hemisphere into four fundamental quadrants, viz., dorsolateral (pyriform lobe); 2) dorso-medial (primordium hippocampi) ; 3) ventro-lateral (striatum complex); 4) ventro-medial, septal complex. To these in mammals there is added (p. 496) a fifth region, the neopallium. In this embryo $(14 \mathrm{~mm}$.) these regions can be recognized save for the confusion of the pyriform, 
or dorso-lateral olfactory areas, with the striatal complex, a condition comparable with that of the adult reptile (Crosby, '17). Because of this confusion and the absence of neopallium in the amphibian, the writer prefers the use of sector instead of quadrant. Accordingly, in this brain each hemisphere can be divided into four sectors: dorso-lateral (neopallium), dorsomedial (primordium hippocampi), ventro-lateral (combined striatum, lateral olfactory area and pyriform lobe), and ventromedial (septum and medial olfactory area). At this particular level the two dorsal sectors are of approximately the same thickness; the wall of the ventro-lateral sector, however, is much thicker than that of the ventro-medial. The dorso-medial sector may be distinguished from the dorso-lateral by a broad white marginal velum within the medial one (fig. 26, Prim. hip.). This same layer of the telencephalic wall within the dorso-lateral quadrant contains many neuroblasts (fig. 26, Neopal.). The matrix or zona ependymalis of the medial sector is not as broad as that of the lateral. The dorso-medial region is separated from the ventro-medial by a sharp ventricular groove, the sulcus limitans hippocampi of Herrick (fig. 26, Sul. vent.). The ventromedial sector itself is divided into two histologically distinct areas: a dorsal thin layer of tissue whose cells, packed closely together, show no definite arrangement, the septum ependymale (fig. 26, Sept. epen.), and a ventral whose thick wall presents an inner dense matrix and an outer zone, containing a few neuroblasts, the septum (fig. 26, Sept.). The two ventral sectors are separated from each other by a slight indentation in the ventricular surface the angulus ventralis (compare Herrick, '10, figs. 13 and 14, $A$. $V$. with fig. .26, Ang. vent.). Lateral to the ventral angle the brain wall bulges into the ventricle, the first evidence of the corpus striatum, specifically, the medial nucleus of the caudate complex. Between this nucleus and the dorso-lateral sector must lie the future lateral olfactory complex and the lateral limb of of the caudate nucleus. The four sectors of the hemisphere are then, 1) the dorso-lateral or the neopallium; 2) the dorso-medial or hippocampal primordium; 3 ) the ventro-medial or the septum and the septum ependymale, and, 4) the ventro-lateral or the 
corpus striatum and the lateral olfactory areas. The particular area which is of immediate interest is the dorso-medial sector, the future hippocampus (fig. 26, Prim. hip.). The peculiar histological character of this tissue, already noted in the $11.8-\mathrm{mm}$. embryo but accentuated here, (that is, the clear practically cellfree marginal velum and the slightly thinner matrix) extends from the region just dorsal of the future olfactory evagination, sicklelike, over the foramen interventriculare to the caudal tip of the hemisphere (see the stippled area in figs. 12 and 14).

Passing caudally, the future hippocampus occupies a progressively more dorsal position in the telencephalic wall (figs. 27 and 28). The amount of neopallial tissue present in the caudal portion of the hemispheric evagination is less than that found at its rostral pole. In figure 27 , a section through the paraphyseal arch (Par. ar.), there lies between the arch and the future hippocampal cortex (Prim. hip.) a curved ependymal wall with the concavity directed outward. This tissue, which joins the hippocampus at the sulcus limitans hippocampi (Sul. vent.) and the lateral limb of the paraphyseal arch, is the first stage in the development of the sulcus of the lateral choroid plexus (figs. 27 and 28, Sul. fu. pl. ch. ven. lat.).

The regions differentiated as histologically distinct areas are as follows: The neopallium, the hippocampus, the corpus striatum, the septum ependymale, the septum, the two divisions of the area chorioidea, the tela chorioidea telencephali medii, and the paraphysis, together with their respective contiguous structures, the area intercalata and the lateral choroid plexus. Besides these, there is the marked ventro-caudal growth of the hippocampus.

The 19.1-mm. embryo, University of Chicago, $H 1 \% 3$ (figs. 15, 16, 29 to 32)

The cell arrangement within the telencephalon of this embryo bears little semblance to that found in the 14- $\mathrm{mm}$. embryo, with one exception, the future hippocampus. This region of relatively cell-free marginal velum can be identified on the medial wall from the region of the base of the olfactory bulb evagina- 
tion to the tip of the temporal pole (see the stippled area in fig. 16). The other components of the vesicle have shifted their places in the sector formation, but continue to maintain their fundamental relationships. The future hippocampus now occupies the centro-medial area, in levels anterior to the lamina terminalis (figs. 29 and 30, Prim. hip.). This tissue swings gradually upward to those levels further caudalward (figs. 31 and 32, Prim. hip). The ventral margin is limited throughout by the sulcus limitans hippocampi (figs. 29 to 32, Sul. vent.). The groove which outlines the future hippocampus on its medial surface is the fissura hippocampi (figs. 29 to 32, Fis. hip.). Not only is the future hippocampus distinguished by the cell-free outer zone, the marginal velum, but also, by the narrower matrix, and a greater thickness of the brain wall itself. Immediately opposite the sulcus limitans hippocampi lies a small group of cells which appear ta be migrating into the marginal velum from the matrix. This group of cells is coincident with the extent of the limiting sulcus, and it is the primordial fascia dentata (figs. 29 to 31, Fas. den.). It lies wholly within the hippocampal formation above the limiting sulcus.

The remainder of the dorsal medial wall is histologically the same tissue as that composing the dorso-lateral one. It is the neopallium (figs. 29 to 32, Neopal.) and is characterized at this stage of development by a dense matrix and a marginal velum, filled with migrating neuroblasts. In amount it is proportionally and actually greater in the rostral than in the caudal division of the telencephalon.

The division of the ventro-medial sector into two areas, similar to those described in no. 940 (the $14-\mathrm{mm}$.), is clearly seen in the section immediately posterior to the level of the tuberculum olfactorium (fig. 31). The more dorsal slender wall is the septum ependymale (fig. 31, Sept. epen.), and the more ventral, the septum (fig. 31, Sept.). In the latter region a minute differentiation in the form of a row of cells lying in the marginal velum may be identified. This is the nucleus medialis septi, which also appears in levels through the tuberculum olfactorium (figs. 29 and 30, Nuc. med. sept.). This cell grouping is continuous 
over the angulus terminalis with those cells already identified as the primordial fascia dentata, though these two cell masses originate in different sectors and have very different morphological significance. The lamina epithelialis, above the foramen interventriculare, has invaginated now to form the lateral choroid plexus.

The last sector, the ventro-lateral, shows plainly the beginnings of the medial and lateral limbs of the caudate complex. The separation of the caudate nucleus from the neopallium is made evident by a shallow ventricular groove. The angulus ventralis, due in the main to the enlargement of the ventricular eminence of the caudate's medial complex (figs. 30 and 31, Cor. str. med.), bounds the septrin laterally.

The following histological changes have taken place between the stage last described, the 14-mm., and the 19.1-mm.:

1. The expansion of a mantle zone in the septal region.

2. The acceleration of growth in the neopallium, accompanied by the complete incorporation of the hippocampal anlage in the medial wall.

3. The appearance of the primordial fascia dentata opposite the sulcus limitans hippocampi. It is continuous with a similar group of cells in the septum, the nucleus medialis septi.

4. The appearance of the plexus chorioideus ventriculi lateralis.

5. The obvious indentation of the hippocampal wall, the fissura hippocampi.

The 20-mm. embryo, Mall Collection, 460 (figs. 17, 33 to 37)

The morphological and histological differentiation of the telencephalon of this embryo resembles in large part that of the 19.1-mm.; the boundary lines of the various areas remain unchanged and they occupy the same relative positions in the four sectors. The fissura hippocampi is a broad bow-shaped bend of the medial wall of the hemisphere involving practically the entire extent of the hippocampal formation and extending from the base of the bulbus olfactorius to the tip of the temporal pole (fig. 17, stippled area). Rostral to the terminal plate, the greatest depth of this fissure lies in the center of the hippocampal forma- 
tion, but caudal to the lamina the greatest depth of this fissure shifts toward the sulcus limitans hippocampi (compare Fis. hip. in figs. 33 and 34 with the fissure in figs. 35 to 37 ). The depth of the fissure, then, is found in the center of the future hippocampus at those levels in which its ventral limb is continuous with the septum itself; when, however, its ventral limb is joined to the thin septum ependymale or the taenia fornicis, the depth of the fissure shifts ventrally.

Within the septum ependymale is now found a thin marginal velum (fig. 35). There is no change in the area intercalata. However, in the lamina epithelialis, the portion which extends to the paraphyseal arch (fig. 36) approaches the cuboidal epithelium of much older stages while that portion contiguous to the outer limb of the velum transversum is as primitive as the whole of the area in the 19.1-mm. embryo.

The primordium of the fascia dentata extends from a region anterior and dorsal to the angulus terminalis almost to the tip of the temporal pole, opposite the sulcus limitans hippocampi (cross-hatched area, fig. 17). In figure 33 (Fas. den.) it lies as a small well-defined group of cells in the marginal velum below the fissura hippocampi (fig. 33, Fis. hip.). Here, as well as in the next figure (fig. 34, Fas. den.), these cells seem to be continuous with the nucleus of the septum, the nucleus medialis septi ( $N u c$. med. sept.). This nucleus always appears ventral to the sulcus limitans hippocampi and can be identified easily in the next level pictured, through the septum ependymale (fig. 35, Sept. epen.). Here also the fascia dentata is well marked. In the last two levels presented this structure maintains its initial relationship to the sulcus limitans hippocampi and the fissura hippocampi (figs. 36 and 37).

The first three figures (figs. 33 to 35 ), when compared with those of the 14-mm., are excellent illustrations of the shifting of the hippocampal primordium to the midmedial region of the cerebral hemisphere. The whole dorsal lateral wall and almost half of the dorso-medial, at this stage, are composed of neopallium. But within the ventro-lateral sector bounded by the sulcus above the lateral limb of the caudate complex and the angulus 
ventralis, that area which in mammals is said to represent the whole lateral half of the hemisphere evagination, only two cellular layers on the ventricular contour of the caudate nuclei and a diffuse cellular mass beneath them can be identified. Upon careful examination a thin layer of cells may be seen, swinging around the ventro-medial corner of the hemisphere in the marginal velum, the first evidence of the cortex of the tuberculum olfactorium. The relationship of tissue within the ventro-medial and ventro-lateral sectors is identical in the $19.1-\mathrm{mm}$. and $20-$ mm. embryos.

This embryo shows an advance over the last in:

1. The appearance of a clear zone in the septum ependymale.

2. Growth of neopallial tissue in the caudal and inferior aspect of the hemisphere.

3. The hippocampal anlage begins to assume its definite shape caudally, i.e., the caudal end of the hippocampal formation has advanced forward to define the temporal lobe (figs. 16 and 17 ).

4. The fascia dentata has differentiated as far as the temporal tip of hippocampal primordium.

The 27.8-mm. embryo, University of Chicago, H.91 (figs.38 and 39)

The general relationships of the various components of the telencephalon are the same in this embryo as those described for the $20-\mathrm{mm}$. However, the intrinsic differentiation within the cortex has become evident. Within the neopallium two cell layers have migrated out of the matrix. The outermost layer is that of the pyramids (fig. 29, Pyr. c. l.), and one next the matrix is the intermediate cell layer (figs. 38, 39, Poly. c. l.). But in the hippocampus the latter group only has appeared. The cells occupy the dorsal lip of the hippocampal fissure. This differentiation is especially marked anterior to the paraphyseal arch. Here also, as before, the primordial fascia dentata (figs. 38, and 39, Fas. den.) lies opposite the sulcus limitans hippocampi (figs. 38 and 39, Sul. vent.). 
The olfactory bulb is in the process of actual detachment, so that its separation from the ventral sectors in the rostral pole has produced the fissura prima in the medial wall. Differentiation characteristic of the neopallium appears in the dorsal lip of this fissure. There is in the other embryos, nos. H 173 (19 $\mathrm{mm}$.) and $460(20 \mathrm{~mm}$.) a small area dorso-frontal to the region where the fila olfactoris enter, which does not show the differentiation characteristic of the hippocampal anlage.

The septum ependymale is divided into two layers, an outer clear zone and an inner matrix (figs. 38 and 39, Sept. epen.). This same tectonic arrangement is characteristic also of that tissue which adjoins the midvault of the foramen interventriculare. The change from a simple epithelium to the two cell layers described seems to be the first step in the process of differentiation in the lamina terminalis, a process which proceeds caudally.

The progress of growth has added the following:

1. Differentiation of the neopallium into three cell layers.

2. Appearance of the intermediate cell layer in the dorsal part of the primordium hippocampi, a process whose development is more marked rostral to the terminal plate.

3. The septum ependymale contains two cell layers throughout, thus differentiating it from the static area intercalata.

\section{The 32.1-mm. embryo, University of Chicago, $\mathrm{H}_{4} 1$ (figs. 40 and 41 )}

At the level of the root of the olfactory bulb (fig. 40) the cortical differentiation extends ventrally as far as the fissura prima. This groove with its dorsal differentiation continues for a short distance upon the rostral end of the medial wall. Caudal to the root of the olfactory bulb there is an area of unmistakably hippocampal formation. 'Here the intermediate cell layer has crept out of the matrix below the level of the fissura hippocampi and the pyramidal cell layer shows itself in the dorsal lip of the fissure. This migration is characteristic of the preterminal hippocampal formation. That part of the future hippocampus 
which lies between the levels of the lamina terminalis and the velum transversum is an area transitional to the sickle-shaped postvelar tissue in which little or no cortical differentiation has taken place. It is in the latter that the fissure is best indicated. The fissure is best developed, then, in the least differentiated part of the hippocampus. The fascia dentata (fig. 41, Fas. den.) is now a continuous band of clumped cells opposite the sulcus limitans hippocampi. The fascia dentata is not coextensive with either this sulcus or with the hippocampal formation. However, the ventricular sulcus limitans hippocampi (Sul. vent.) seems to delimit its ventral extent except in that region where the anlage of the hippocampus gradually fades into the olfactory bulb.

The condition of the septum and septum ependymale is the same as that of $H 91(28.7 \mathrm{~mm}$.), with the exception that its most dorsal portion is much wider measured antero-posteriorly.

The growth changes may be summed as follows:

1. More ventral differentiation of the preterminal portion of the hippocampal anlage with a coincident decrease in the depth of the fissura hippocampi, ventrally.

2. Further thickening of the outer layer in the septum ependymale.

The 39.1-mm. embryo, University of Chicago, H 163 (figs. 42 to 46 )

At the level of the tuberculum olfactorium (fig. 42 , cf. fig. 18, $t u b$. olf.) the vault of the hemisphere from the corpus striatum laterally to the sulcus limitans hippocampi medially presents the typical cortical differentiation. Following the tissue which lies immediately dorsal to the sulcus limitans hippocampi to the level of the lamina terminalis, the typical cortical layers do not extend as far ventrally as the sulcus. In the marginal velum opposite it lies the fascia dentata (fig. 43, Fas. den.). This tissue is the most rostral limit of the hippocampus. The area immediately ventral to the hippocampus is that of the septum. Its growth is very marked in all directions. That growth is largely the result of differentiation of a new diffuse nucleus. 
Already in the marginal velum in embryos H 173 and 460 a thin layer of cells, the nucleus medialis septi, was evident. Now, lying between this nucleus and the matrix is a large diffuse group of cells, the nucleus lateralis septi (fig. 43, Nuc. lat. sept.). Here, also, rostral to the anterior commissure, the separation of the ventro-lateral from the ventro-medial sector is emphasized by a prolongation of the angulus ventralis (fig. 43, Ang. vent.). Its accentuation in this embryo is due to the growth of the medial nucleus of the caudate complex. The ventricular angle marking the boundary between the dorso-lateral and the ventrolateral sectors has become more acute because of changes in the corpus striatum, namely, a ventricular extension of the lateral root of the caudate complex and the appearance of the anlage of the lentiform nucleus (figs. 43 and $44, N u c$. lent.).

Examining the relationships of tissue at a level passing through the more caudal part of the lamina terminalis (fig. 44, Lam. term.) we find the septum is narrow. However, three groups of cells may be seen, the inner matrix, a middle diffuse group, the nucleus lateralis septi (fig. $44, N u c$. lat. sept.), and an outer thin layer, the nucleus medialis septi (fig. 44, Nuc. med. sept.). Their development will be considered in the second study. The hippocampus joins this tissue dorsally. Within the hippocampus the pyramidal cell layer extends past the middle of the fissura hippocampi, while the intermediate cell group lies in its ventral lip, just dorsal to the level of the sickle-shaped sulcus limitans hippocampi (fig. 43, Sul. vent.). Along the extreme ventral margin of the hippocampus extending dorsally from the region of the sulcus mentioned lies the fascia dentata (fig. 43, Fas. den.). In the space between the fascia dentata and the matrix lie the fornix fibers. These fibers also occupy the space between the medial and lateral septal nuclei. From this level, caudally, throughout the compass of the hippocampus, the fascia dentata grows dorsally along its most ventral margin (figs. 43 to 46 , Fas. den.).

In figure 45 , a section through the paraphysis, the lateral choroid plexuses join the lateral limbs of the paraphyseal arch (Par. ar.). The small tubules lying in cross-section on either 
side of the arch are the rostral evagination of the roof of the third ventricle, the postvelar tubules of Warren (P. vel.t.). However, in the midline above the arch there are two small tubules whose continuity with the membranous roof is found anterior to the velum transversum. They form a real pouch which extends forward over the telencephalic roof plate (fig. 18, Par. $p$.). This condition of the human paraphysis is strikingly like that figured by Warren ('17) in the 25-mm. embryo (figs. 14 and 15). Rostral to the anterior limb of the paraphysis is the tela chorioidea telencephali medii. It is undifferentiated, a true epithelial tissue. The tissue, which joins it dorso-laterally, is separated into two layers, an inner matrix and an outer layer, which contains fibers, emerging from the hippocampus, the fornix (fig. 45, For.)

In a section parallel with the length of the fissura hippocampi (fig. 46, Fis. hip.) the fascia dentata (fig. 46, Fas. den.) is a thin band of cells lying in the marginal layer of the hippocampus. This section cuts the sickle-shaped fissura hippocampi tangently so that the typical hippocampal structure may be seen at two ends.

The 48-mm. embryo, Mall Collection, 886 (figs. 47 to 50)

Orientation is difficult in this embryo, because it was cut coronally to the long axis of the cerebral evagination. A comparison of the levels from which the figures were taken with the median sagittal view (fig. 20) is illuminating. Figure 47 passes longitudinally through the rostro-dorsal extent of the fissura hippocampi. The fascia dentata lies as a band in the outer margin (Fas. den.). The intermediate cell layer is well differentiated, while that of the pyramids extends only across the margin of the hippocampus. Lying between the fascia dentata and the matrix are the developing fibers of the fornix system.

Figure 48 was taken at a level farther caudally, below the dorsal arch of the fissura hippocampi. The architecture of the hippocampus is the same in its anterior and posterior extent with the exception that the number of developing fornix fibers is greater posteriorly. Following the posterior limb to its caudal 
end, there is no change in these relationships. Anteriorly, however, the cortical differentiation is coincident with the sulcus limitans hippocampi (fig. 49, Sul. vent.) and seems to be continuous with the same type of differentiation which lies dorsal to the root of the olfactory bulb. At both of these levels the septum contains three groups of cells as outlined in $\mathrm{H} 163$ (39.1 mm.) and is separated from the hippocampus by the sulcus limitans hippocampi. There are no discernible paraphyseal pouch or postvelar tubules.

Development in these two embryos may be summarized as follows:

1. Cortical differentiation in the region of the hippocampal formation, anterior to the paraphyseal arch, and the coincident reduction in depth of the fissura hippocampi in this region.

2 . The great growth of the lamina terminalis in all directions and an intrinsic differentiation into three cell groups, the septal nuclei.

3. The dorsal extension of the fascia dentata along the margin of the medial wall.

4. The development of the anterior commissure and the fornix system.

The eight brains described in the preceding pages have been arranged according to the time interval between the initiation of the growth process and its arrest, measured as the greatest length attained by the individual. The greater the difference in length the greater the growth changes. These embryos may be divided into the following groups:

1. The $11.8-\mathrm{mm}$.

2. The $14.0-\mathrm{mm}$.

3. The $19.1-\mathrm{mm}$. and the $20.0-\mathrm{mm}$.

4. The $27.8-\mathrm{mm}$. and the $32.1-\mathrm{mm}$.

5. The $39.1-\mathrm{mm}$. and the $43.0-\mathrm{mm}$.

This division is also a logical one, for when these groups are compared to the curve of change through which this particular protoplasm has passed, certain similarities are noticed, from which it seems that the recapitulation of phylogenetic processes is 
woven into the fabric of their development in such a manner that later additions of brain substance have not erased the early history of the long passage. Consequently, there is a possible interpretation of early growth in the human telencephalon based upon a comparison of its growth with that attained by various representatives of the vertebrate phyla. However, it may appear when this study is complete that this so-called biological inertia which has been used to explain the striking similarities of development in the brains of the vertebrate series has its roots not in heredity as such, but in the more fundamental necessity of the mechanics of growth. Although certain recapitulations are complete, there is no stage of development whose rhythms of growth repeat in any way accurately earlier phylogenetic stages. If, however, the development of one particular tissue is watched with care, the sequence of intrinsic differentiation will appear in the order of a phylogenetic recapitulation. It is possible that the disturbing element is the growing neopallium, whose initial acceleration influences the growth rhythms of the other parts of the telencephalon and may therefore have modified the early phylogenetic relationships of this tissue.

\section{DISCUSSION}

Certain factors seem to be implicit in the growth changes of the telencephalon. They are the landmarks or points in the midline which show individual differentiation. These points are delimited by a peculiar histological structure and a characteristic external morphology. With such a series of stages as presented, the early development in the midline, together with those changes in the telencephalic vesicle whose various parts are confluent with them, may be followed.

\section{Telencephalon medium}

The midplane structures of the telencephalon medium have been divided into two main divisions by the angulus terminalis, the lamina terminalis and the area chorioidea. The lamina terminalis grows progressively thicker, rostro-caudally, and the thickening approaches the angulus terminalis progressively from 
younger to older stages so far as studied. The area chorioidea is differentiated early into two regions, one of whose lateral limbs becomes the thin lamina epithelialis of the lateral plexus and the other an area in which changes are insignificant. The former is the paraphyseal arch and the latter is the tela chorioidea telencephali medii.

In table 4 the writer has attempted to measure, somewhat crudely to be sure, two dimensions of these midline structures. The total lengths of the telencephalon medium were taken by

TABLE 4

Measurements of divisions of the telencephalon medium

\begin{tabular}{|c|c|c|c|c|c|c|c|c|}
\hline \multicolumn{2}{|c|}{ EMBRYO } & \multirow{2}{*}{$\frac{\begin{array}{c}\text { TELENCE- } \\
\text { PHALON } \\
\text { MEDTUM }\end{array}}{\text { Length }}$} & \multicolumn{2}{|c|}{ LAMINA TERMINALTS } & \multicolumn{2}{|c|}{$\begin{array}{c}\text { TELA CHORIO IDEA } \\
\text { TELENCEPHALI } \\
\text { MEDII }\end{array}$} & \multicolumn{2}{|c|}{ PARAPHYBIS } \\
\hline Number & Length & & Length & $\begin{array}{l}\text { Greatest } \\
\text { width }\end{array}$ & Length & Width & Length & Width \\
\hline & $m m$. & $m m$. & $m m$. & $m m$. & $m m$. & $m m$. & $m m$. & $m m$. \\
\hline 1121 & 11.8 & 2.388 & $0.94^{1}$ & 0.054 & $0.248^{1}$ & 0.02 & 1.24 & 0.02 \\
\hline 940 & 14.0 & 1.620 & $1.048^{1}$ & 0.088 & $0.168^{1}$ & 0.028 & 0.404 & 0.032 \\
\hline $\mathrm{H} 173$ & 19.1 & 2.52 & 1.72 & 0.17 & 0.29 & 0.03 & 0.51 & 0.04 \\
\hline 460 & 20.0 & 2.516 & 1.60 & 0.15 & 0.40 & 0.036 & 0.516 & 0.036 \\
\hline H 91 & 27.8 & 2.645 & 2.27 & 0.51 & 0.15 & 0.02 & 0.225 & 0.05 \\
\hline H 41 & 32.1 & 2.834 & 2.40 & 0.644 & 0.184 & 0.041 & 0.25 & 0.064 \\
\hline H163 & 39.1 & 3.24 & 2.56 & 0.80 & 0.21 & 0.72 & 0.470 & 0.044 \\
\hline 886 & 43.0 & 3.34 & 2.94 & 0.73 & 0.15 & 0.75 & 0.2 & 0.045 \\
\hline
\end{tabular}

1 These are estimates, because the angulus terminalis is not present.

measuring the distance between the recessus preopticus and the velum transversum at the magnification of the model studied. That length was then divided by the magnification. Consequently, the figures are approximately the actual length in millimeters as found in the particular embryo and therefore comparative.

The distribution of the increase lies entirely in the lamina terminalis. The telencephalon medium grows in length mainly because the lamina terminalis increases in length. If the accompanying figures 1 to 6 be examined, especially figures 3 to 6 sketch 1 and $1 \mathrm{~d}$, through the ventral and dorsal divisions of the 
terminal plate, the growth in depth and width is apparent. This change is a continuous one and, as far as the evidence presented in this paper is concerned, it seems to be one which accompanies the intrinsic growth and differentiation of the contiguous structures. Certain it is, that following the initial differentiation of the septum into matrix and marginal velum and the subsequent appearance of the two septal nuclei, the matrix layer becomes noticeably poor in cells. The whole seems to be a growth at the expense of the cells in situ and not a migration of cells from other centers. In the two oldest embryos only, the anterior

\section{ABBREVIATIONS}

A.ch., area chorioidea

A.ep., area epithelialis

A.int., area in tercalata

Ant.com., anterior commissure

Ang.term., angulus terminalis

Ang.vent, angulus ventralis

Ant.l.hyp., anterior lobe of hypophysis

Bul.olf., bulbus olfactorius

Cer., cerebellum

Cor.mam., Corp.mam., corpus mamillare

Cor.str., Corp.str., corpus striatum complex

Cor.str.lat., Corp.str.lat., corpus striatum laterale

Cor.str.med., Corp.str.med., corpus striatum mediale

Def.fas.den., fascia dentata

Dien., diencephalon

Dien.r.pl., diencephalic roof plate

Di-tel.gr., di-telencephalic groove

Ep.ev., epiphyseal evagination

Epith., epithalamus

Fas.den., fascia dentata

F.b.op.ch., bed of the optic chiasma

Fil.olf., fila olfactoria

Fis.hip., fissura hippocampi

Fis.pr., fissura prima

For., fornix

For.int., foramen interventriculare

$H a b .$, habenula

Hab.com., habenular commissure
Hip., hippocampus

Hypoth., hypothalamus

Inf., infundibulum

Is.cal., islands of Calleja

Lam.ep., lamina epithelialis

Lam.ter., Lam.term., lamina terminalis

Lat.olf.tr., lateral olfactory tract

Lim.men., limitans meningea

Man.l., marginal velum

Mat., matrix

Mes., Mesen., mesencephalon

Mes.f.pl., mesencephalic floor plate

Mes.r.pl., mesencephalic roof plate

Met., Meten., metencephalon

Myel., myelencephalon

Neopal., neopallium

Nuc.ac., nucleus accumbens of Kappers

Nuc.lat.olf.tr., nucleus lateralis tracti olfactorii

Nuc.lat.sept., nucleus lateralis septi

Nuc.lent., nucleus lentiformis

Nuc.med.sept., nucleus medialis septi

Olf. bulb, olfactory bulb

Olf.evag., evagination of olfactory bulb

Op.c., optic chiasma

Op.evag., Opt.evag., optic evagination

Op.s., Op.st., optic stalk

Par.ar., paraphysea, arch

Par.p., paraphyseal pouch

$p . c$. , pars crassa of lamina terminalis

P.com., Post.com., posterior commissure 
Pl.ch.vent.lat., plexus chorioideus ventriculi lateralis

Pl.ch.vent.quart., Pl.ch.v.quar., plexus chorioideus ventriculi quarti

Pl.ch.vent.ter., plexus chorioideus ventriculi tertii

Poly.c.l., intermediate layer of migrating neuroblasts

Post.hyp., Post.l.hyp., posterior lobe of hypophysis

P.Ra., P.Rat., pouch of Rathke

Prim.hip., primordium hippocampi

p.t., pars tenuis of lamina terminalis

P.vel.r., postrelar arches

P.vel.t., postvelar tubules

Pyr.c.l., pyramidal cell layer

Rec.inf., recessus infundibuli

Rec.mam., recessus mamillaris

Rec.op., optic ventricle

Rec.postop., recessus postoptieus

Rec.preop., recessus preopticus

Reg.par.ar., region of the paraphyseal arch

Reg.sept., region of the septum epen. dymale

Rhom.fos., rhomboid fossa

Sept., septum
Sept.epen., septum ependymale

sul,dors., sulcus dorsalis thalami

Sul.fim.den., sulcus fimbrio-dentatus

Sul.fu.pl.ch.vent.lat., sulcus futurus plexus chorioidei ventriculi lateralis

Sul.lim., sulcus limitans

Sul.mon., sulcus Monroi

Sul.vent., sulcus limitans hippocampi

Tel., telencephalon

Tel.ch.tel.med., tela chorioidea telencephali medii

Tel.evag., telencephalic evagination

Tel.r.pl., telencephalic roof plate

Te.pl.ch.vent.lat., taenia plexus chorioidei ventriculi lateralis

Te.pl.ch.vent.quar., taenia plexus chorioidei ventriculi quarti

Te.pl.ch.vent.ter., taenia plexus chorioidei ventriculi tertii

Thal., thalamus

Tub.cin., tuber cinereum

Tub.olf., tuberculum olfactorium

Undif.f.den., Undiffas.den., undifferentiated fascia dentata

Vel.trans., velum transversum

Ven.lat., Vent.lat., ventriculus lateralis

Vent.tert., ventriculus tertius

\section{EXPLANATION OF SYMBOLS}

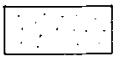

hippocampus.

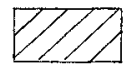

fascia dentata

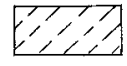

area epithelialis

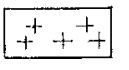

subcortical olfactory centers

\begin{aligned} \hline$+{ }^{+} \\ t_{+}^{+}++_{+}^{+}\end{aligned}$septal nuclei

sulcus limitans hippocampi 
commissure has grown across the midline. The bed for these fibers is laid down long before the fibers themselves appear. Further, the growth is appositional, taking place ventral to the center of the main body of the terminal plate and progressing both dorsally and ventrally. The most marked growth is found in the former region, and not in the vicinity of the angulus terminalis or the recessus preopticus.

There is no constant change in the non-plexiform portion of the area chorioidea and if the structures adjoining this region are examined (figs. 1 to 6 , sketch 2) they appear to be constant.
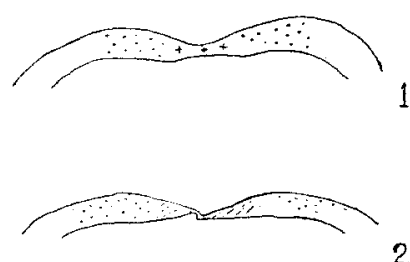

2

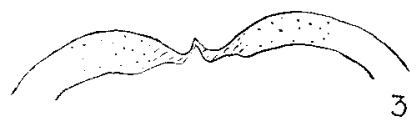

3
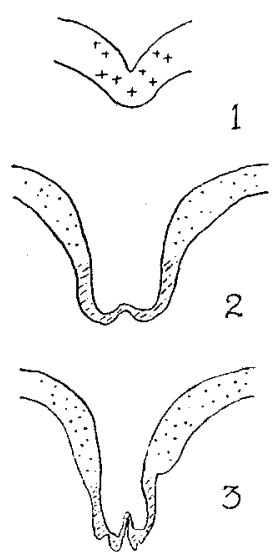

2
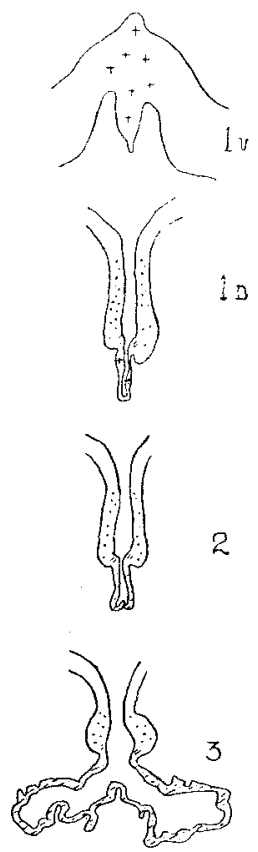

3

Figs. 1 to 6 These are pen sketches of the midregion of transverse sections of the telencephalon, showing the position of cell groups in the tissue; they were drawn either from photographs of the sections or from projections made with the Edinger apparatus.

Fig. 1 The 11.8-mm. embryo, no. 1121, Mall Collection. $\times 25$

Fig. 2 The 14.0-mm. embryo, no. 940, Mall Collection. $\times 25$

Fig. 3 The $19.1-\mathrm{mm}$ embryo, $\mathrm{H} 173$, University of Chicago. $\times 16 \frac{2}{3}$. 

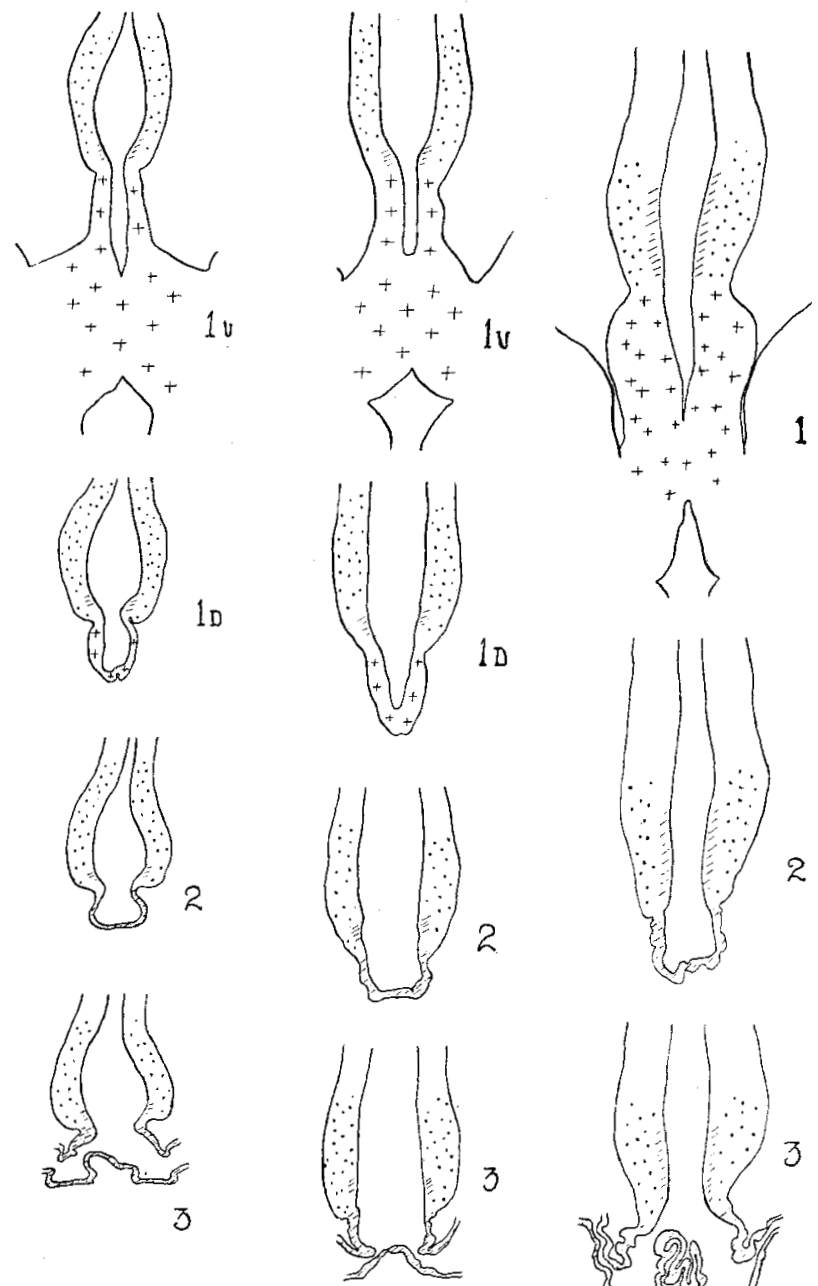

3

4

5

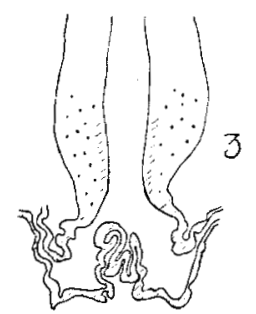

6

Fig. 4 The 27.8-mm. embryo, H 91, University of Chicago. $\times 12 \frac{1}{2}$.

Fig. 5 The 32.1-mm. embryo, H 41 , University of Chicago. $\times 12 \frac{1}{2}$.

Fig. 6 The 39.1-mm. embryo, H 165, University of Chicago. $\times 12 \frac{1}{2}$.

The levels from these various embryos are designated as follows: 1) through the lamina terminalis; $1 \mathrm{v}$ ) through the ventral part of the lamina terminalis; $1 \mathrm{~d})$ through the dorsal part of the lamina terminalis; 2 ) through the tela chorioidea telencephali medii; 3 ) through the paraphysis.

The various regions of the medial wall contiguous to the midline structures are self-explanatory, see the legend below the list of abbreviations. 
The only deduction which the present series allows is that the growth in this region is immaterial. In such a case this measurement lends another landmark to the study of the midline. Probably the most striking group of figures presented are those of the paraphyseal arch. There is little change in the antero-posterior length; in this particular series, the younger embryos possess the longer arches. The shortening of the distance between the

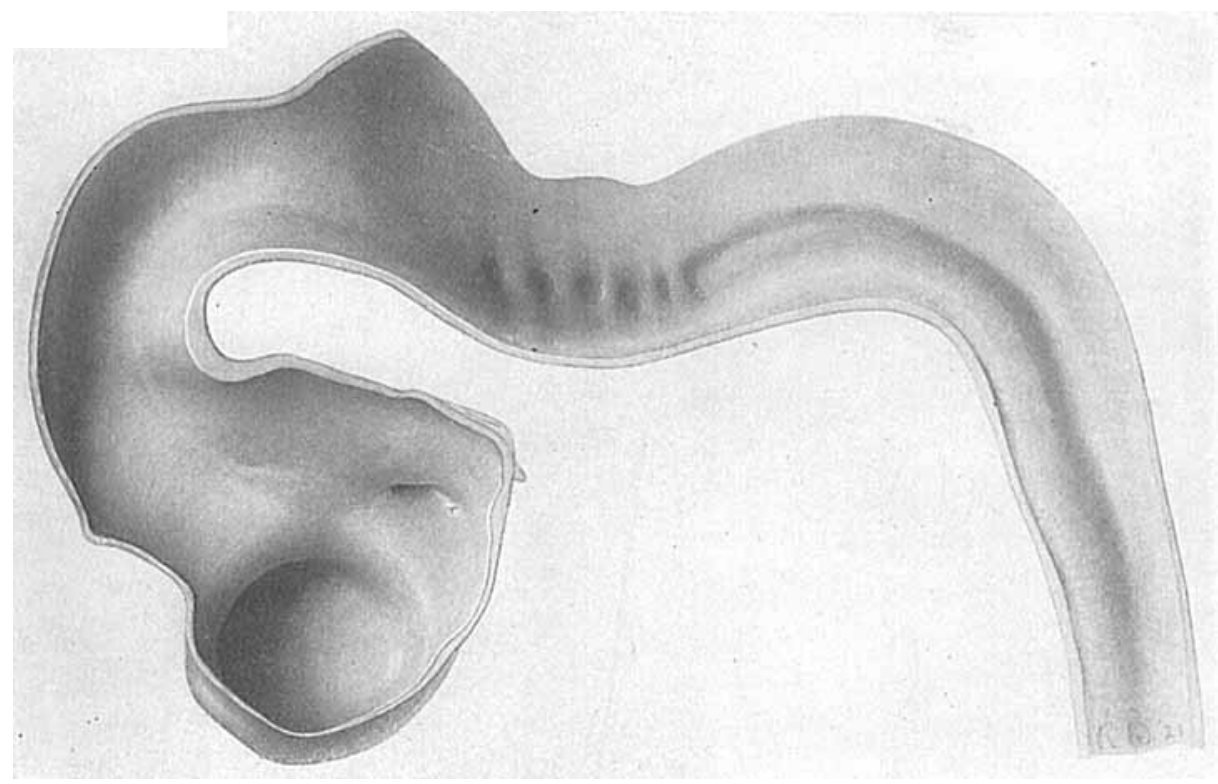

Fig. 7 Medial sagittal view of a model of a 11.8-mm. embryo belonging to the Mall Collection in Baltimore, no. 1121. $\times 16 \frac{2}{3}$.

anterior and the posterior limb coincides with the decrease in width and the formation of the actual plexus itself. The constant feature is not the pouch; it is rather the simple arch itself. If these figures are substantiated by subsequent work, the paraphyseal arch will be a more prominent feature of the younger stages than of the older ones. This finding seems to place the human embryo in phylogenetic line with other mammals, the difference being not in its relative extent, but in the complexity of its bizarre outpouchings. This does not disagree with the work 
of Warren and Bailey; it simply calls attention to a fact not recognized before, that the paraphyseal areh is present even in very young embryos in a simple form, extensive when compared to the whole midline, especially in these brains. It of necessity retains its fundamental importance as a midline structure.

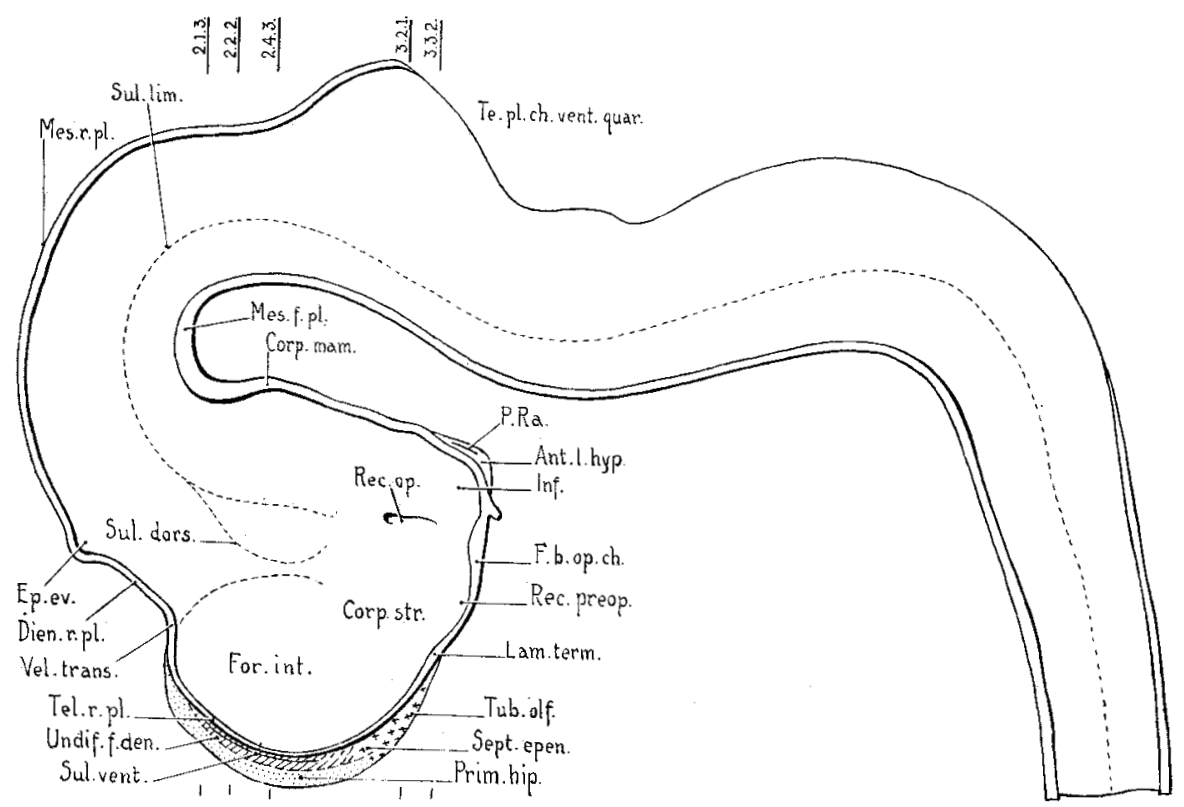

Fig. 8 This is a pen-and-ink outline of the same model as that shown in figure 7. Histologically distinct areas in the telencephalic medial wall are projected in their relative positions upon its surface. The key to these areas as well as those of the other models will be found below the list of abbreviations (p. 121). The annotations on all of the models refer to numbers of specific sections, whose photographs are reproduced in this paper or will appear in those which follow.

If these midline structures prove to be the landmarks which the writer has shown them to be in the embryos so far studied (and certainly all the well-preserved embryos between the ages mentioned which have been studied in the Department of Anatomy at Chicago and the Mall Collection in Baltimore substantiate that decision), the growth of the telencephalon adjoining them may be followed accurately. Herein lies an approach to data which 
will enable the growth of the medial hemisphere wall to be interpreted more wisely. It may also give new data upon the development of the new parts of the cortex lying on the medial wall of the hemisphere.

\section{Area epitheliatis}

The area epithelialis lies between the telencephalon medium and the sulcus limitans hippocampi. In the 11.8-mm. embryo this tissue is almost neglible in the rostral division of the hemisphere, but it becomes markedly greater in the caudal portions of that evagination. This difference is one of fundamental importance (figs. 1 to 6 , sketches 2 and 3). Along the dorsal margin of the area epithelialis on the opposite side of the sulcus limitans hippocampi, the fornix is developed. This sulcus is regarded as the ventral limit of the cerebral cortex and the epithelial tissue is the derivative of the most dorso-medial portion of the roof of the primitive evaginated telencephalon. In such a primitive condition, the fornix formed a fringe along its lateral border and the anlage of the hippocampus lay laterally of it (i.e., morphologically ventral to it). This condition is almost exactly realized in the brain of Ichthyomyzon concolor (Herrick and Obenchain, '13). In the process of evagination the relations of the area epithelialis to the fornix and the hippocampus are reversed; that is, the two latter areas are turned first outward, then upward, so that in the medial wall of the hemisphere they come to lie dorsally of the area epithelialis. This seems to be a true statement of the case, because in the $11.8-\mathrm{mm}$. brain the sulcus limitans hippocampi is coextensive with the epithelial

Fig. 9 This is the anterior view of the model shown in figures 7 and 8, no. 1121 of the Mall Collection. $\times 16 \frac{2}{3}$. There is a slight depression in the midline separating the initial evagination into two halves.

Fig. 10 This is the anterior view of the same model as that shown in figures 13 and 14. This 14-mm. embryo belongs to the Mall Collection in Baltimore, no. $940 . \times 16 \frac{2}{3}$.

Fig. 11 This is a pen-and-ink sketch of the same view as that shown in figure 9, no. 1121. $\times 16 \frac{2}{3}$. The areas indicated in figure 8 are shown in their dorsal extent. The planes of section of figures 21 to 25 are indicated.

Fig. 12 Anterior view of no. 940, same en bryo as figure $10 . \times 16_{3}^{\frac{2}{3}}$. 

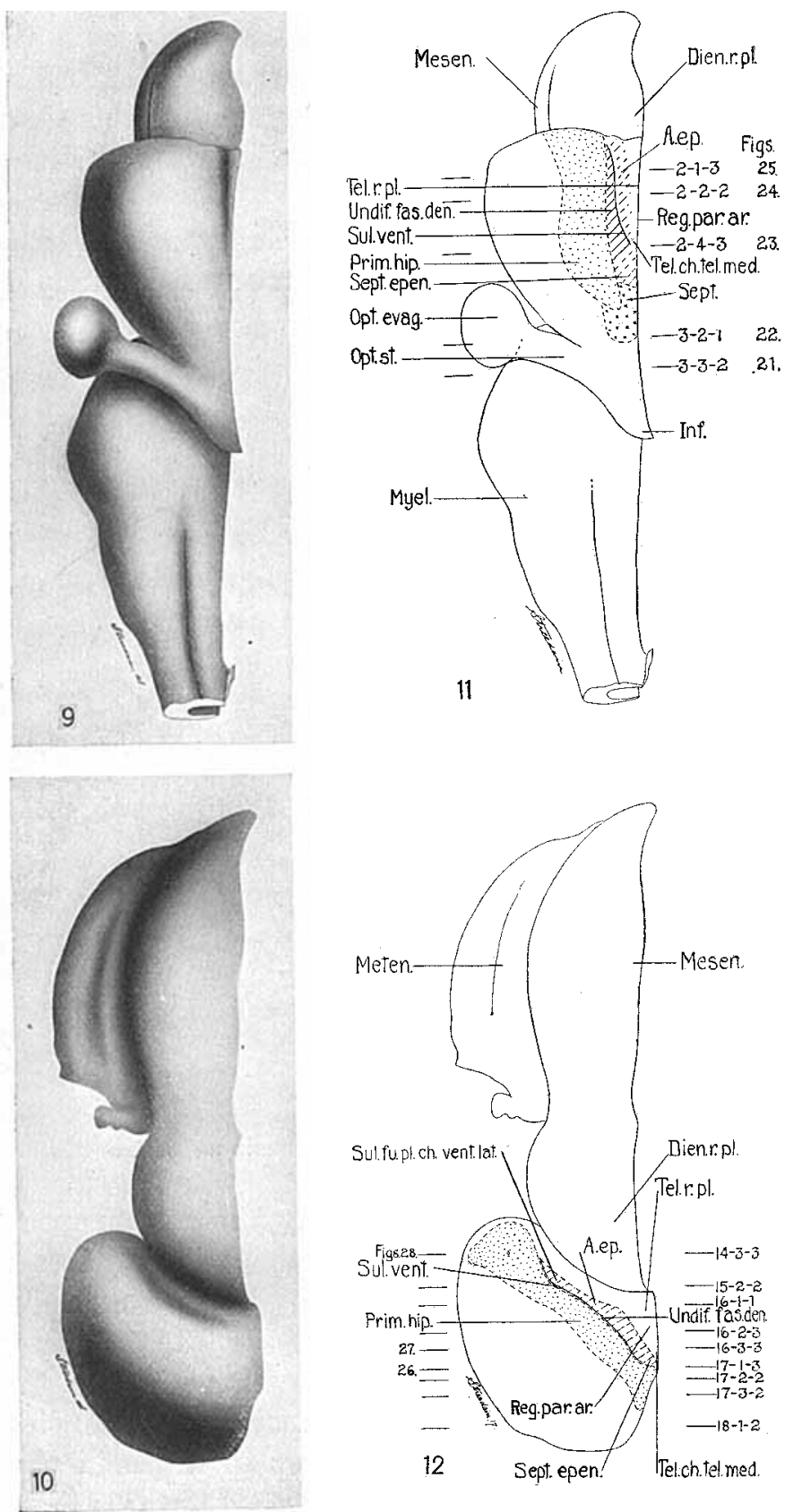
tissue and approaches the extent of the differentiation in the hemisphere wall termed the primordial hippocampus (figs. 8 and 24). The interpretation of the further development of this tissue must be correlated with this finding, as well as with the facts of its phylogenetic development.

This region of generalized morphology and histology was divided for descriptive purposes into three areas, entirely upon the

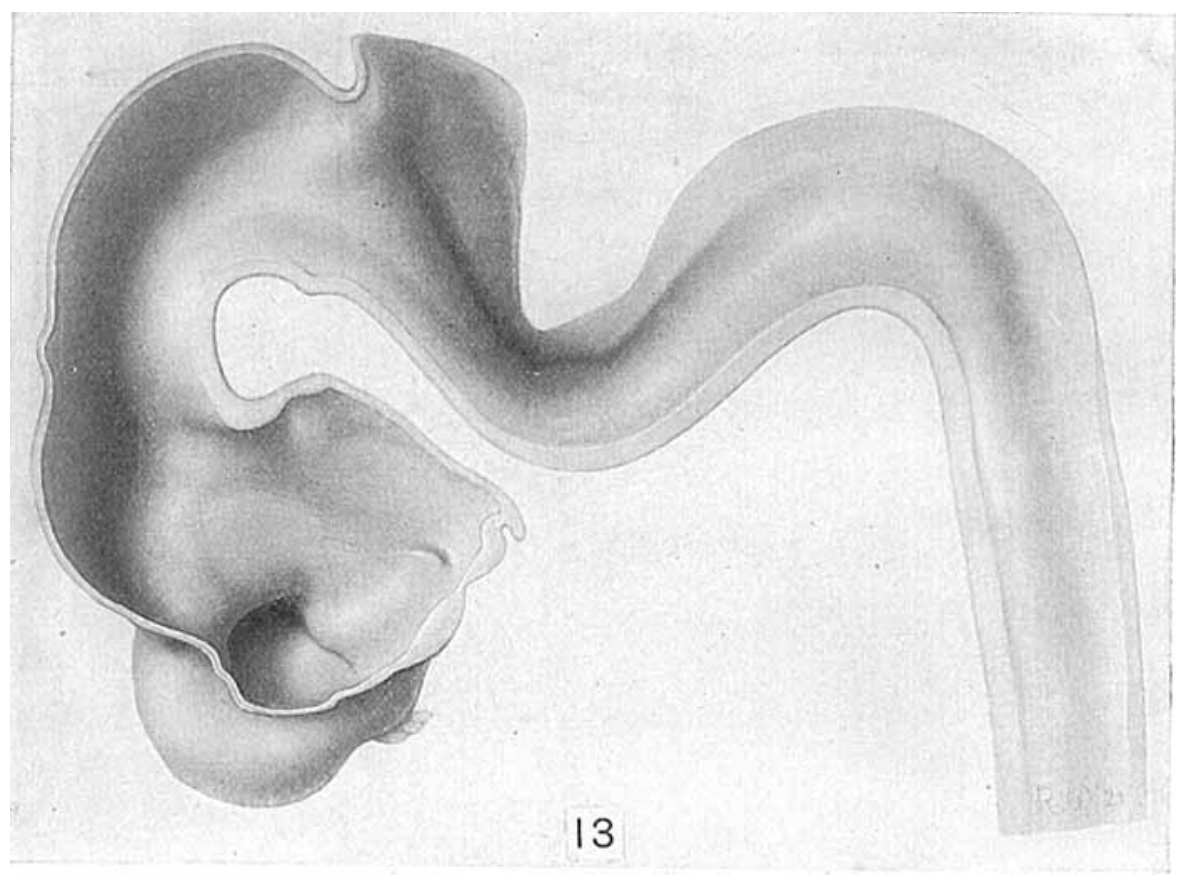

Fig. 13 Medial sagittal view of the model of brain no. $940,14 \mathrm{~mm} . \quad \times 16 \frac{2}{3}$.

basis of their respective destinics, namely, the septum ependymale, the area intercalata, and the lamina epithelialis. The relative growth of the septum ependymale may be seen at a glance by comparing the sections marked $1 d$ in figures 3 to 5 . This region, an undifferentiated epithelium in the brains of the first four embryos described, begins to show a marginal velum in the 20 $\mathrm{mm}$. embryo, which persists and grows in width in the brains of this group. The differentiation proceeds towards the angulus 
terminalis as a limit. There is always some tissue, therefore, which retains the initial two layers of the early conditions. The area intercalata changes little in morphology. Its extent increases most noticeably in the dorso-ventral direction. Intrinsic differentiation is practically identical throughout the older brains of the series (19.1 mm. to $43 \mathrm{~mm}$.).

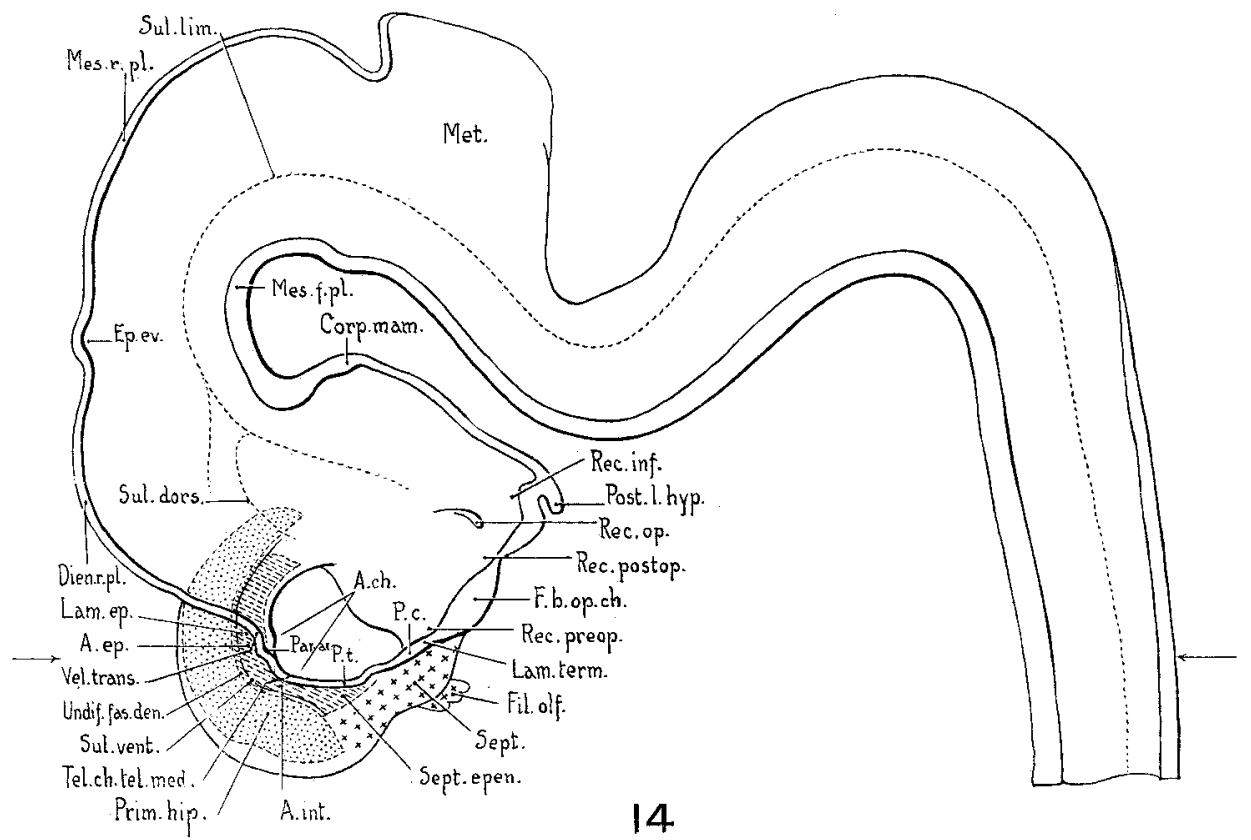

Fig. 14 Pen-and ink outline of the same brain taken from the same point of view as that shown in figure 13. The extent of the medial olfactory areas is projected upon the medial wall of the telencephalon. The arrows indicate the plane of section.

The lamina epithelialis lying between the lateral limb of the paraphyseal arch and the sulcus limitans hippocampi increases in relative importance in the older embryos. In the $11.8-\mathrm{mm}$. the amount of epithelial tissue adjoining the lateral limb of the paraphyseal arch is more extensive than that adjoining the unarched portion of the roof of the telencephalon medium. There is no lateral choroid plexus here; neither is the telencephalon more than a slight evagination. However, in the 14-mm. embryo 
the paraphyseal arch is a definite dorsal protrusion of the roof plate just anterior to the velum transversum. The tissue contiguous to it is convex lateralward, the first indication of the invagination of the lateral choroid fissure. In all the rest of the series, the plexus exists as described for man by Bailey ('16a), namely, the choroid plexus of the lateral ventricle consists of two divisions, an anterior, whose lateral taenia is that of the fornix and whose medial is the lateral limb of the paraphyseal

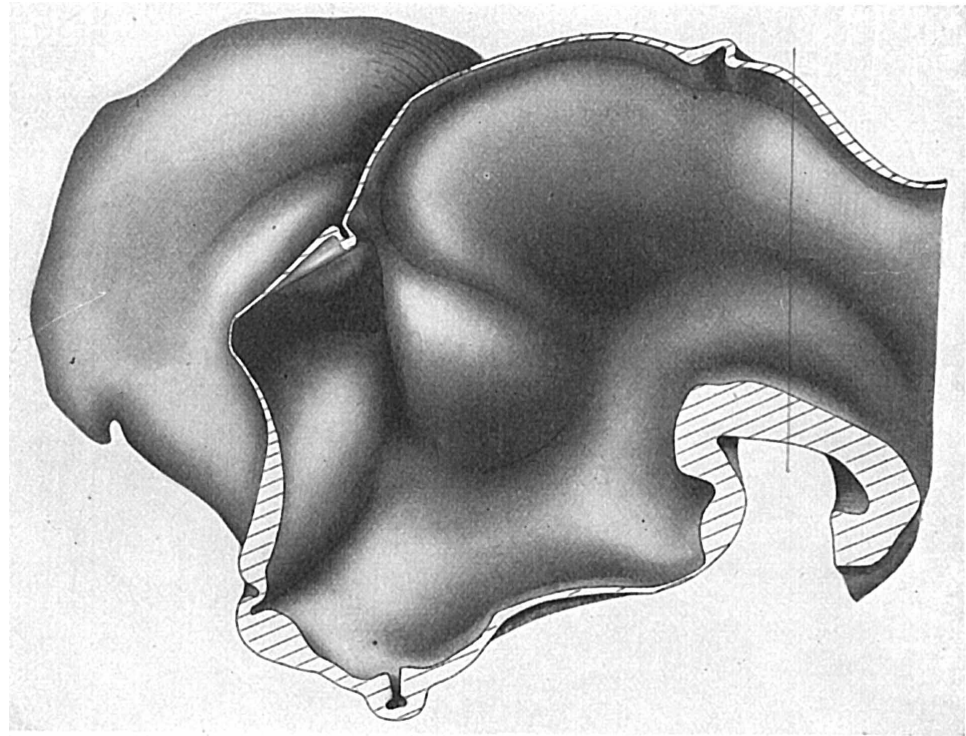

Fig. 15 Median sagittal view of the forebrain of $\mathrm{H}$ 173. a 19.1-mm. human embryo, belonging to the Chicago collection. $\times 16 \frac{2}{3}$.

arch, and a posterior, whose lateral taenia is the same as that of the anterior division, but whose medial taenia is the telencephalic limb of the di-telencephalic groove, the taenia chorioidea. In these older embryos the hippocampus forms a complete crescent dorsal and lateral to the plexus. In all stages the primordial hippocampus precedes the choroid plexus as the hemisphere grows caudally.

Bailey ('16a, fig. 15, a. c. p.) has suggested that the growth of the posterior limb of the lateral choroid plexus is a simple 
continuous invagination of tissue which lay undifferentiated in the sickle-shaped telencephalic wall adjoining the di-telencephalic groove. There is no indication in the $11.8-\mathrm{mm}$. or in the 14$\mathrm{mm}$. embryo of an area peculiarly differentiated in that region. The primitive hippocampus arches over the caudal pole of the developing hemisphere. Since the hippocampal tissue precedes

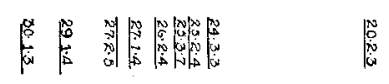

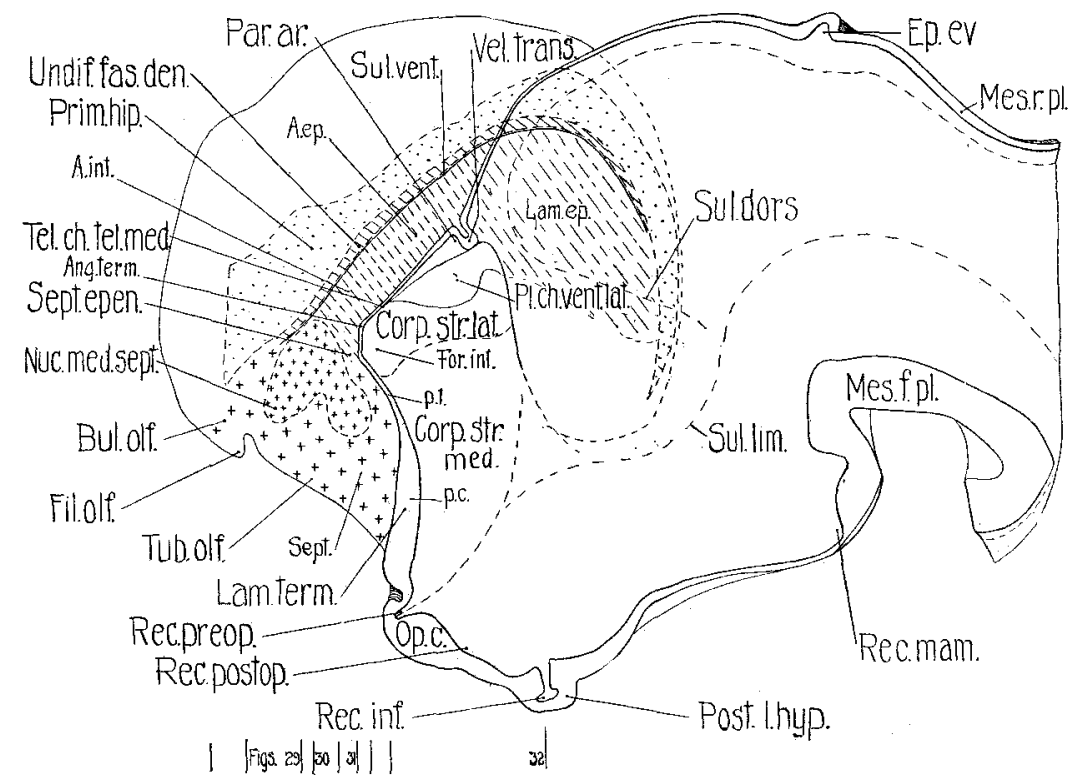

Fig. 16 Outline sketch of the same brain as that shown in figure 15. The dotted line, continuous with the telencephalon above the diencephalic roof plate, indicates the most caudal boundary of the cerebral hemisphere. The planes of section of figures 29 to 32 are indicated.

the choroid plexus in differentiation, it is natural to place the anlage of the plexus in the epithelial tissue which lies between the definitive hippocampus and the paraphyseal arch and velum transversum. These two divisions of the lateral choroid plexus are fundamentally the same and their development coincides with the ventro-caudal growth of the hippocampus. The more extensive that growth is, the more extensive the so-called pos- 
terior limb, and the less extensive, the less that portion will be developed. Bailey ('16b) says, discussing the morphogenesis of the choroid plexus:

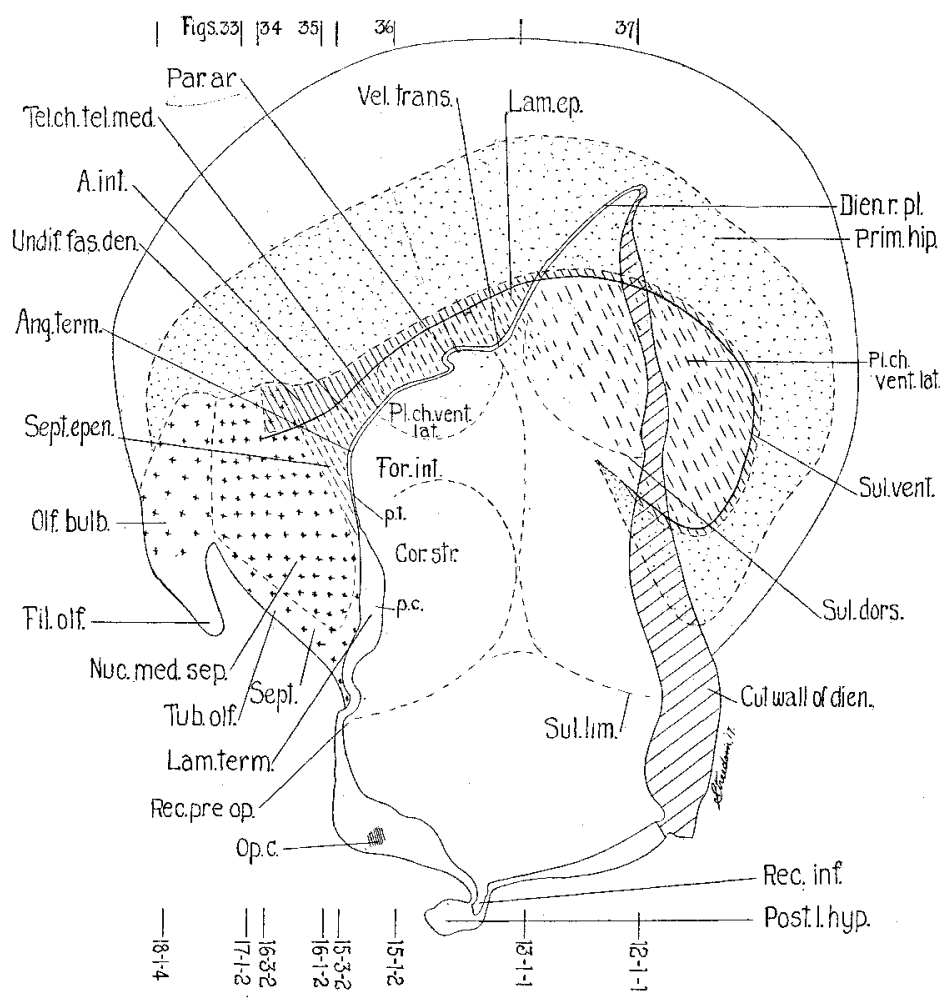

Fig. 17 This is an outline sketch of the brain of a $20-\mathrm{mm}$. embryo, no. 460 , belonging to the Mall Collection. The area indicated by stippling corresponds to the extent of the fissura hippocampi. The planes of section of figures 33 to 37 are indicated.

In all forms below Chelonia, the lateral telencephalic plexus develops in what I have called elsewhere (Bailey, ' 16 a) the anterior lateral telencephalic chorioidal area, in the roof plate of the telencephalon between the paraphysis and the taenia fornicis of the medial hemisphere wall. With Chelonia comes a change. The lateral plexus arises in the anterior area chorioidea lateralis telencephali, as has been previously described, but in its later development crosses the taenia fornicis and invaginates also the posterior area chorioidea lateralis telencephali in the medial hemisphere wall. . . . . This involvement of the medial hemisphere comes more and more to predominate in the develop- 


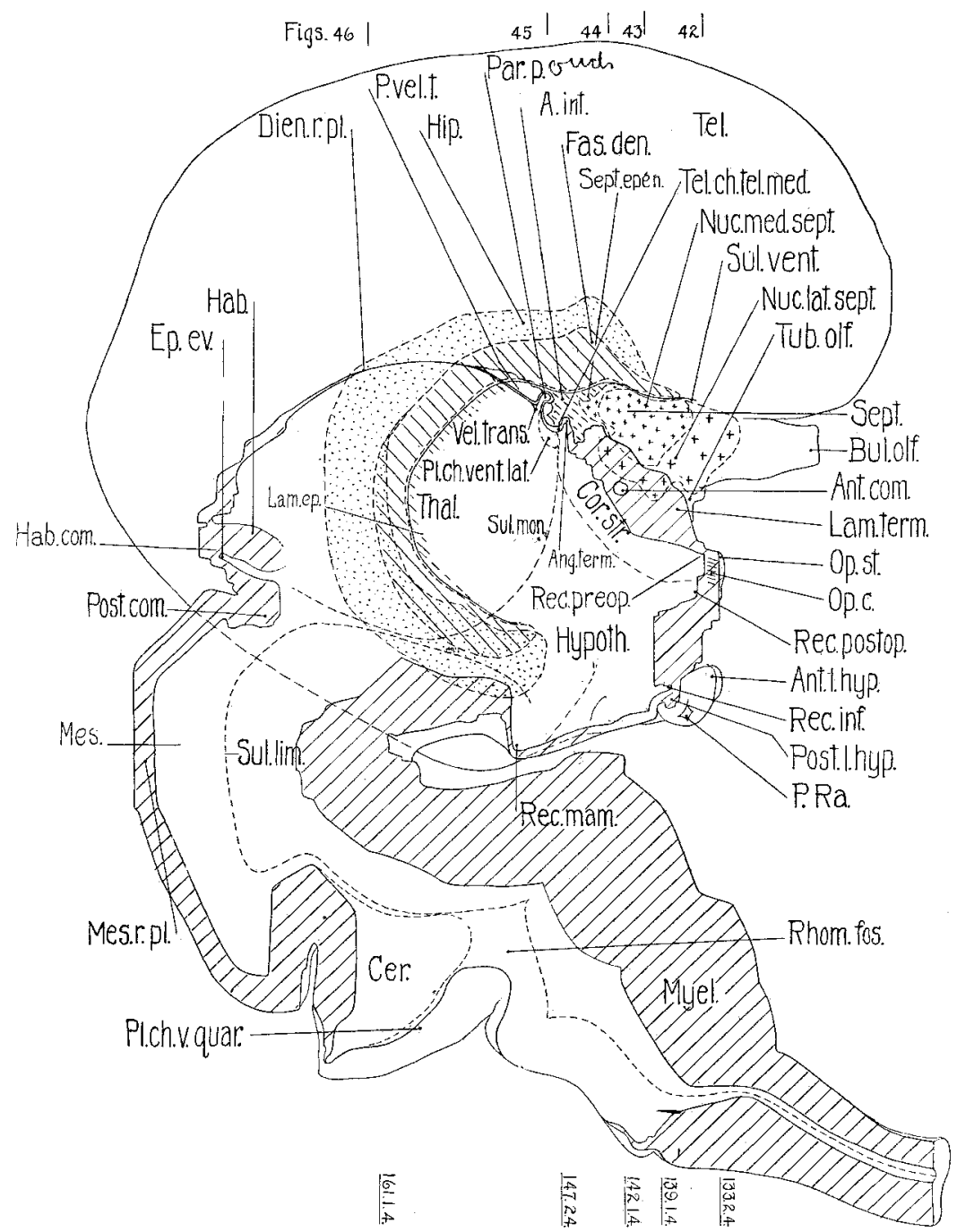

Fig. 18 Median sagittal view of the wax model made from the brain of a 39.1-mm. human embryo $\mathrm{H} 163$ of the Chicago collection. $\times 8 \frac{1}{3}$. The positions of the sulcus limitans and the thalamic midgroove are indicated by broken lines. The olfactory area is identified on the medial wall and sketched as if the thalamic wall were transparent. The planes of section of figures 42 to 46 are indicated. 
ment of the lateral plexus as the hemispheres come more and more to dominate the development of the telencephalon (pp. 526 and 527).

However, it dominates only because of the progressively increasing importance of the portion of the hippocampus which is developing in the ventro-caudal direction concomitant with the growth of the hemisphere in that same direction to form the

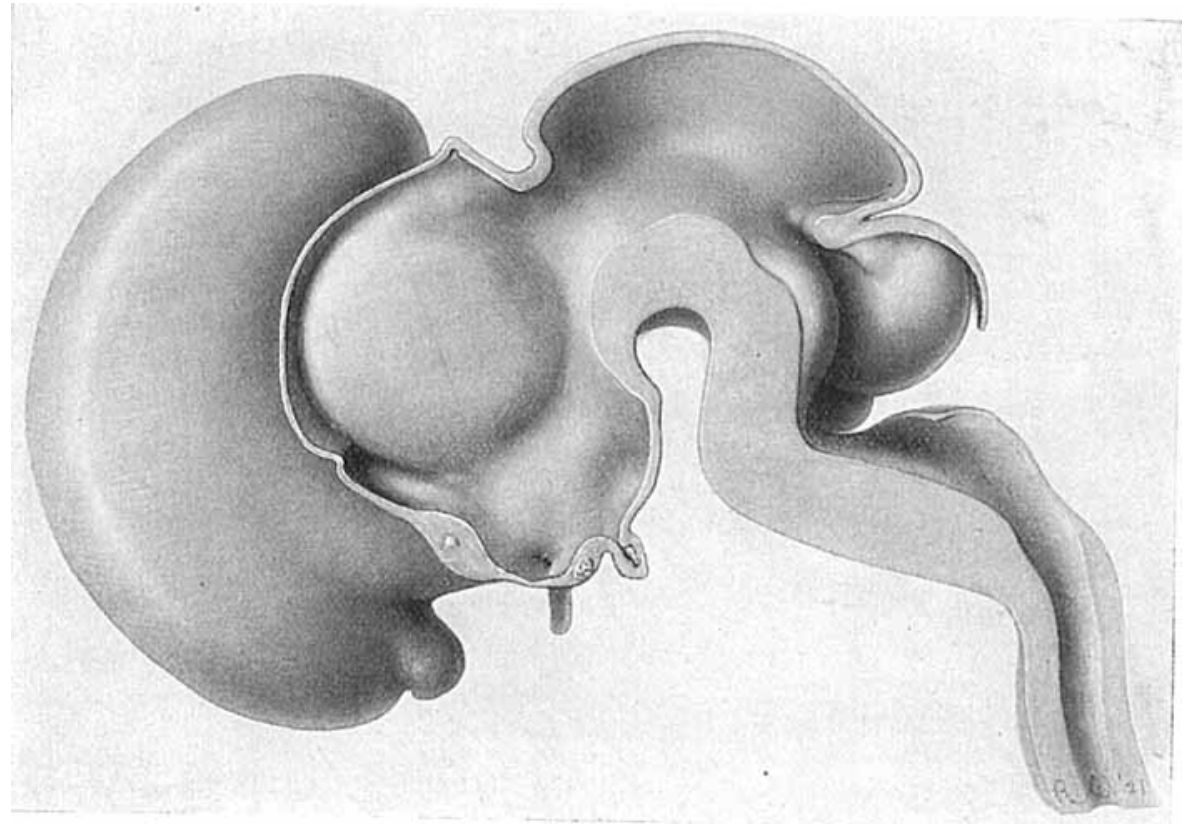

Fig. 19 Median sagittal view of a model made from the brain of a 43-mm human embryo belonging to the Mall collection, no. $886 . \times 6 \frac{2}{3}$.

temporal lobe. It seems more reasonable, therefore, to place the anlage of the telencephalic lateral plexuses, even in man, in the epithelial tissue which lies between the taenia fornicis or the sulcus limitans hippocampi and the paraphyseal arch and velum transversum and limited rostro-caudally by the anterior limb of the paraphyseal arch and the velum transversum. From this dorsally placed anlage it grows ventro-caudally. If this be true, the primordium of both divisions of the two lateral choroid plexuses lies immediately contiguous to the roof plate of the early unevaginated telencephalon. 


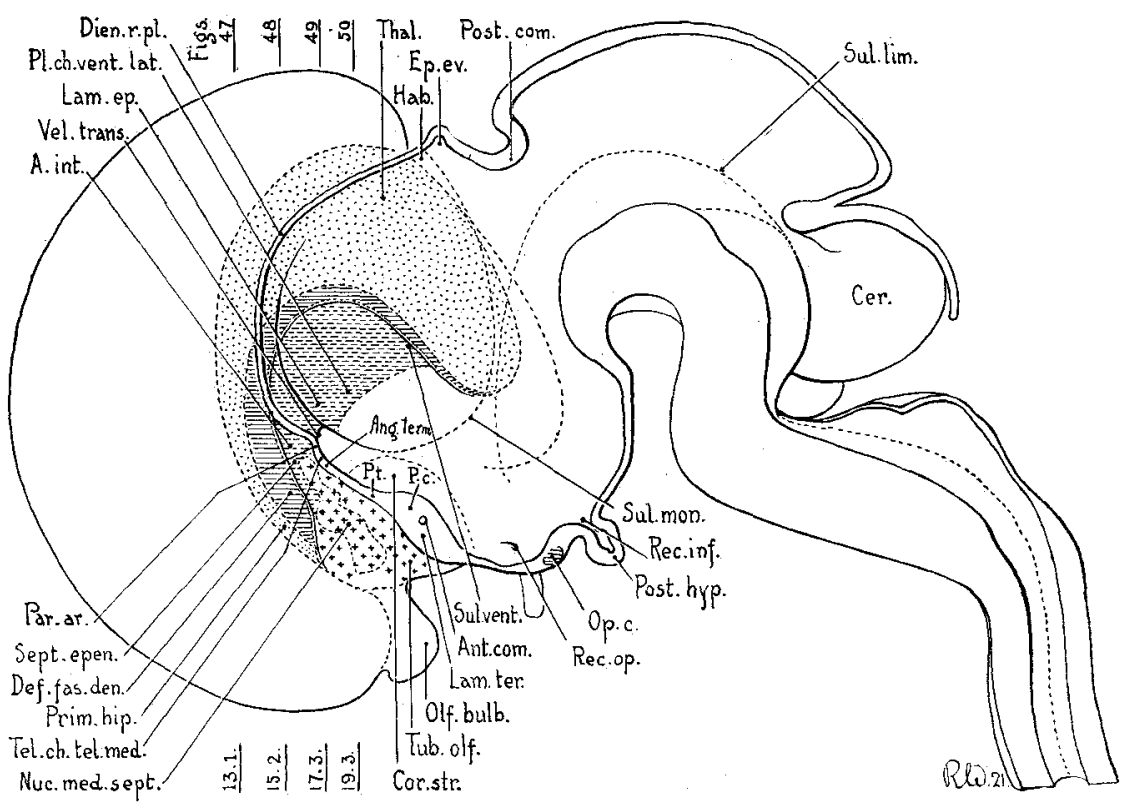

Fig. 20 Outline sketch of the same model as that shown in figure 19. The broken lines indicate the position of the sulcus limitans, the most caudal boundary of the telencephalic evagination, and the separation of the thalamus from the hypothalamus. The extent and the boundaries of the olfactory area projected upon the medial wall of the telencephalon can be seen through the main body of the thalamus. The planes of figures 47 to 50 are indicated.

Figs. 21 to 25 A series of transverse sections, pen-and-ink outlines, made with the Edinger apparatus, through the various levels of the telencephalon of no. 1121, the $11.8-\mathrm{mm}$. embryo. The numbers below the sections correspond to those in figures 8 and 11 and each indicates a specific section. $\times 50$.

Fig. 21 At the level of the optic evagination.

Fig. 22 Through the middle of the lamina terminalis.

Fig. 23 Through the tela chorioidea telencephali medii.

Fig. 24 Through the paraphysis. In this and the preceding figure the wall of each cerebral hemisphere shows four distinct zones. Beginning in the midplane they may be designated as follows: 1) A thin septal area, telencephalic roof plate; 2) A thicker homogeneous area, the septum ependymale, bounded laterally by a shallow ventricular sulcus, the sulcus limitans hippocampi; 3) A small area showing a narrow mantle layer emerging from the matrix, the future hippocampus; 4) An adjoining and still more lateral area where no clear mantle zone is visible, the neopallium. 


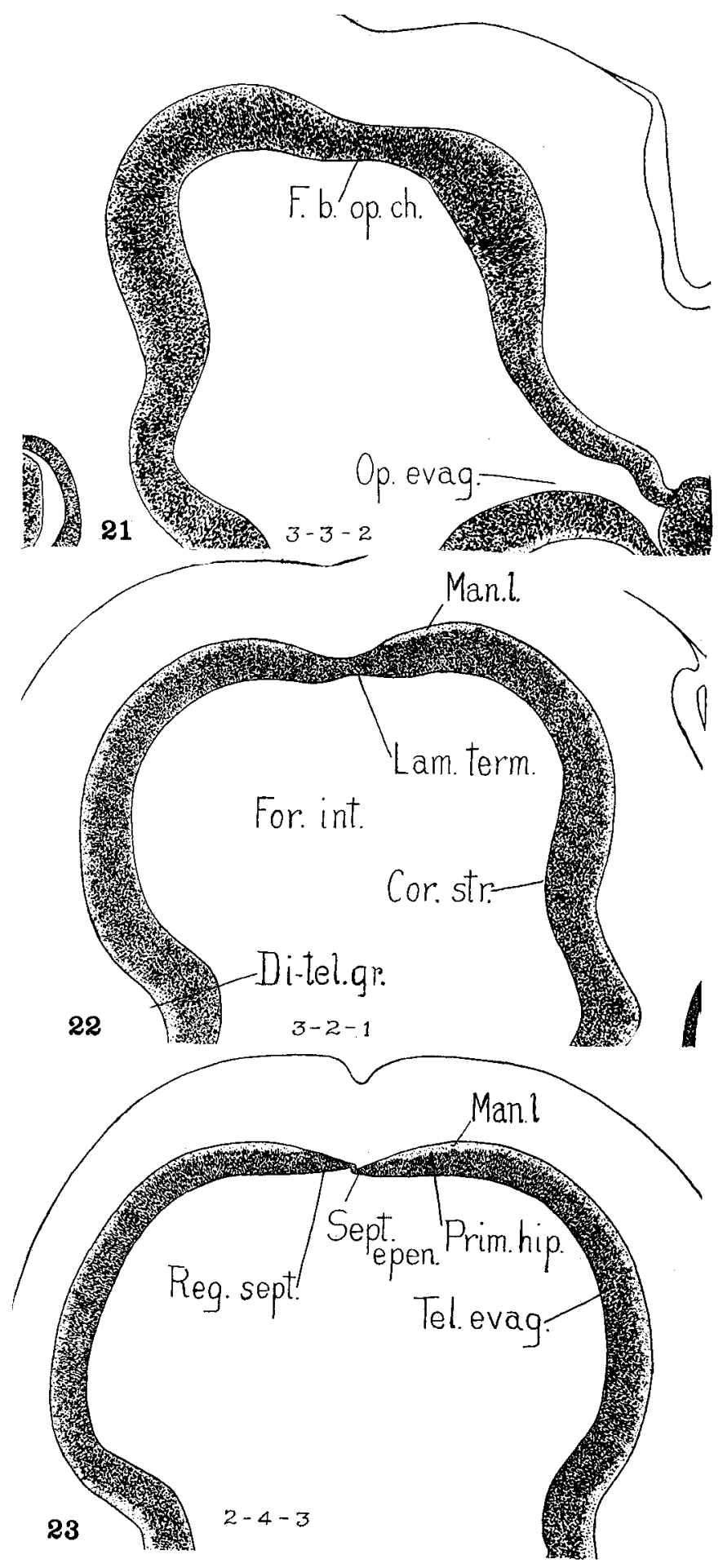



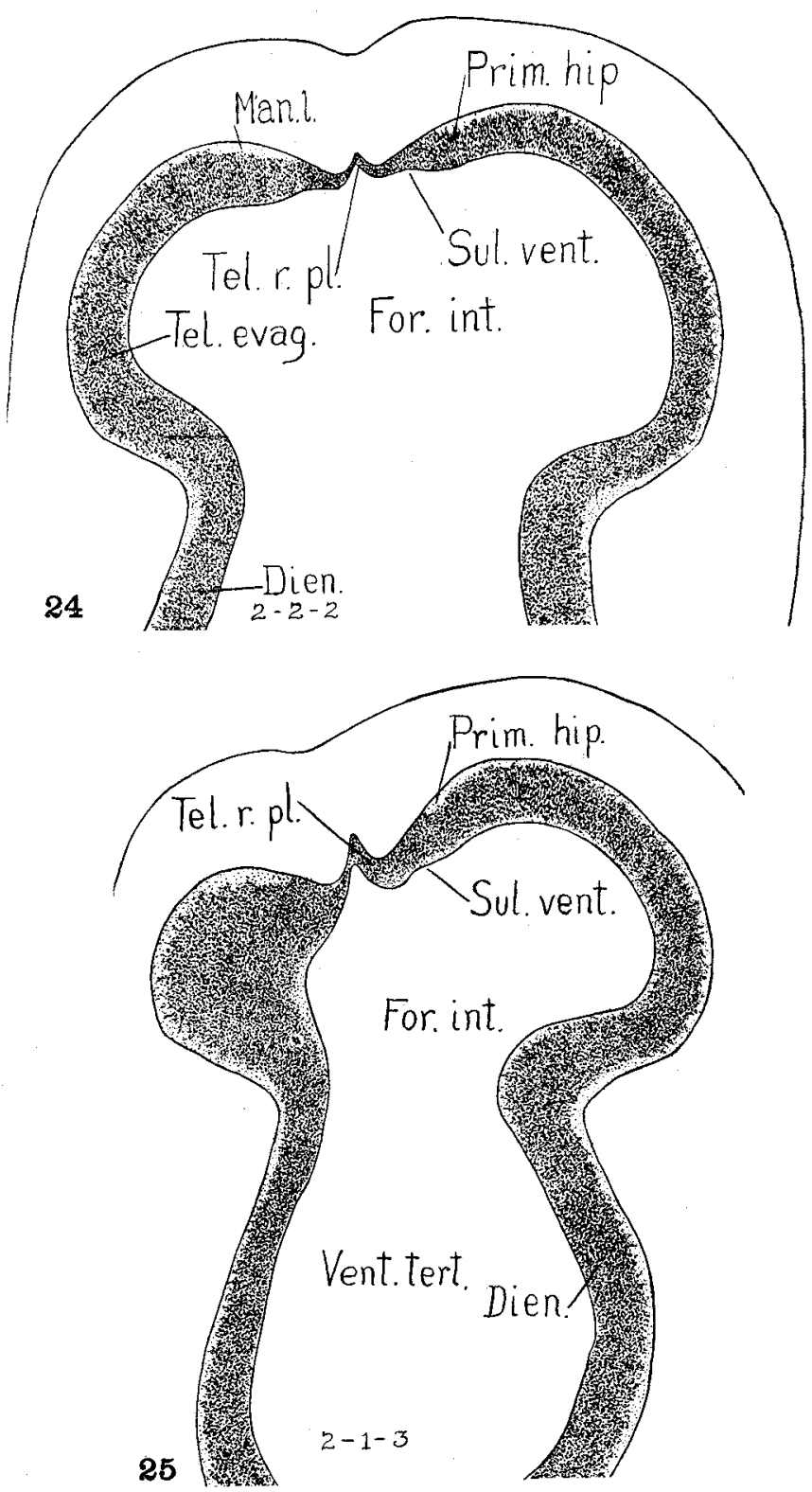

Fig. 25 This is taken slightly cephalad on the left, but passes through the paraphysis on the right. Upon the right the differentiation of the dorsal telencephalic wall may be divided into four histologically distinct areas as seen in figures 23 and 24.

THE JOURNAL OF COMPARATIVE NEUROLOGY, vOL, 34 , No. 1 


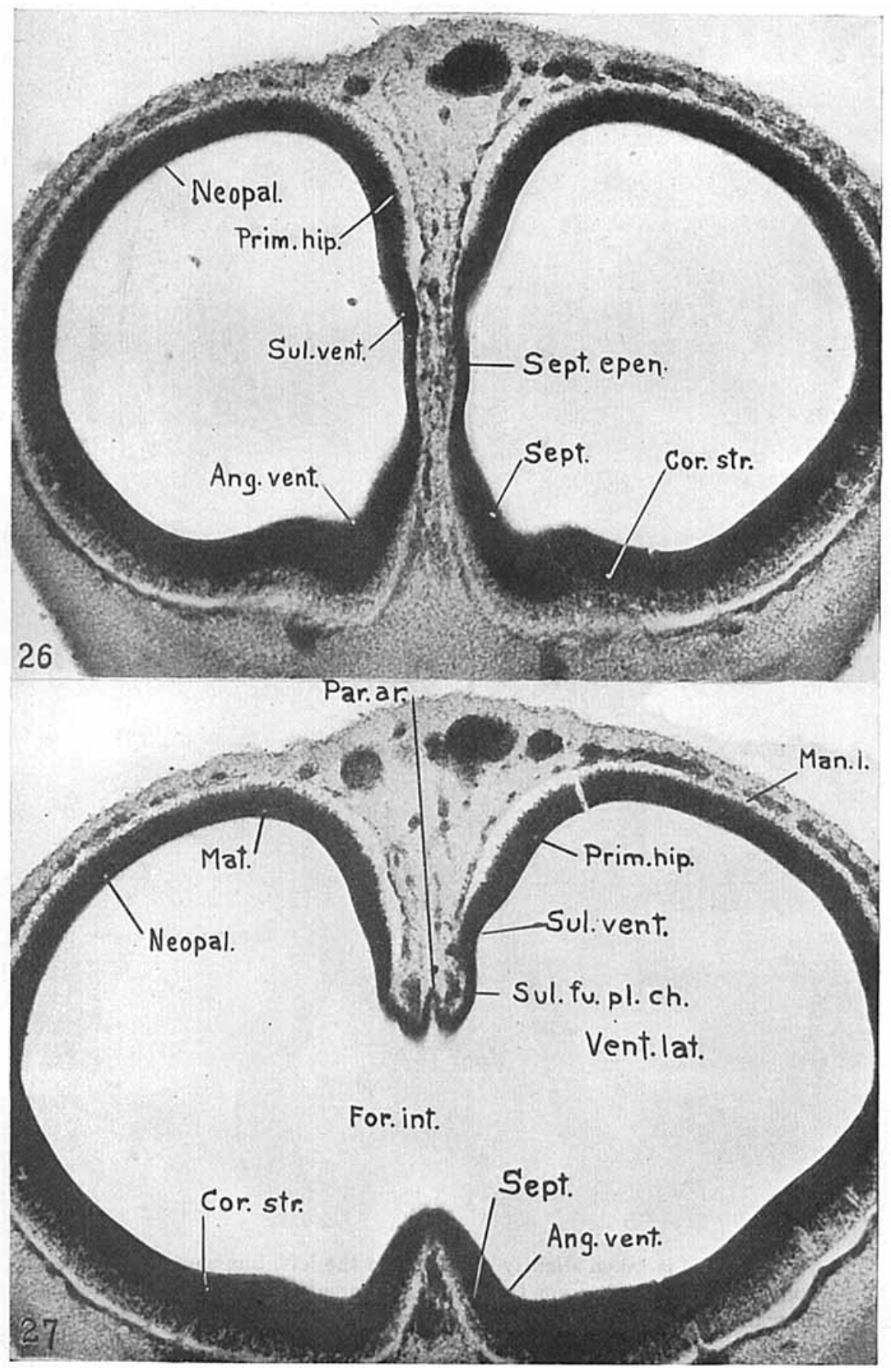




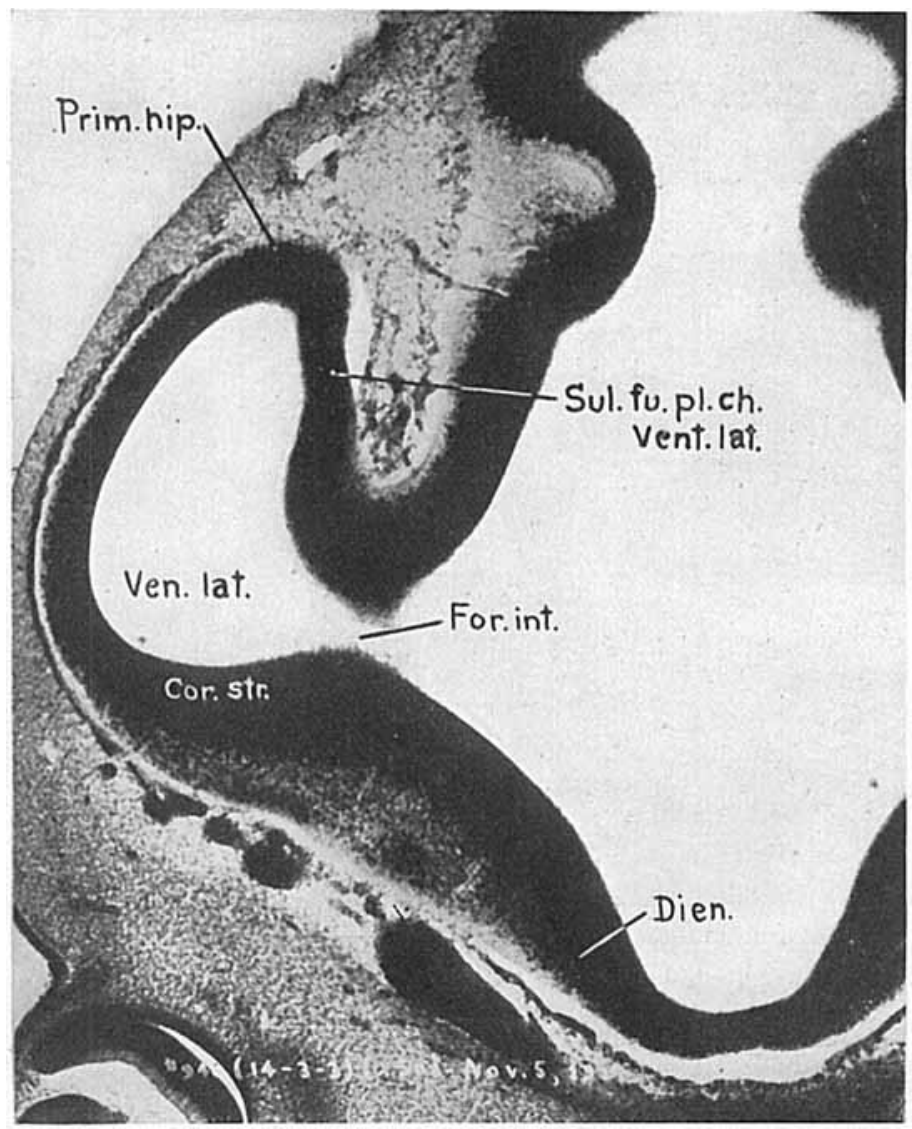

Figs. 26 to 28 Photographs of three transverse sections through the 14-mm. embryo, no. 940. Two views of a model of this brain are shown in figures 10, 12,13 , and 14 and planes of sections are illustrated in figure 12.

Fig. 26 Section just anterior to the lamina terminalis and the tela chorioidea telencephali medii. The division of the medial wall into three regions is evident, namely, 1) a dorsal or neopallial; 2) a dorso-medial or hippocampal; 3) a ventral or septal.

Fig. 27 Through the paraphysis. In comparing this with figure 24 of no. 1121, the same upward curve in the membranous roof and the division of the dorsal half of the hemisphere vesicle into four regions may be noted. $\times 60$.

Fig. 28 Through the di-telencephalic groove. Note the thin marginal velum bordering the limitans meningea on the dorsal aspect of the evagination in the primordial hippocampus. The massive undifferentiated area joining the diencephalon medially is the telencephalic limb of the di-telencephalic groove cauda to the ehoroid plexus evagination. 

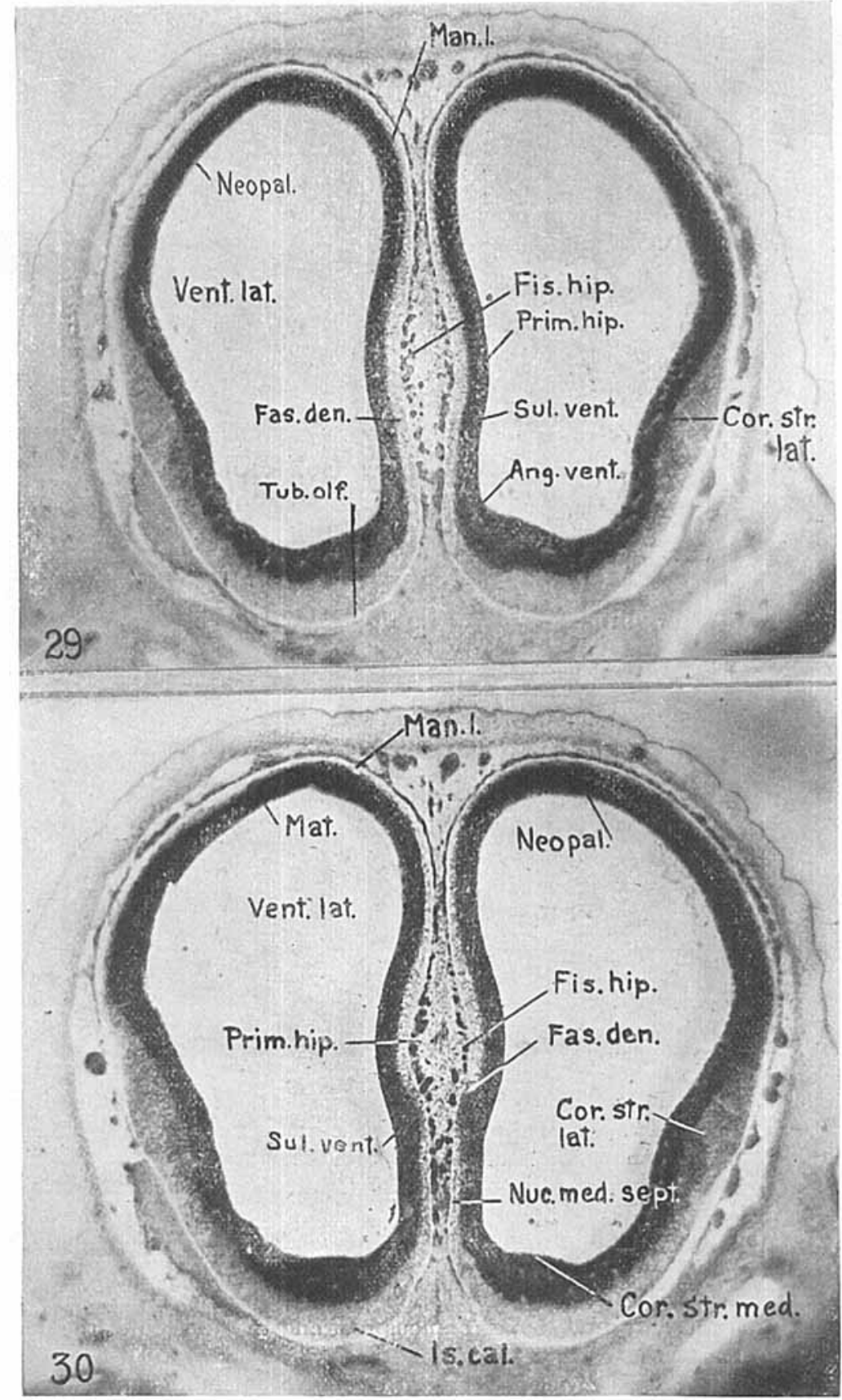

Fig. 29 Through the anterior part of the tuberculum olfactorium, showing the division of the medial wall into four histologically distinct areas, tuberculum olfactorium, septum, primordial hippocampus, and neopallium.

Fig. 30 Through the more caudal part of the tuberculum olfactorium. The region of the hippocampus is more accentuated, the groove is less shallow, the sulcus limitans hippocampi a more prominent feature. A group of cells, the fascia dentata, can be distinguished just above the sulcus. 


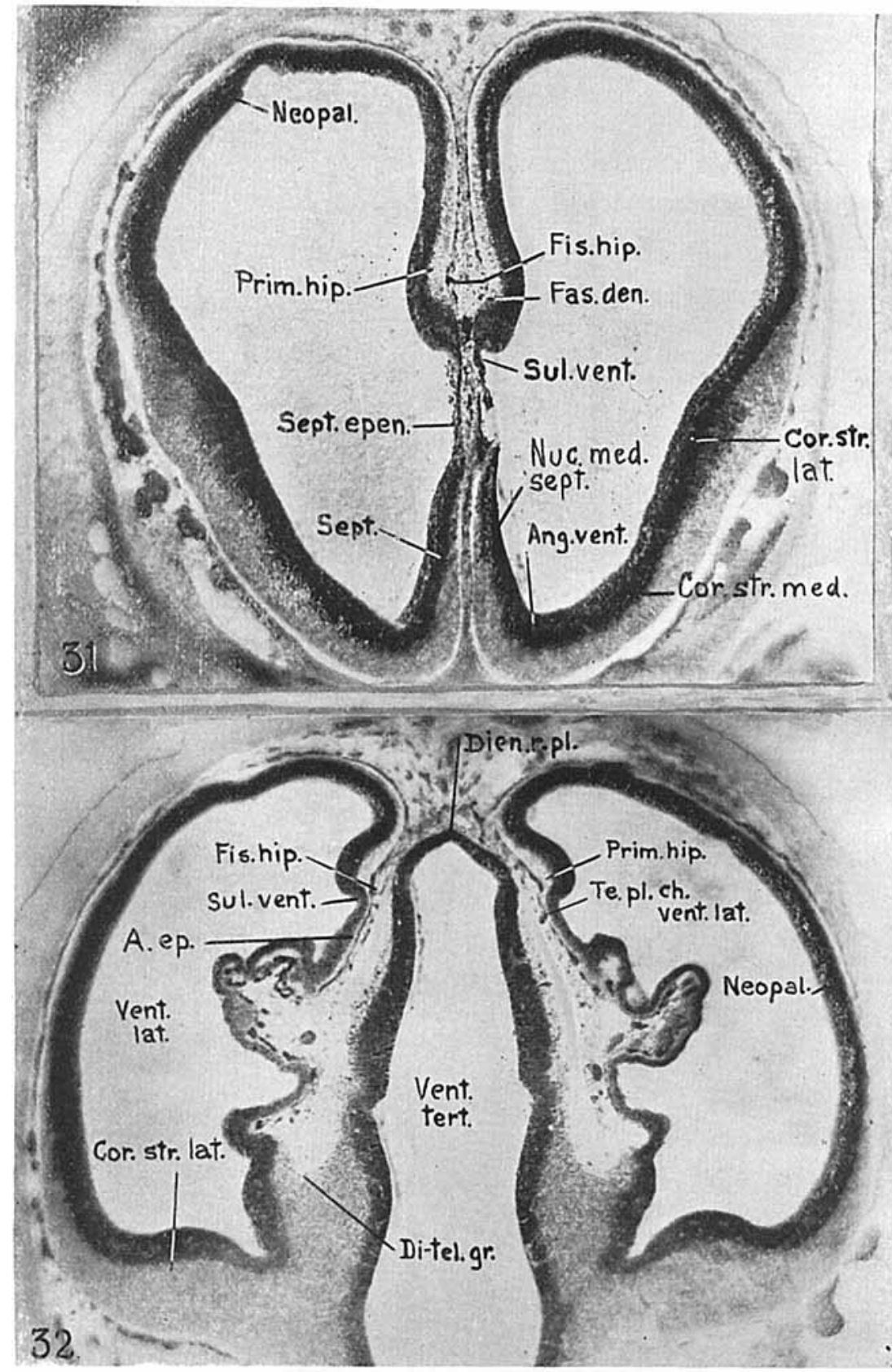

Fig. 31 Through the septum ependymale, just rostral to the lamina terminalis region.

Fig. 32 Through the di-telencephalic groove, showing the invagination of the plexus chorioideus ventriculi lateralis, with the taenia fornicis.

Figs. 29 to 32 This series of reproductions through the forebrain was taken from embryo $\mathrm{H} 173,19.1 \mathrm{~mm}$., of the Chicago collection. This brain was out transversely to the telencephalon. For the exact positions of these sections refer to figure $16 . \times 20$. 

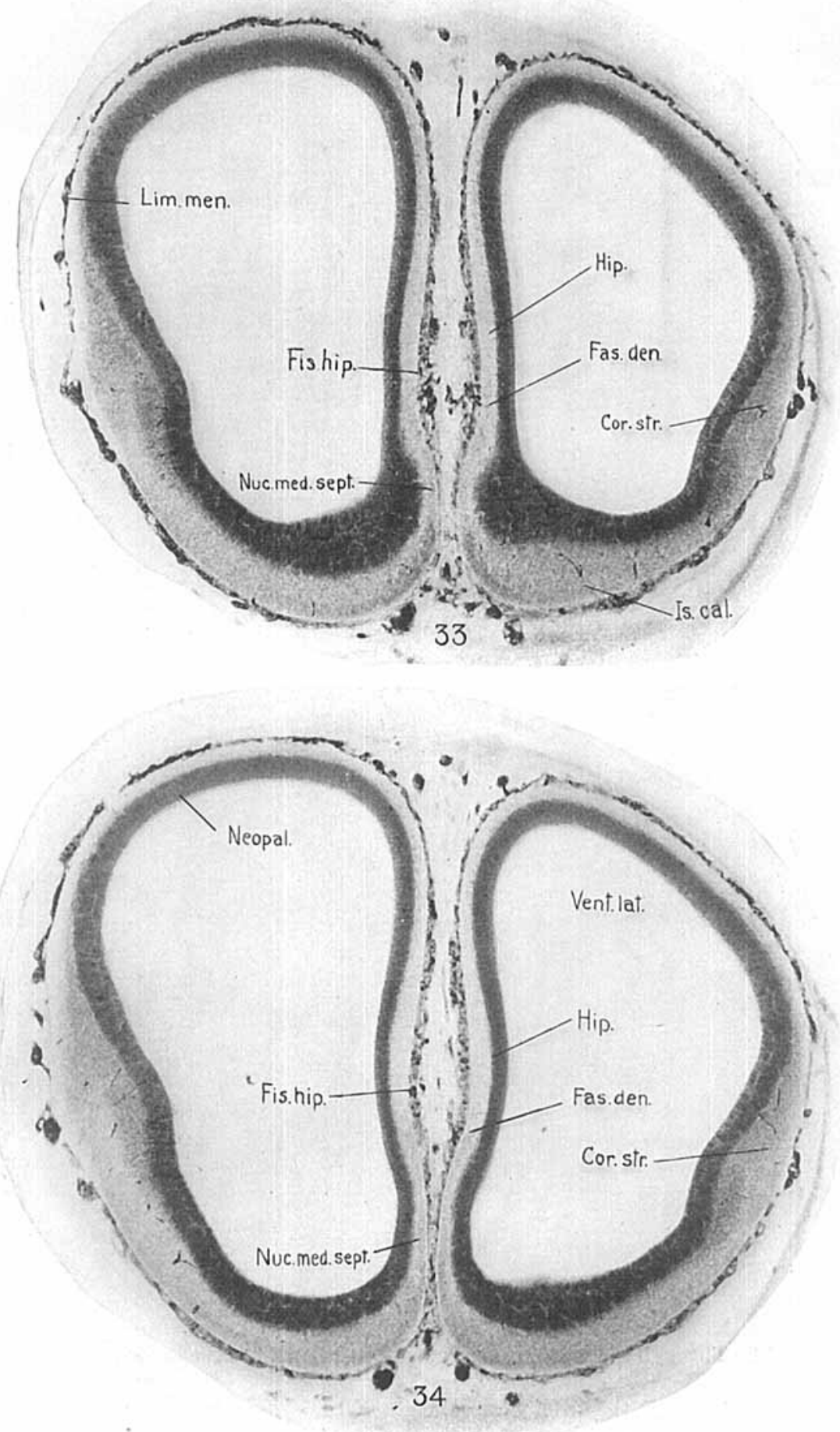

Figs. 33 to 37 These are photographs of selected sections from a transverse series of the telencephalon of a $20-\mathrm{mm}$. human embryo, no. 460 , at the Carnegie Institution, the Mall Collection. $\times 25$. A model of the forebrain may be studied by turning to figure 17 . The levels at which typical sections were photographed are indicated. 

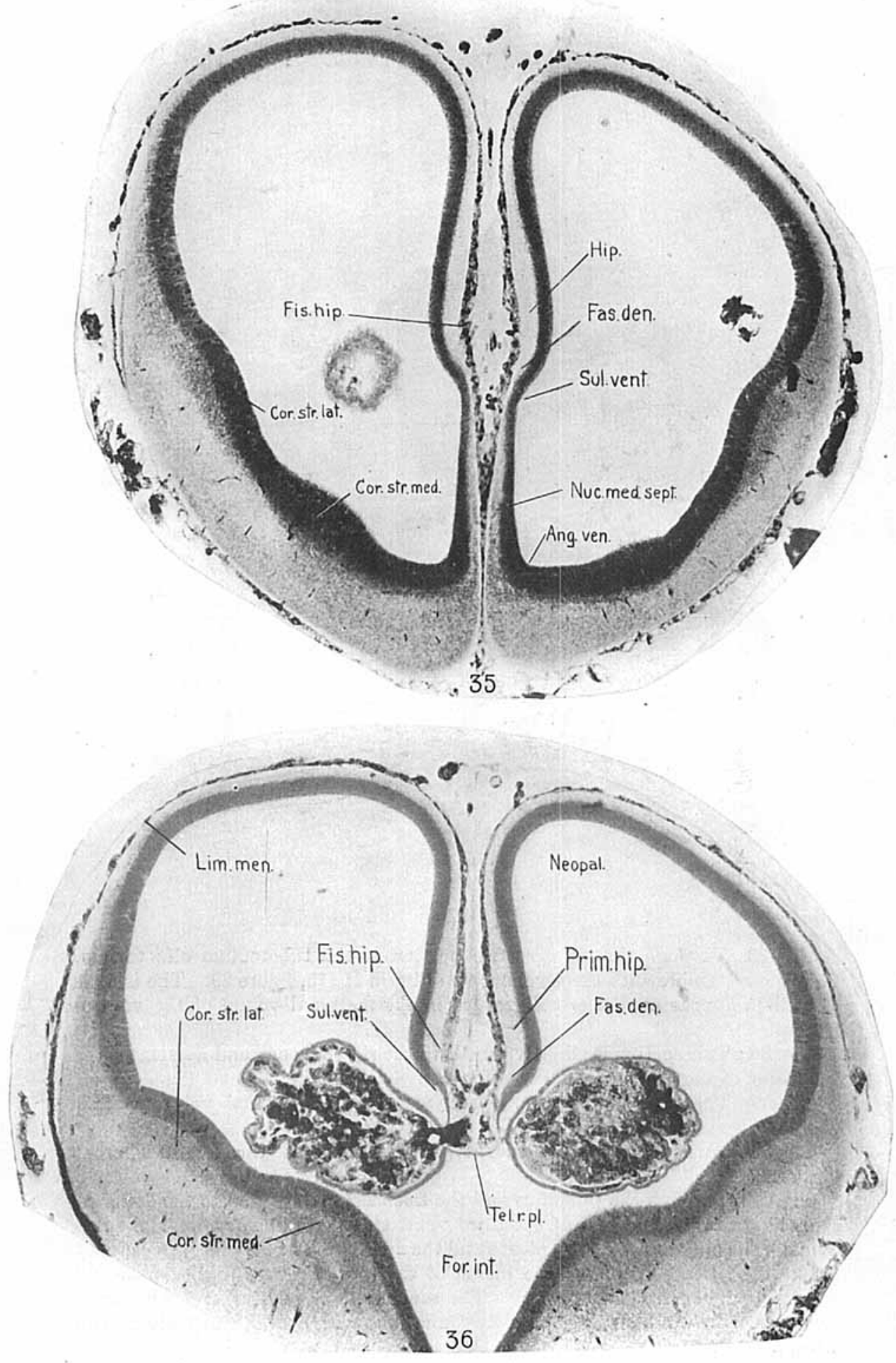


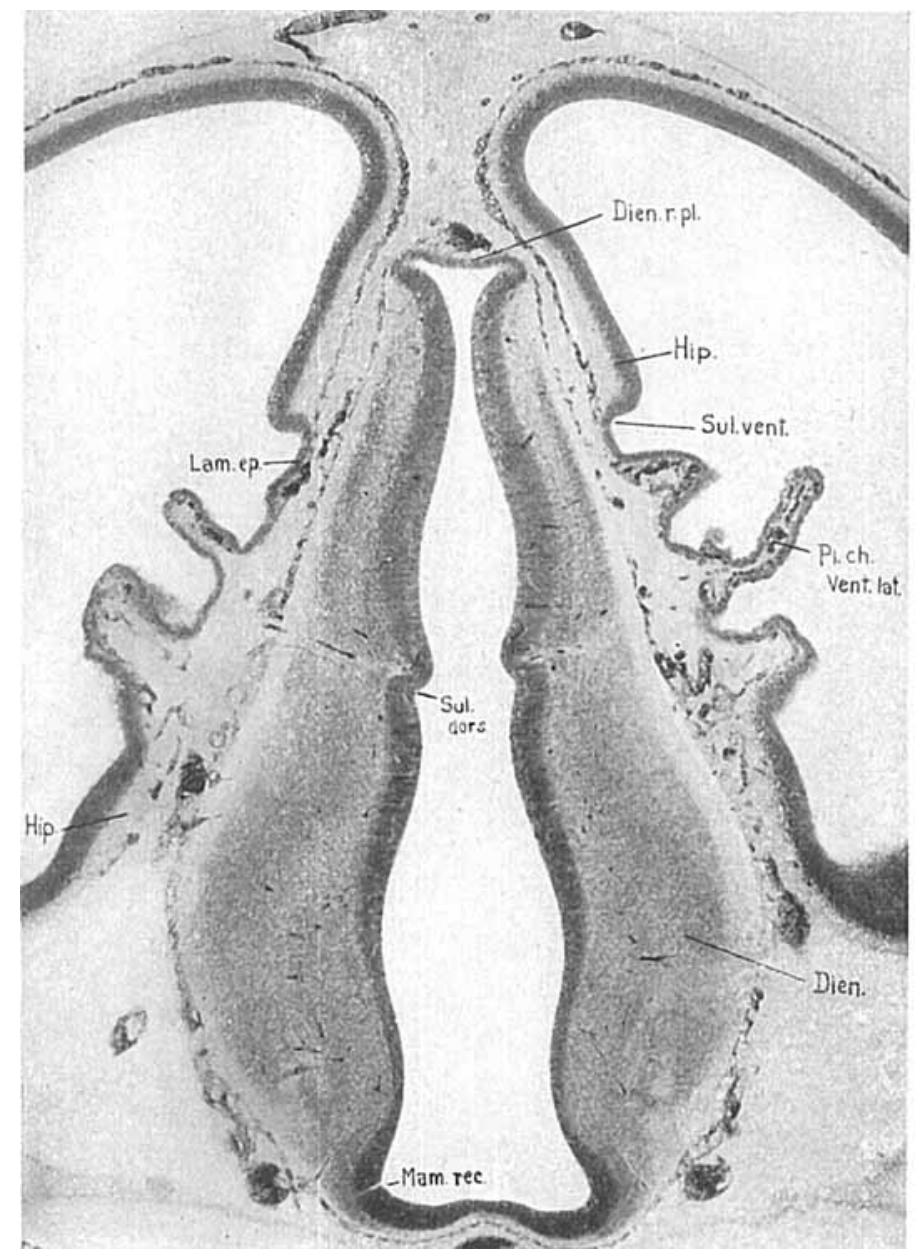

37

Fig. 33 Through the more rostral portion of the tuberculum olfactorium. This is comparable with the level shown of brain $\mathbf{H ~} 173$, figure 29 . The islands of Calleja appear as denser cell groups in the marginal velum of the ventral region.

Fig. 34 This section is slightly caudal to the previous one and illustrates the deepening of the embryonic fissura hippocampi.

Fig. 35 Through the septum ependymale. The marginal velum is just visible.

Fig. 36 Through the foramen interventriculare and the lateral choroid plexuses.

Fig. 37 Through the thalamus and the telencephalon caudal to the di-telencephalic groove. The roof of the third ventricle is non plexiform. The ependymal walls of both the lateral plexus and the diencephalic roof plate appear very thick. The tissue adjoining the taenia of the lateral plexus, both dorsal and ventral to it, is the hippocampus. The same type of cellular arrangement as that shown in the depth of the embryonic fissura hippocampi in more rostral levels is seen. 


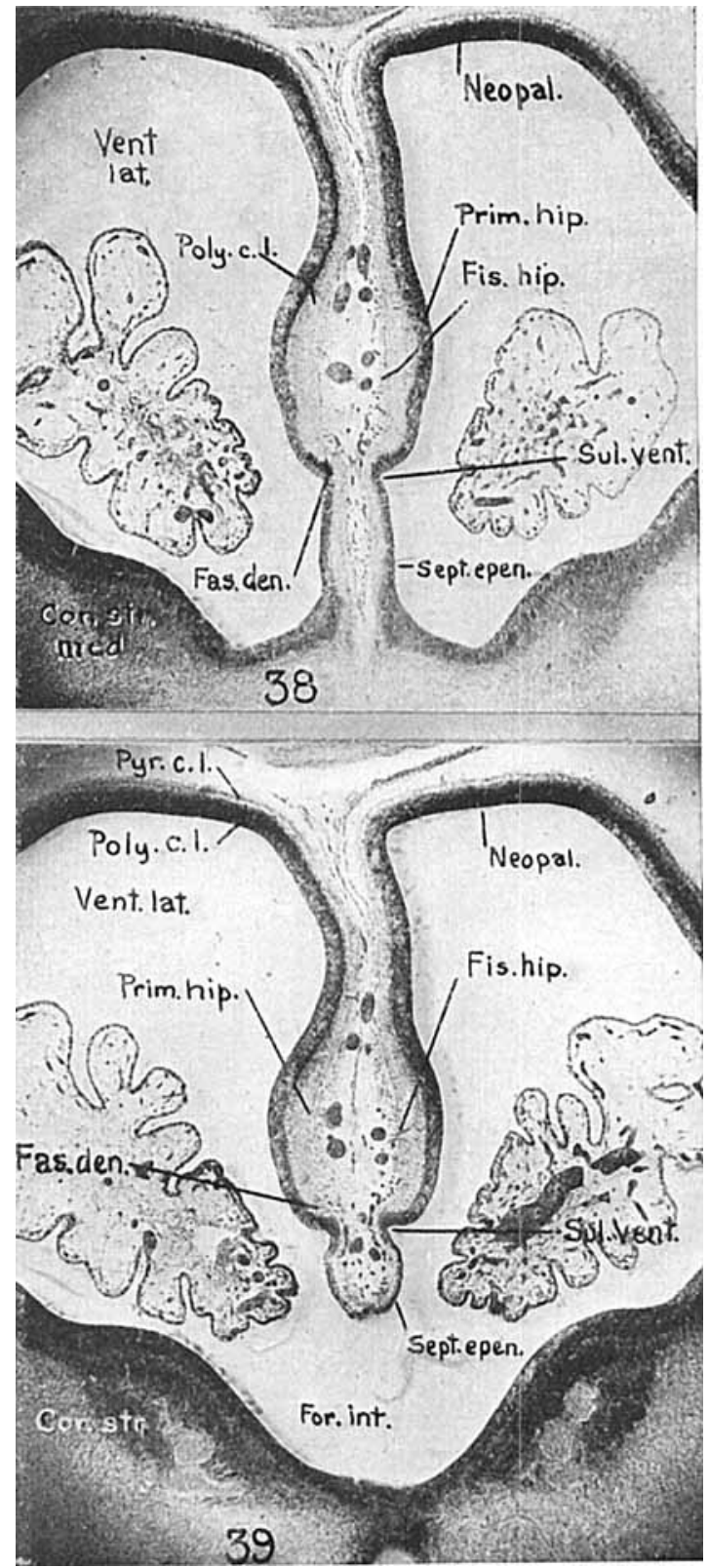

Figs. 38 and 39 These figures are reproductions of photographs of a 27.8-mm. embryo, belonging to the Chicago Collection. $\times 28$.

Fig. 38 Through the septum ependymale and the lamina terminalis.

Fig. 39 Through the tela chorioidea telencephali medii and the foramen interventriculare. 


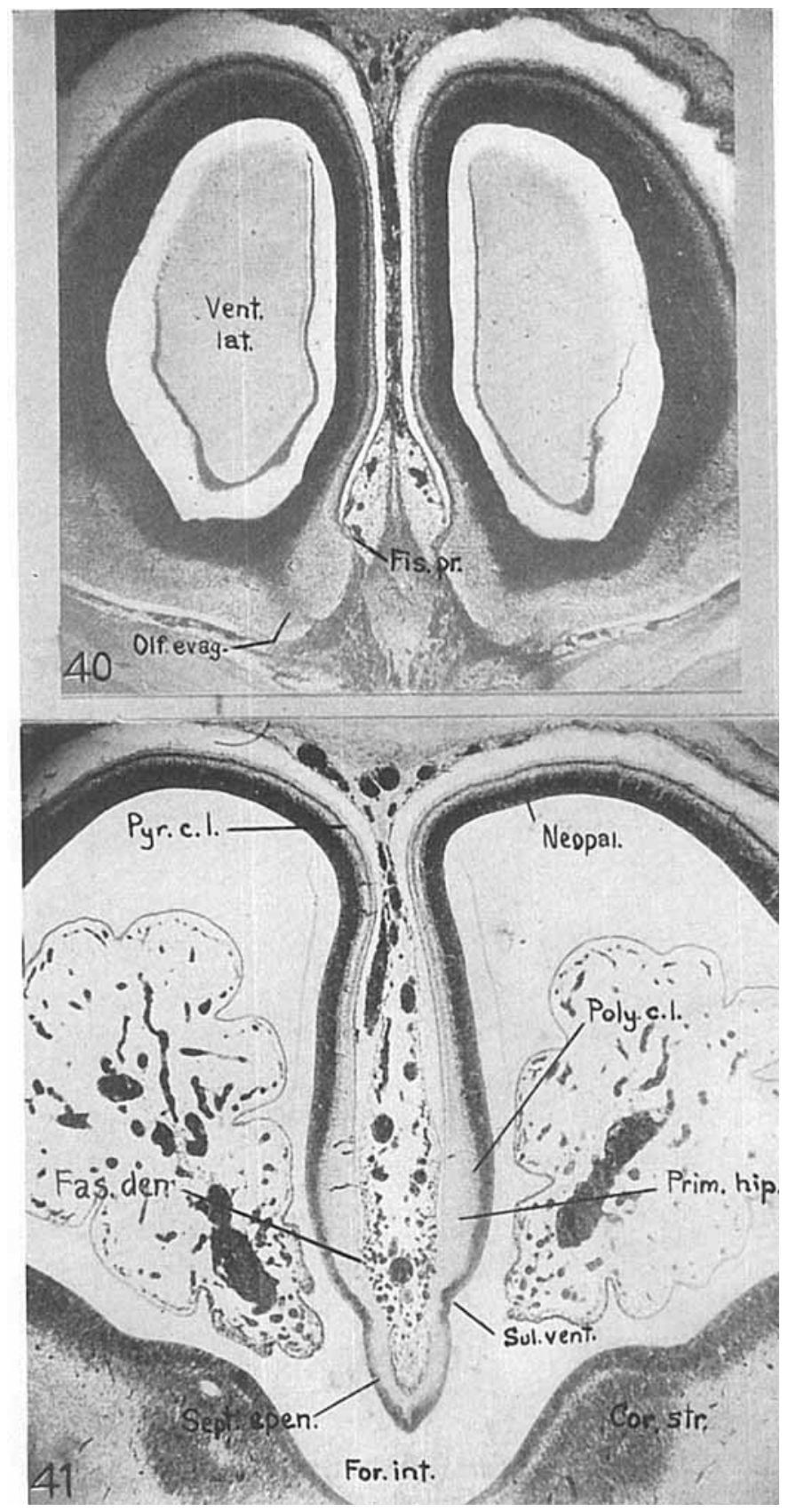

Figs. 40 and 41 These photographs were taken from a transverse series of a human embryo $32.1 \mathrm{~mm}$. in length, belonging to the Chicago Collection, $\mathrm{H} 41$. $\times 28$. 

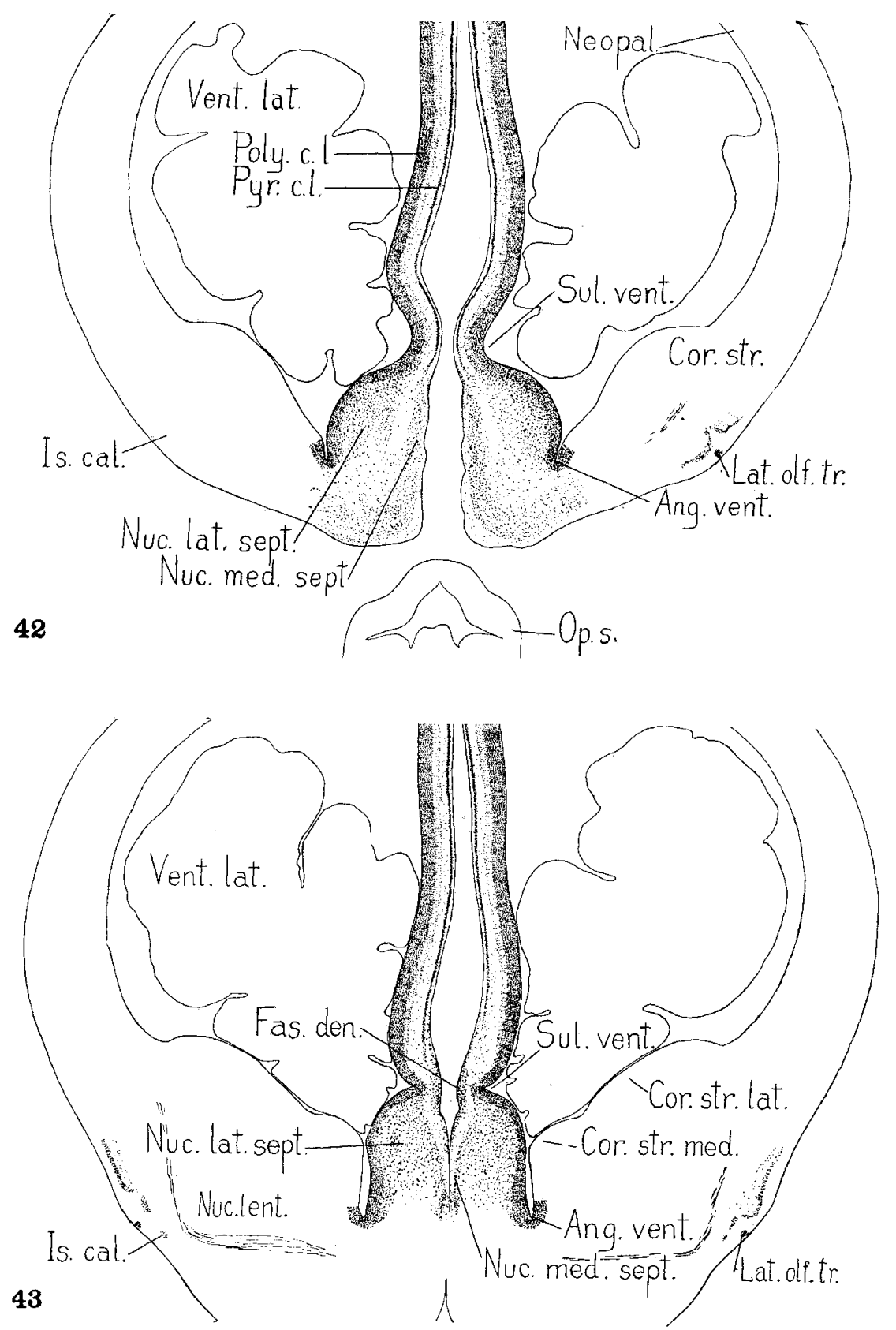

Fig. 40 Through the root of the bulbus olfactorius, showing the curve in the medial wall described by $\mathrm{His}$ as the fissura prima.

Fig. 41 Through the tela chorioidea telencephali medii. The primordial hippocampus is bounded by the sulcus limitans hippocampi ventrally, and by the neopallium dorsally. The lamination of the neopallial cortex is easily discernible. Ventral to the sulcus limitans hippocampi is the septum ependymale. Emerging from the matrix a narrow marginal velum is seen. 

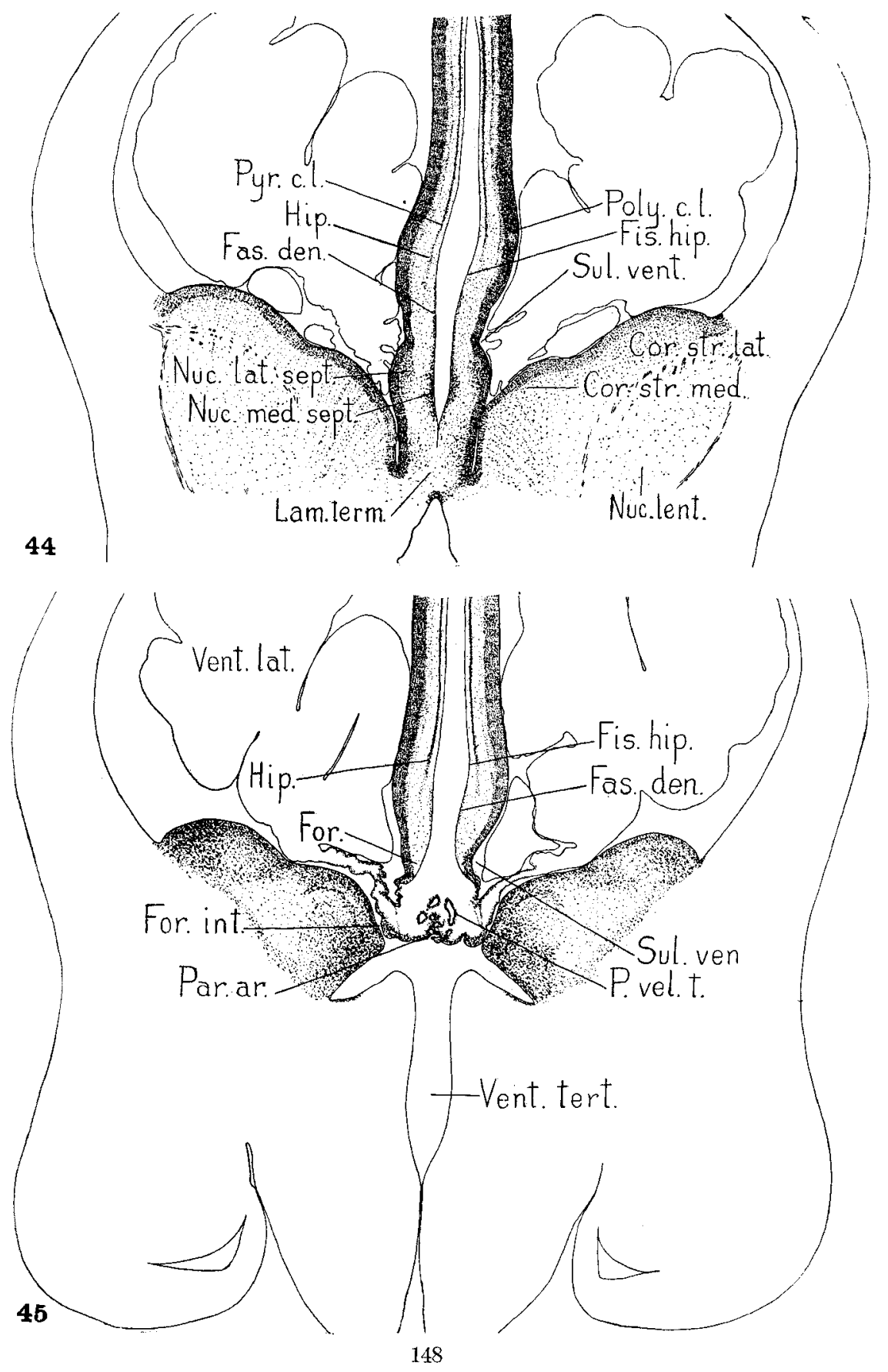


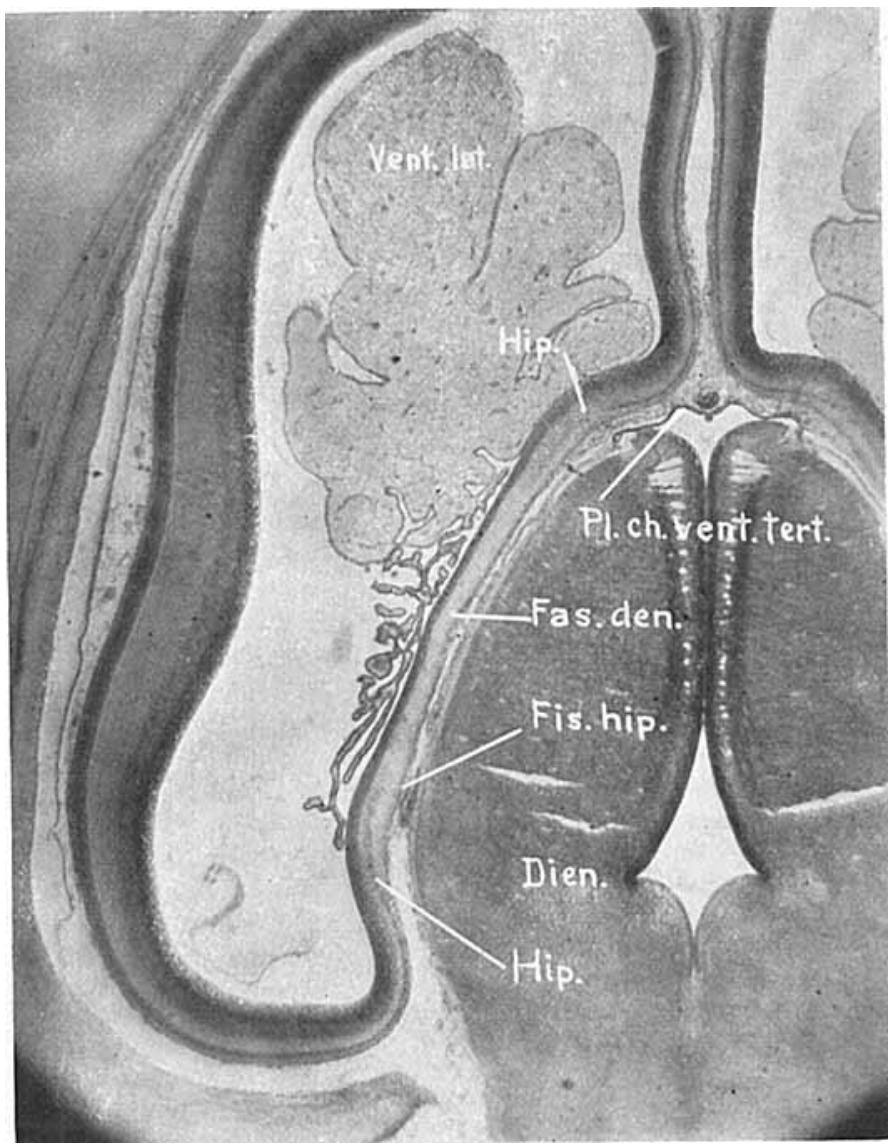

46

Figs. 42 to 45 Pen drawings of sections through the 39.1-mm. embryo, $\mathrm{H} 163$. The planes of section are indicated on the drawing of the model, figure 18.

Fig. 42 Through the septum and the postoptic recess.

Fig. 43 Through the rostral portion of the lamina terminalis. The eortical lamination in the hippocampus reaches almost to the sulcus limitans hippocampi. The differentiation of the pyramidal cell layer seems tardier than that of the polymorphous layer.

Fig. 44 This section was taken through a more caudal part of the lamina terminalis. The slight groove in the medial wall, dorsal to a line joining both sulci limitantes hippocampi is the remnant of the fissura, hippocampi of the earlier stages. The polymorphous and pyramidal cell layers are not well as differentiated in the regio hippocampi as they are in the two previous figures. 

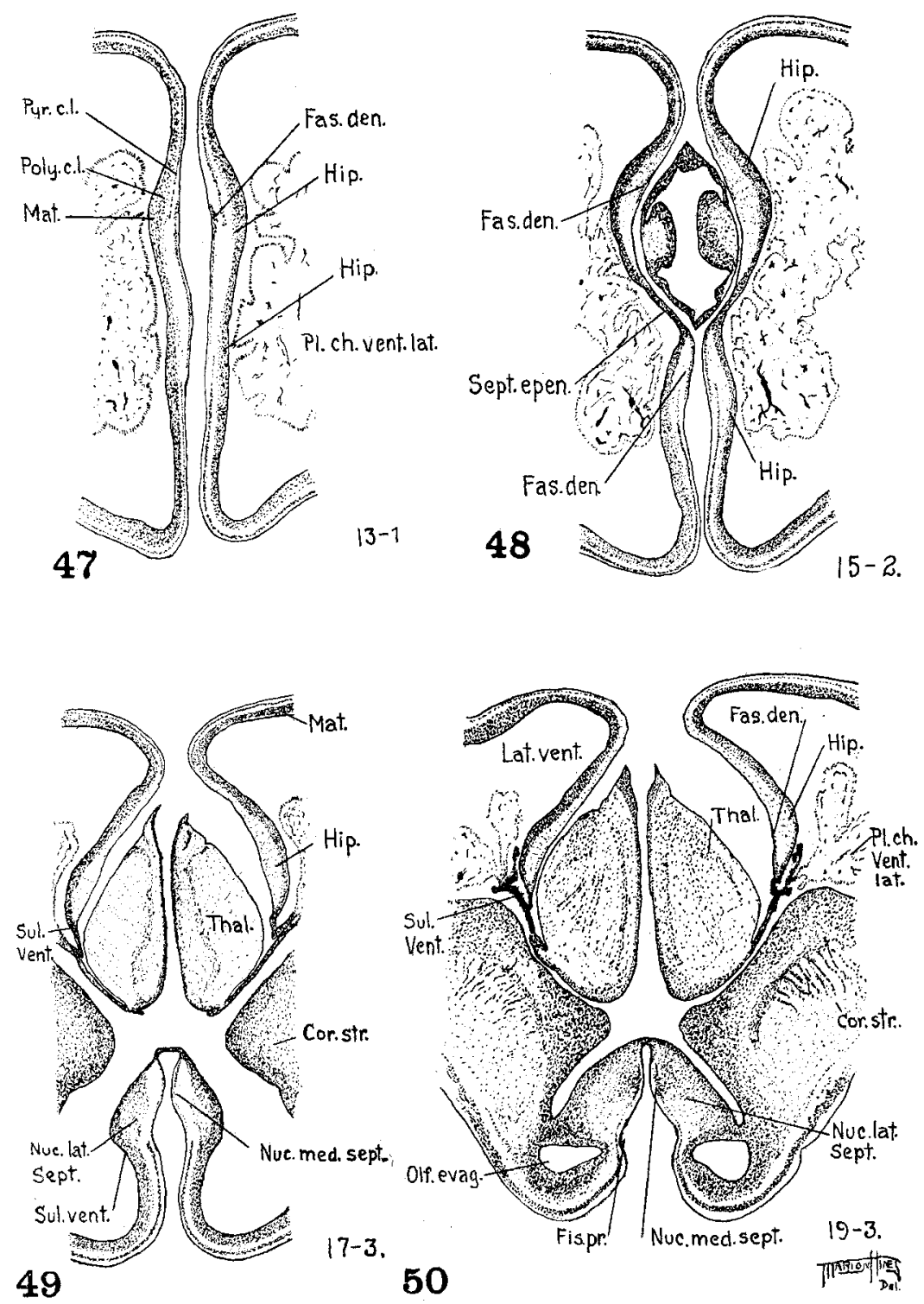

Fig. 45 Section through the paraphyseal arch, showing a few postvelar tubules, the lateral choroid plexuses, and the foramen interventriculare. The cortical layers are not visible in the hippocampus, although they are well developed in the neopallium.

Fig. 46 Photograph from the same specimen as the last, through the depth of the hippocampal fissure. For plane of section see figure 18. A thin row of cells lies in the most medial part of the mantle zone of the hippocampus, fascia dentata. $\times 14$. 


\section{Fascia dentata}

In the medial margin of the hemisphere wall in the 19.1-mm. embryo opposite the sulcus limitans hippocampi lies a group of cells, the fascia dentata. This group of cells does not appear in the younger embryos, but persists in the rest of the series as a mass of cells, which seem to have migrated out of the matrix lying opposite the dorsal limit of the sulcus. This differentiation begins anteriorly and passes posteriorly, following in development the initial differentiation of the future hippocampal region into the outer marginal velum and inner matrix layers. These cells slip along the marginal velum of the developing hippocampus. In the 39.1-mm. embryo and the 43- $\mathrm{mm}$. they form a slender band almost coextensive on the medial wall ventro-caudally with the development of the hippocampal cortex. The rostral limit of the fascia dentata lies in close proximity to the rostral limit of the sulcus limitans hippocampi. The four sketches, in figure 51, present comparable levels through the region under discussion from four different embryos. A, a 16-mm. embryo, shows no differentiated fascia dentata, but in B, a $20-\mathrm{mm}$., a group of differentiated cells opposite the sulcus limitans hippocampi may be seen. In C, a 39.1-mm., these cells have slipped along the marginal velum of the hippocampus; while in $D$, an 85-mm.. they show the characteristic crescentic line-up. In the levels delimited only that of the $85-\mathrm{mm}$. demonstrates the relation of the sulcus fimbrio-dentatus to the growing fascia dentata. Here the fornix fibers lie ventral to the dentate band, among undifferentiated cells of the primordium hippocampi, separated from that gyrus by the sulcus fimbrio-dentatus.

Figures 47 to 50 These drawings were made from a coronal series of the forebrain of a 43-mm. human embryo, no. 886, of the Mall Collection. Refer to figures 19 and 20 for the medial sagittal section of the model and the planes of these sections. $\times 6 \frac{2}{3}$.

Fig. 47 Through the hippocampus, showing that tissue in both its caudal and rostral aspects.

Fig. 48 A section through the upper border of the thalamus, the septum ependymale, and the anterior and the posterior divisions of the hippocampus.

Fig. 49 Through the septal region and the posterior part of the hippocampus. Note the cellular groups in the septum.

Fig. 50 Through the caudal hippocampus, the middle of the thalamus and the olfactory bulb. 


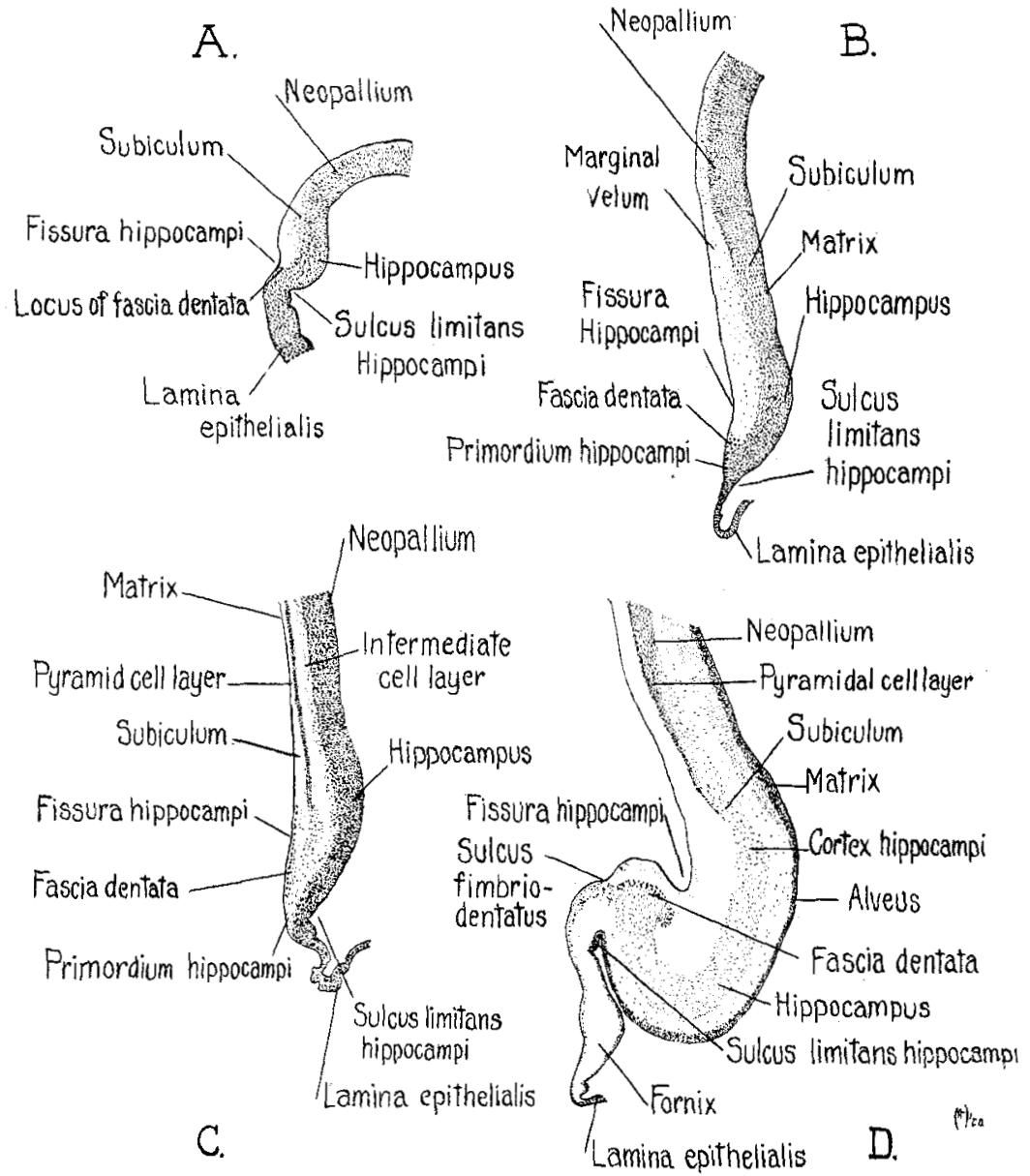

Fig. 51 'These four pen-and-ink sketches were drawn either with the Edinger projection apparatus or were taken as tracings from photographs of known magnification. They show the relative histological development of the neopallium, the hippocampal formation, the fascia dentata and the lamina epithelialis, through a level which subtends the lateral choroid plexus itself or its primordium.

Sketch A. $\times 35 \frac{5}{7}$. No. $465,16 \mathrm{~mm}$. (section 11-2-6), University of Chicago Collection. The hippocampal region is clearly delineated by the thickened marginal velum, the thin matrix, and the great convexity toward the ventricular surface. Ventral to the hippocampal formation lies the lamina epithelialis, the site of the lateral choroid plexus evagination. Here it is a thick wall made up of many small undifferentiated cells. The matrix of the neopallium interdigitates with the marginal velum. The fissura hippocampi is a shallow groove beneath which lies the locus of the future fascia dentata. 
This last is essentially the reptilian condition, and, since some of these fornix fibers in both cases enter the alveus in the adult, it follows that the reptilian dorso-medial cortex is comparable with the human hippocampal cortex rather than with the fascia dentata, as supposed by Meyer ('92) and Levi ('94). Moreover, the embryological evidence presented by these embryos is decisive in favor of the same conclusion. The fascia dentata arises from cells of the matrix immediately dorsal to the sulcus limitans hippocampi, from which position its cells migrate dorsalward along the outer margin of the hippocampal formation. This mode of origin corresponds in all major particulars with

Sketch B. $\times 35 \frac{5}{7}$. No. 460, $20 \mathrm{~mm}$. (section 15-1-2), Carnegie Institution, Baltimore. The histological characters of the hippocampus are the same as those described for the $16-\mathrm{mm}$. embryo. The area itself is greater dorso-ventrally and the fissura hippocampi, although shallow, includes a greater sweep of tissue. The lamina epithelialis is thinner, composed of only a few rows of epithelial cells. Opposite the sulcus limitans hippocampi within the marginal velum lie a group of cells, the undifferentiated fascia dentata.

Sketch C. $\times 7 \frac{6}{7}$. No. H 163,39.1 mm. (section 147-1-4), University of Chicago Collection. The medial wall in the region of the hippocampal primordium bulges prominently into the ventricle, its ventricular convexity being greater than its medial concavity. Within the dorsal lip of the fissura hippocampi three cortical lamina are present: 1 ) the inner, or matrix;2) the middle, or the intermediate cell layer, and, 3) the outer or row of young pyramids. The intermediate cell layer, like the matrix, is never as wide in the center or ventral lip of the fissure as it is in the dorsal lip or in the neopallium. The lamina epithelialis is more convoluted and presents at this level a concave surface outward, an indication, the writer believes, of the sulcus fimbrio-dentatus. The fascia dentata has migrated dorsally in the marginal velum of the hippocampus. The locus from which these cells come shows no cortical lamination, although between the foscia dentata and the matrix a few undifferentiated cells remain.

Sketch D. $\times 10 \frac{6}{7}$. No. 1400-23, $85 \mathrm{~mm}$. (section 34-1-4). A brain belonging to the private collection of Dr. George L. Streeter, studied at the Carnegie Laboratory of Embryology, Baltimore. The hippocampal formation lies in the depth of the fissure. The fascia dentata seems caught in a characteristic twirl. Ventral to the fascia dentata lies a small sulcus, the sulcus fimbrio-dentatus. The fornix fibers are intermingled with undifferentiated cells, the persistent primordium hippocampi. It takes no leap of fancy to bridge the growth process from this stage to the adult.

NoTE. In the untouched photographs from which figures $29-31,33-36,38,39$ and 41 were reproduced the histological differentiation of the facsia dentata was clearly visible, as indicated in the pen drawings, figures $42-45,47-51$. This detail in some of the photographs is lost in the reproduction. 
Levi's ('04) description of the development of the fascia dentata in the rat, but his interpretation requires revision.

The identification of the reptilian dorso-medial cortex with the fascia dentata of Meyer and Levi has been questioned by Cajal ('11) and by Elliot Smith ('10), who believes, however, that it is undergoing differentiation toward fascia dentata, a view supported also by Crosby ('17) and in a modified form by Johnston ('13, p. 391, and '15, p. 419).

By what criterion shall the fascia dentata be known-nerve connections, intrinsic chromatin staining, position, or history? To determine nerve connections in this material is impossible. The primordial fascia dentata shows the characteristic intensive nuclear staining even in its earliest stages of development. But its morphological disposition can be so followed from stage to stage up to the adult form that there is no doubt as to its identity. In vertebrates below the lowest mammals there is no representative of this structure. Levi ('04) has pictured the dorsomedial cortex of reptiles as containing a cortical lamination of deeply staining cells, whose connections according to Smith and Cajal are those of the hippocampus. Its boundaries have nothing in common with those of the mammalian fascia dentata. But knowing the origin of this tissue in human development, we naturally turn to the homologous region in the lower vertebrates. Such an area in both reptiles and mammals is the undifferentiated primordium hippocampi in the region of the developing fornix fibers. If the fascia dentata is a center for cortical reenforcement, as Cajal ('11) thinks the neurone connections indicate, and not the main receiving station for incoming impulses over the medial olfactory tracts, as Elliot Smith ('96) maintains, then it would seem natural for its development to be in abeyance in lower vertebrates. But if the reverse be true, we are at a loss to supply a reason for its undifferentiated condition in lower forms. It seems logical that it may develop from the cells of the primordium hippocampi, opposite the sulcus limitans hippocampi, and that the development will be delayed in accordance with Cajal's hypothesis of its function, until cortical associational mechanisms are well elaborated. Be that as it may, its anatomi- 
cal site of development supports the generalization of Elliot Smith ('96) for monotremes, that this tissue is the fringe of the cortex.

\section{Hippocampus}

Coincident with the appearance of the small area characterized by thicker marginal velum in the dorsal wall of the evaginating hemisphere in the 11.8-mm. embryo, there is a slight thickening of the wall itself. These two features furnish the first differentiation of the primordial hippocampus. The histological and morphological differentiation is more apparent in the 14-mm., and in the $19.1-\mathrm{mm}$. and the $20-\mathrm{mm}$. the whole extent of this tissue is involved in a groove, the fissura hippocampi. Here its wall is slightly thicker than the wall of any other part of the cortex. There is little cell migration from the matrix into the marginal velum. In fact, at this stage of development of the cerebral vesicle, this is the only region where a true cell-free margin is found. The tissue which lies immediately dorsal to the hippocampus is neopallium and that which is ventral is either septum or a derivative of the area epithelialis. This fissure, in all probability, is not formed by an invagination due to more rapid growth of the central part of this tissue, but rather by a buckling of the wall on itself as the result of the appositional growth of the neopallium between the endorhinal fissure and the dorsal limit of the hippocampus, plus perhaps the lack of support, except at one point, by the epithelial tissue ventral to it. The fissure is deeper and less broad where the ventral support is narrow. Since this fissure or groove lies above the sulcus limitans hippocampi and the fascia dentata and involves the whole wall containing the primitive hippocampus, there can be little doubt as to its identity. It is the fissura hippocampi or the fissura arcuata of His, the Bogenfurche of other authors. This fissure must not be confused with the sulcus limitans hippocampi or the sulcus fimbrio-dentatus. It corresponds to the fissura arcuata of Herrick ('10) in reptiles, Johnston ('13) to the contrary notwithstanding, if the evidence above be accepted, namely, that the definitive hippocampus is derived from the reptilian dorso-medial cortex. 
In this case the ventral boundary of the hippocampal formation may be drawn by passing a plane through the wall at the level of the sulcus limitans hippocampi. Such a limit would correspond to one similarly drawn diagonally through the medial wall of the brain of Phrynosoma cornutum (Herrick, '10, fig. 61, p. 533 ) joining the sulcus limitans hippocampi and a groove on the ventricular surface just dorsal to nucleus lateralis septi. In the brain of the turtle (Johnston, '13, p. 391, and fig. 17, p. 435) a sulcus which lies above this hypothetical plane described by Herrick is called the sulcus fimbrio-dentatus. This is Herrick's fissura arcuata.

If, now, Johnston and others are correct in assuming that the mammalian fascia dentata is derived from the ventral part of the reptilian area of differentiated cortex above this so-called fimbrio-dentate sulcus, then the reptilian primordium hippocampi gives rise only to the mammalian fimbria and fornix bed and the term fimbrio-dentate sulcus is clearly appropriate, for this sulcus is defined by Johnston ('13, p. 391) as "lying between the fimbria and the developing fascia dentata." But, on the other hand, it has been shown in this contribution that the human fascia dentata actually is developed, not from the differentiated hippocampal cortex downward, but upward from the extreme ventral border of the primordium hippocampi. The hippocampal primordia of reptiles and of these human embryos are apparently strictly comparable structures. The fimbrio-dentate sulcus as defined by Johnston cannot, therefore, lie dorsal to the primordium hippocampi as he describes it.

We conclude, then, that there is no fimbrio-dentate sulcus either in reptiles or in the human embryos here described. The mode of its appearance in later developmental stages has not been determined in sufficient detail to enable the writer to treat the subject exhaustively, although sketch $\mathrm{D}$ in figure 51 , taken from an embryo $85 \mathrm{~mm}$. in length, clearly delineates the fact that the sulcus in question develops later than the fascia dentata and appears ventral to both the fascia dentata and the sulcus limitans hippocampi. It would appear to follow from the conclusion that if the reptilian fissura arcuata of Herrick's description (fimbrio- 
dentate sulcus of Johnston) is represented in the human embryo at all, it must be homologous with the fissura arcuata of His and with the fissura hippocampi of the adult. If, however, this conclusion is adopted, it must be recognized that the fissure is very differently disposed with reference to the chief mass of the differentiated hippocampal cortex in adult reptiles and mammals. But the embryology of the region as far as followed in this paper is almost the exact duplication of the situation as described for reptiles by Herrick ('10, pp. 464, 465). And the writer is inclined to think that future study will prove those differences discussed by Herrick to be slight indeed, for the fascia dentata arises from cells in the ventral lip of the fissura, immediately opposite or slightly dorsal to the ventricular sulcus limitans hippocampi. The fibers of the fornix lie between the matrix and the fascia dentata in this region. Moreover, the ventral lip of the fissura hippocampi shows no cortical lamination in the stages presented. This differentiation of the early hippocampus into a dorsal cortical portion and a ventral non-cortical resembles the reptilian condition, with the exception that opposite the sulcus limitans hippocampi lies the undifferentiated fascia dentata. There is nothing, according to Johnston or Crosby which compares to this differentiation of fascia dentata in either the turtle or the alligator. The writer suggests that the regions in adult reptiles called by these authors primordium hippocampi are the source of the fascia dentata.

There are some points, essential for the completion of this argument which remain obscure. In the material avialable it is impossible to determine the absolute ventral limit of the primordium hippocampi caudal to the angulus terminalis.

The paraphysis is universally regarded as a differentiation within the roof plate. The lamina epithelialis in all probability should not be so regarded since it takes part in the evagination of the hemisphere. Its subsequent position, however, is not evident until the 14-mm. embryo is studied. The sulcus limitans hippocampi in this contribution is regarded as markng the ventral boundary of the hippocampal formation. In the region rostral to the angulus terminalis (figs. 3 to 6 , sketches $1 \mathrm{v}$ ) it 
separates cortical from subcortical regions; but throughout the regions bordering the post-terminal area epithelialis it separates the thin area intercalata and (in the adult) the choroid fissure from the hippocampal formation. In the series presented no cortical areas are found ventral to it, nor are there any cells which can be proved to be neuroblasts ventral to it. But in figure 51, sketch $\mathrm{D}$, it seems impossible to determine just where the boundary between the primordium hippocampi and the lamina epithelialis should be drawn. In the sketches it has been assumed to lie as indicated, below the area containing undifferentiated cells of the primordium hippocampi. On this interpretation that portion of the fimbria marked Fornix (fig. 51, D) is a segment of the lamina epithelialis which has been secondarily thickened by the invasion of fornix fibers; but possibly, it should be regarded as belonging within the primordium hippocampi, a possibility which cannot be disregarded until the methods of neurological technique have demonstrated otherwise. Doctor Herrick suggests to me that a close series of developmental stages of this region in reptiles or lower mammals would probably be favorable material for the solution of this question.

\section{Fissura hippocampi}

Having established the homology of the fissura hippocampi with the reptilian fissura arcuata of Herrick, we are desirous of clearing the situation as it exists in the history of the embryology of this region. As development proceeds, the primitive hippocampus presents a smooth contour from its earliest definition $(9 \mathrm{~mm}$.) to $16 \mathrm{~mm}$. From that length to approximately $24 \mathrm{~mm}$. the fissure extends into the medial wall from the base of the olfactory evagination to the end of the hippocampal primordium as a shallow groove involving the whole of this peculiarly differentiated area. For approximately the next 10 $\mathrm{mm}$. of growth in greatest length, the fissure grows progressively shallow in the region above the area chorioidea, so that from the surface it appears to be divided into two segments. However, there is no interruption of the hippocampal formation itself. 
During this time of development a new groove appears on the medial wall, the result of active olfactory bulb evagination, the fissura prima of His. The $27.8-\mathrm{mm}$. and the $32.1-\mathrm{mm}$. belong to this group. In the $39.1-\mathrm{mm}$. and the $43-\mathrm{mm}$. the anterior segment of the fissura hippocampi has disappeared, but the posterior and the fissura prima persist. The cortical lamination of the dorsal lip of the fissura hippocampi is coincident with the flattening of the medial wall.

If a dorsal commissure were added to the anterior commissure, . now lying in the much-thickened lamina terminalis, the relationships of commissure, fissura hippocampi, and fascia dentata would resemble those of the marsupial. Elliot Smith ('97, p. $67)$ wrote of this comparison as follows:

In the Marsupial we have a fissura arcuata or hippocampi, extending from the tip of the temporal pole right round the mesial wall of the hemisphere towards the olfactory peduncle; so, in the fetal child or kitten, we find the Bogenfurche (which we might, with Mihalkovics, appropriately call 'Ammonsfurche') following a similar course and shading away towards the cephalic pole of the hemisphere. And it is necessary to remark, in passing, that the so-called part of the 'Vordere Bogenfurche,' which His calls 'fissura prima' has nothing whatever to do with the true Bogenfurche or fissura arcuata, if we regard the latter as the primitive fissura hippocampi.

Smith refers to the 1891 paper of Marchand. Moreover, Marchand ('09) denied the existence of such a fissure and Smith ('03) reports that Hochstetter's work on fissuration of the medial wall proves beyond a doubt that all the fissures are artefacts. But the conditions of these tissues in the brains of the 39.1-mm. and the $43-\mathrm{mm}$. are essentially the same as described by Smith in his first paper. His himself ('04) states plainly that the fissura prima has no relation to the fissura arcuata or the hinterer Bogenfurche; he defines it as follows: "The continuation of the fissura mesorhinica extends for a distance over upon the medial wall of the hemisphere as the fissura prima. By a deepening of the surrounding sulcus the termination of the lobus olfactorius or this bulbous portion becomes separated more and more from the overhanging frontal lobe. The bulbous portion retains its sagittal direction and becomes separated laterally from a 
transversely directed portion by a deep sulcus" (p. 66). This fissure is considered by His to be the same as the "vordere Bogenfurche.' The first embryo to have such a fissure is Se $(16 \mathrm{~mm}$. G. L.) thought by His to be six weeks of age. There is little doubt that this measurement in no way compares with those in this series. Here there is no well-developed olfactory bulb until the $27.8-\mathrm{mm}$. is examined, although there is a slight olfactory evagination in the $19.1-\mathrm{mm}$. Then the fissure in all of the series after $27.8 \mathrm{~mm}$. is the same as that of His' description. It is quite possible that the bulb in His' embryos was delimited artificially. His also models a small bulb in C. R. (13.6 mm.), in which case the writer believes that some of the olfactory fila may have been included in the drawings of the projection of the brain. In the later stages the anatomy of the fissure is the same in all cases. Further, he thinks it divides the olfactory system into two parts. "At no time does it extend posterior to the lamina terminalis. Its remnant is the fissura parolfactoria posterior of the B. N. A." (His, '04, p. 76). This fissure is not, then, the anterior portion of the fissura arcuata; rather it is continuous with the mesorhinic fissure.

Besides this fissure in embryos of the second month, His finds a sickle-like fissure extending posteriorly beginning in the region of the terminal plate. He finds also that in many cases the mesenchyme fills the fissure and that there are no evident postmortem artefacts. He finds the same kind of thickening in the medial wall in the cat embryos of $14 \mathrm{~mm}$. G. L., as Zuckerkandl ('01) showed in his paper on the development of the corpus callosum. The hintere Bogenfurche lies dorsal to the fissure of the choroid plexus, its anterior limit does not pass beyond the terminal plate. This fissure is undoubtedly the one the writer has identified as the fissura hippocampi. However, besides these, His described another, the 'accessoriche Bogenfurche,' in his drawings of three- and four-month embryos. This lies on the anterior part of the medial wall, arching over the terminal plate. The writer finds nothing to correspond with this fissure and considers it an artefact. 
Martin ('94), on the other hand, uses vordere Bogenfurche as synonymous with fissura prima and reports that it appears dorsal to the choroid fissure. He thinks also that the hintere Bogenfurche, a groove in the medial wall in the midst of the posterior hippocampus, does not join the anterior Bogenfurche until later in development. If his illustrations are carefully studied, it appears that Martin's vordere Bogenfurche is the anterior limb of the hippocampal fissure and seems to become continuous with the hintere Bogenfurche when the tip of the temporal pole has grown ventrally and rostrally. This finding, if so interpreted, agrees in all points with mine. There can be no doubt that Martin's vordere Bogenfurche and His' fissura prima are not the same. Grönberg ('01), however, found no separation of the Bogenfurche into anterior and posterior limbs in the hedgehog. This finding of Grönberg agrees in all points with that in man, namely, a fissure coextensive with the primordium of the hippocampus upon the medial wall.

Such workers as Hochstetter, Retzius, Goldstein, and Symington report that in the region of the primordium hippocampi there is a slight thickening of the wall, but no definite infolding, although upon careful examination the medial wall at this point is not smooth. In other words, these fundamental findings agree with those presented in this paper. Investigators who concerned themselves with well-fixed brains of the third and fourth month did not find the radial folds of the earlier work, nor could they identify the fissura arcuata of His. The confusion arose out of failure to distinguish between artefacts of fixation and the accentuation of normal findings. There is no doubt but that maceration plays havoc with the normal contour of the medial wall of the hemisphere before the fibers of the corpus callosum have lent their stiffness toward its support. His failed to emphasize the histological structure which he found in the fissura arcuata as peculiarly distinguishing that fissura from the accessory fissure above.

My special contribution to this particular phase of the investigation is the discovery that at a certain stage in development, the fissura hippocampi is coextensive with the hippocampal 
primordium and that, as cortical differentiation proceeds in that portion which lies anterior to the velum transversum, the hippocampal fissure disappears. But posterior to the velum transversum the fissura remains as the adult fissura hippocampi (fig. 51, sketch D).

\section{The relation of the hippocampus to the neopallium}

The tissue which manifests the most marked and most regular acceleration is the neopallium. In the youngest embryo there is no clear line of lateral demarcation of this tissue. But in the 14-mm. the wall of the ventro-lateral sector is noticeably much thickened. This division between the two lateral sectors is more marked in the 19.1-mm., where a slight ventricular groove appears. The position of the hippocampus in the developing vesicle depends largely upon the amount of neopallium joining the hippocampus and the latero-ventral complex. Further, the intrinsic differentiation of the neopallium which is first seen in the 27.8-mm. progresses more rapidly than that of the hippocampus, although that tissue was the first to become at all evident in the developing telencephalon. The process of evaginaton is largely one of growth between the hippocampus and the region of the pyriform lobe, uncus and tail of the caudate nucleus.

The appended table 5 gives an idea of the relative differentiation in the vesicle of these various embryos.

With these data in hand two factors appear to be involved in the position of the developing archipallium. The first of these is the disposition of the old cortex in the wall of evagination, coincident with the noteworthy acceleration of the neopallium. The second factor is the intrinsic differentiation of the hippocampus itself. From these relationships it is possible to delineate the method of growth in the evaginating telencephalon.

Recalling the form of the telencephalon at a stage where no cortical area has been evaginated from the telencephalon medium into the cerebral hemisphere as exemplified by the case of Ichthyomyzon concolor already cited (Herrick and Obenchain, '13, figs. 3 and 4), it is evident that in the process of further 
evagination the most dorsal edge of the massive side wall will become the most ventral edge of the complete evagination and help form the roof of the foramen Monroi (p. 126). Anterior to the lamina terminalis the most dorsal border will meet the most ventral edge, making a seam or junction along the medial wall of the growing telencephalon.

This seam or junctional zone on the medial wall of the cerebral hemisphere in front of the lamina terminalis is always marked in amphibian and reptilian brains by a cell-free limiting zone and often by a ventricular groove, a sulcus limitans hippocampi. This area is necessarily transitional in type because, besides the approximation of the hippocampal formation with the septum (the primitive dorsal column with the primitive ventral column), it marks the union of the thinner dorsal part of the telencephalic roof plate bordering the hippocampal formation with the septum, the major portion of which sooner or later becomes greatly thickened. The sulcus limitans hippocampi marks the border of the hippocampal formation for its entire length, and rostral to the foramen interventriculare it also marks the junction of the hippocampal formation with the septal complex.

In this series the cerebral hemispheres of the 11.8-mm. embryo have reached what may be called the first stage in the evagination; the primordial hippocampus is dorsal throughout and there is no medial wall anterior to the lamina terminalis. The hippocampal formation lies as a crescent over the top of this evagination, never quite reaching either the anterior or the posterior pole of the vesicle, yet lateral and dorsal to the sulcus limitans hippocampi. In the $14-\mathrm{mm}$. the hippocampus is entirely medial, anterior to the angulus terminalis, and climbs, as it were, over the crest of the hemisphere to the posterior pole. Here again the differentiation only approaches the posterior pole, but does not reach it. The amount of neopallium is greater in this embryo at the anterior pole than at the posterior. This process continues, so that the formation in the $19.1-\mathrm{mm}$. and the $20-\mathrm{mm}$. lies entirely upon the medial wall. In the latter embryo, however, the neopallial tissue in the posterior pole has increased. In the $27.8-\mathrm{mm}$. and the $32.1-\mathrm{mm}$. the neopallium has grown greatly 
Summary of dea

\begin{tabular}{|c|c|c|c|c|c|c|c|}
\hline \multicolumn{2}{|c|}{ EMBRYO } & \multirow{2}{*}{$\begin{array}{l}\text { TUBERC ULUM } \\
\text { OLFACTOREM ; } \\
\text { OLFACTORY BULA }\end{array}$} & \multirow[b]{2}{*}{ SEPTLM } & \multicolumn{4}{|c|}{ AREA CHORIOIDEA } \\
\hline 当安 & 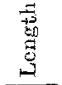 & & & $\begin{array}{c}\text { Septum } \\
\text { ependymale }\end{array}$ & $\begin{array}{l}\text { Area } \\
\text { inter- } \\
\text { calata }\end{array}$ & $\begin{array}{l}\text { Lamina } \\
\text { epithelialis }\end{array}$ & Cors \\
\hline 1121 & $\begin{array}{l}m m . \\
11.8\end{array}$ & Olfactory fila only & Thick wall & Thin wall & $\begin{array}{l}\text { Thin } \\
\text { wall }\end{array}$ & Thin wall & $\begin{array}{r}\text { Ventre } \\
\text { thic: }\end{array}$ \\
\hline 940 & 14.0 & $\begin{array}{l}\text { Olfactory fila }+ \text { a } \\
\text { slight evagination }\end{array}$ & Same & Sarue & Same & $\begin{array}{l}\text { Concave out- } \\
\text { ward }\end{array}$ & $\begin{array}{l}\text { Angul } \\
\text { peas } \\
\text { al } \\
\text { thic] }\end{array}$ \\
\hline $\mathrm{H} 173$ & 19.1 & $\begin{array}{l}\text { Same with slightly } \\
\text { more evagination; } \\
\text { cortex of tubercu- } \\
\text { lum olfactorium } \\
\text { just visible }\end{array}$ & $\begin{array}{l}\text { Nucleus medialis } \\
\text { septi }\end{array}$ & Samo & Same & $\begin{array}{l}\text { Lateral cho- } \\
\text { roid plexus }\end{array}$ & $\begin{array}{l}\text { Two } t \\
\text { few } \\
\text { later }\end{array}$ \\
\hline 400 & 20.0 & $\begin{array}{l}\text { Same; cortex of tu- } \\
\text { berculum more } \\
\text { prominent }\end{array}$ & $\begin{array}{l}\text { Same plus margi- } \\
\text { nal velum }\end{array}$ & Same & Sane & Same & Same \\
\hline H91 & 27.8 & $\begin{array}{l}\text { True olfactory bulb } \\
\text { and fissura prima; } \\
\text { same }\end{array}$ & Same & $\begin{array}{l}\text { Same + mar- } \\
\text { ginal velum }\end{array}$ & Same & $\begin{array}{l}\text { Posterior limb } \\
\text { oflateraleho- } \\
\text { roid plexus } \\
\text { greater in } \\
\text { extent }\end{array}$ & $\begin{array}{l}\text { Marke: } \\
\text { cells } \\
\text { theot } \\
\text { and } \\
\text { lum }\end{array}$ \\
\hline $\mathrm{H} 41$ & 32.1 & $\begin{array}{l}\text { Same }+ \text { differentia- } \\
\text { tion of layers of } \\
\text { bulb }\end{array}$ & $\begin{array}{l}\text { Beginning of nu- } \\
\text { cleus laterulis } \\
\text { septi }\end{array}$ & $\begin{array}{l}\text { Increase in } \\
\text { marginal } \\
\text { velum, } \\
\text { whole area } \\
\text { thicker }\end{array}$ & Same & Same & $\begin{array}{r}\text { Same } \\
\text { nale }\end{array}$ \\
\hline H.163 & 39.1 & $\begin{array}{l}\text { Same; pronounced } \\
\text { islands of Calleja }\end{array}$ & $\begin{array}{l}\text { Large nucleus lat- } \\
\text { eralis septi }+ \\
\text { nucleus accum- } \\
\text { bens, anterior } \\
\text { commissure }\end{array}$ & $\begin{array}{l}\text { Wide margi- } \\
\text { nal velum }\end{array}$ & Same & Same & $\begin{array}{l}\text { Nucleu } \\
\text { inter } \\
\text { nal o }\end{array}$ \\
\hline 886 & 43.0 & Same & Same & Same & Same & Same & Same \\
\hline
\end{tabular}


s of the cerebral hemisphere

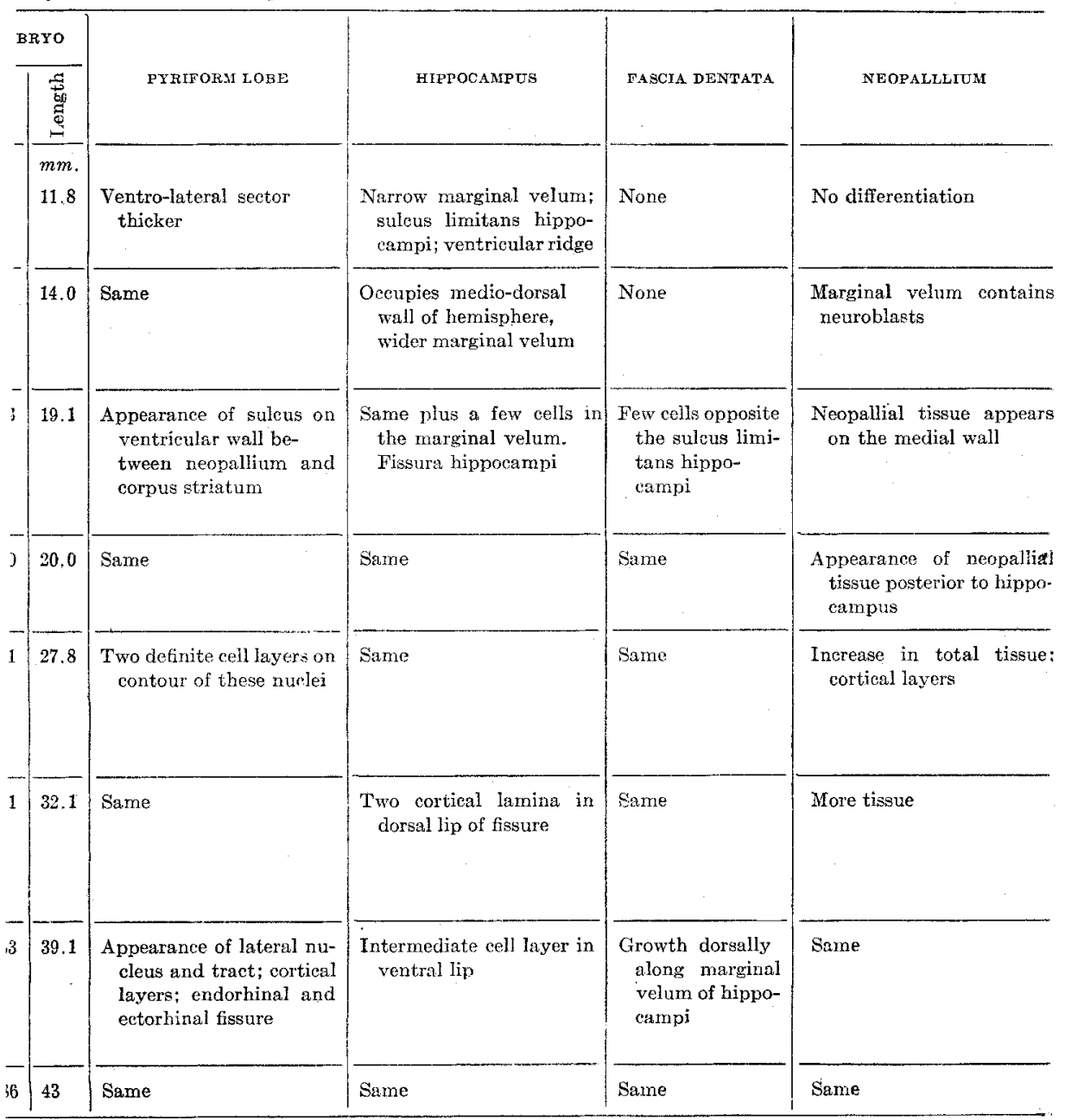


in the posterior pole and the hippocampus has made the ventrocaudal twist into the temporal lobe so characteristic of it. In the last two embryos of the series, the $39.1-\mathrm{mm}$. and $43-\mathrm{mm}$., remarkable growth has taken place in all regions of the neopallium, so that relatively little area, comparatively speaking, contains the hippocampal formation. And it is worth noting that the major portion of the hippocampus in these last two brains lies in the medial wall posterior to the velum transversum. Thus tracing the history of its position in the developing hemisphere lends adequate support to a portion, at least, of Herrick's quadrant theory of telencephalic evagination. But, further, this brief history of hippocampal position points to the conclusion that its extent is inversely proportional to neopallial growth. It also gives some facts concerning the regional acceleration of this neopallial growth, namely, that acceleration seems to shift from the frontal to the dorsal and then to the posterior poles of the developing hemisphere.

Concomitant with this change there is the intrinsic differentiation characteristic of the hippocampus itself. Although set aside as the first cortical area, its subsequent differentiation progresses so slowly that such layers as are characteristic of the cortex appear in the neopallium long before they are completed in the hippocampus.

The differentiation does not proceed in any logical sequence, but seems rather to be subject to rhythms of acceleration. These rhythms of acceleration do not correspond absolutely to those expressed in any arrangement of the adult brains of the vertebrate phylum. In other words, given the stage in human development of the hippocampus, the differentiation of the fascia dentata or the neopallium will not correspond to the phylogenetic development of the first-named tissue. It is possible, however, to take any one tissue and follow it through a complete development whose changes fit into its phylogeny. The developing neopallium seems to act as a disturbing factor, not, however, as one which obliterates, but rather as one which obscures the phylogenetic history by suddenly leaping into the foreground and by its great increase in amount and complexity of tissue 
demanding immediate and engrossing attention. It is a disturber of growth rhythms and an obscurer of elementary phylogenetic 'patterns.' It is the belief of the writer that there is actually some relationship between these two; that is, that the acceleration of the neopallium results in a change of rhythm of growth in different parts although it has no effect upon the actual differentiation, except that of obscuring it.

\section{SUMMARY}

1. The medial wall of the cerebral hemisphere of human embryos $16 \mathrm{~mm}$. to $30 \mathrm{~mm}$. in length is not 'perfectly smooth.' Its otherwise even contour is broken by a shallow groove. This groove extends from the region of the olfactory bulb to the tip of the temporal pole. It is the fissura hippocampi, the 'Bogenfurche' of His. It is homologous with the fissura arcuata of reptiles as described by Herrick.

2. In embryos as young as $11 \mathrm{~mm}$. the primordial hippocampus can be recognized along the line of the future fissura hippocampi. This primodium is identified by the following histological peculiarities: ]) a thicker wall;2) a narrower matrix; 3) a clearly defined margiral velum; 4) a limiting sulcus, the sulcus limitans hippocampi. This is the first cortical differentiation known in man.

3. The fascia dentata arises in the matrix of the hippocampal formation from cells in the dorsal limb of the sulcus limitans hippocampi. These cells grow dorsalward, slipping along the marginal velum of the hippocampus. In the series studied no other cortical differentiation has occurred in this region. It is comparable to the persistent primordium hippocampi of amphibians and reptiles.

4. The fissura prima of His first appears in embryos of about $25 \mathrm{~mm}$. The appearance s coincident with the marked evagination of the olfactory bulb. It has no connection with either the fissura hippocampi or the hippocampal primordium.

5 . The various regions of the telencephalon medium are distinguished by a characteristic morphology and histology in all the embryos of this series except the $11.8-\mathrm{mm}$. In the 
remainder of the group described the angulus terminalis separates the midline structures into terminal plate and roof. The former is the lamina terminalis; the latter, the area chorioidea. The lamina terminalis increases in length and width throughout the series. The area chorioidea changes little in total length. Its anterior division, the tela chorioidea telencephali medii, is practically stationary. Its posterior division, the paraphyseal arch, in the younger embryos forms a tent-like evagination in the roof; in older stages it may become a pouch-like paraphysis with two lateral pockets.

6. The portion of the medial wall of the hemisphere contiguous with the area chorioidea and the dorsal thin part (pars tenuis) of the lamina terminalis is termed the area epithelialis. It may be divided into the following parts, enumerated from ventral to dorsal borders:

1) The septum ependymale (fig. 14, Sept. epen.) is that portion of the area epithelialis which lies ventrally of the angulus terminalis and borders the dorsal thin portion of the lamina terminalis. In later stages it thickens, beginning at the ventral border, differentiating first into matrix and marginal velum, with later migration of neuroblasts of the septal nuclei into the latter. The dorsal portion remains thin and undifferentiated.

2) The area intercalata (figs. 14, 16, A. int.) lies contiguous to the tela chorioidea telencephali medii. It remains membranous and increases but slightly in total surface and thickness.

3) The lamina epithelialis (figs. 14, 16, Lam. ep.) borders the paraphyseal arch and becomes transformed into the lamina epithelialis of the lateral choroid plexus of the adult. Its anterior moiety subtends the paraphyseal arch and the invagination of the choroid fissure begins between the $14-\mathrm{mm}$. and the 16-mm. stages. Its posterior moiety contiguous to the ditelencephalic fold of the velum transversum thereafter rapidly expands.

7. The neopallium grows more rapidly than any other part of the telencephalon. Its initial differentiation follows that of the hippocampus; its subsequent development surpasses that of the latter. The identification of the future hippocampus in the 
young stages suggests a certain type of relative growth in the telencephalon. In measuring the growth of the histologically distinct regions of the telencephalon medium and the areas contiguous to them, lying in the evaginated portion of the hemisphere, we are able not only to measure the relative amount of growth of the telencephalon, but also to determine the manner in which this growth takes place.

In the embryos studied the medial wall was observed to grow in the following manner: first, by the intrinsic growth in the midline, especially in the region of the lamina terminalis and in that of the di-telencephalic fold; second, by the out-growth of a series of arcs of new tissue which forms the incipient frontalparietal, occipital, and temporal poles.

\section{BIBLIOGRAPHY}

Anton, G. 1886 Zur Anatomie des Balken Mangels im Grosshirne. Zeits. für Heilkunde, Bd. 7, Prag, S. 53-64.

BAilex, P. 1916 a Morphology of the roof plate of the forebrain and lateral choroid plexuses in the human embryo. Jour. Comp. Neur., vol. 26, p. 79 .

$1916 \mathrm{~b}$ The morphology and morphogenesis of the choroid plexuses with special reference to the development of the lateral choroid plexus in Chrysemys marginata. Jour. Comp. Neur., vol. 26, p. 507.

Bischoff, T. L. W. 1868 Die Grosshirnwindungen des Menschen. Adh. d. k. Bayerisch Akad. d. Wiss., Bd. 10, Abth. II, S. 446.

CAJAL, S. R. Y 1911 Histologie du Système Nerveux de l'homme et des Vertébrés. Paris, T. 2, pp. 752-754.

Crosby, E. C. 1917 The forebrain of Alligator mississippiensis. Jour. Comp. Neur., vol. 27, pp. 325-402.

Cunningham, D. J. 1892 Contribution to the surface anatomy of the cerebral hemispheres. Dublin.

ECKer, Alex. 1869 Zur Entwicklungsgeschichte der Furchen und Windungen der Grosshirn Hemisphären im Foetus des Menschen. Archiv f. Anthrop., Bd. 3, S. 203-225.

Goudstein, K. 1904 Zur Frage Existenzberichtigung, ete. Anat. Anz., Bd.24, S. 579-595.

Grönberg, G. 1901 Die Ontogenese eines niedern Säugergehirns nach Untersuchungen an Erinaceus europaeus. Zool. Jahr., Abth. Morph., Bd. 15, S. 261.

Herrick, C. J. 1910 The morphology of the forebrain in Amphibia and Reptilia. Jour. Comp. Neur., vol. 20, pp. 413-547.

Hıs, W. 1890 Die Formentwicklung des menschlichen Vorderhirnes. Abh. Math.-phys. Kl. des Kg. Sächs. Ak. d. Wiss. Leipzig. 
His, W. 1889 Die Formentwicklung des menschlichen Vorderhirns vom ersten bis zum Beginn des dritten Monats. Abh. math.-phys. Kl. d. Kgl. Sächs Ges. Wiss., Bd. 15, S. 675-736.

1904 Die Entwicklung des menschlichen Gehirns. Leipzig.

Hochstetrer, F. 1898 Beiträge zur Entwicklungsgeschjchte des Gehirns. Stuttgart.

1904 Ueber die Nichtexistenz der sogenannten Bogenfurche an den Gehirnen lebenfrisch konservierter Menschlicher Embryonen. Anat. Anz., Bd. 25, Ergänzungsheft, S. 27-34.

Johnston, J. B. 1909 On the morphology of the forebrain vesicle in vertebrates. Jour. Comp. Neur., vol. 19, pp. 457-539.

1913 Morphology of the septum, hippocampus, and pallial commissures in reptiles and mammals. Jour. Comp. Neur., vol. 23, pp. $371-438$.

1915 Cell masses in the forebrain of the turtle, Cistudo carolina. Jour. Comp. Neur., vol. 25, pp. 393-468.

Köllikar, A. 1879 Entwicklungsgeschichte des Menschen und der höheren Thiere, Ed. 2. Leipzig.

Levi, Gruseppe 1904 a Ueber die Entwicklung und Histogenese der Ammonshornformation. M. Schultze Archiv, Bd. 64, pp. 389-403.

$1904 \mathrm{~b}$ Sull'origine filogenetica della formazione ammonica. Archivio Anat. Embriol., T. 3, pp. 234247.

MaLL, J.P. 1903 On the transitory or artificial fissures of the human cerebrum. Am. Jour. Anat., vol. 2, p. 333.

MaRChaNd, F. 1891 Ueber die Entwicklung des Balkens im menschlichen Gehirn. Arch. f. mikr. Anat., Bd. 37, s. 298-334.

1909 Entwicklung von Mangel des Balkens im menschlichen Gehirn. Abh. der Königl. Sächs. Gesellschaft der Wissenschaften, 58, Math. Phys., Klasse, 31, pp. 371-402.

Martin, Paut 1894 Bogenfurche und Balkenentwicklung bei der Katze. Jenaische Zeitschrift für Naturwissenschaft, Bd. 29, Neue Folge 22, S. 221.

Mecked, J. F. 1815 Deutsches Arch. f. Physiol. Halle und Berlin, S. 1-108; $334-422$.

Miнalkovics, V. 1876 Die Entwicklung des Gehirnesbalken und des Gewölbes. Centralbl. f. d. med. Wiss. nr. 19.

Mingazzini, G. 1888 U. d. Entwklg. Furchen und Windung des menschlichen Gehirns. Moleschott's Untersuchungen zur Naturlehre, Bd. 13, S. $498-562$.

Meyer, A. 1892 Ueber das Vorderhirn einiger Reptilien. Zeit. f. wiss. Zool.; Bd, 55, S. 63-133.

Retzids, G. 1901 Zur Frage von den sogenannten transitorischen Furchen des Menschengehirns. Anat. Anz., Engänzungsheft, Bd. 19, S. 91. 1902 Zur Frage der transitorischen Furchen des embryonalen Menschenhirns. Biol. Untersuchungen, Neue Folge, Bd. 10, Stockholm, S. 65 .

Richter, A. 1887 Ueber der Windungen des menschlichen Gehirns. Virchow's Archiv, Berlin, Bd. 108, S. 398-422. 
SchapdR, A. 1904 Zur Frage der Existenzberichtigung der Bogenfurchen am Gehirne menschlicher Embryonen. Anat. Anz., Ergänzungsheft, Bd. 25, S. 35-37.

Schmid, F. 1862 Beiträge zur Entwicklungsgeschichte des Gehirns. Zeitschr. f. wiss. Zool., Bd. 11, S. 43-51; 64-65.

Smith, G. Elliot 1894 a A preliminary communication upon cerebral commissures of the Mammalia. Proceedings Linnean Society of New South Wales, vol. 2, series 2, Oct., p. 655 .

$1894 \mathrm{~b}$ Brain of foetal Ornithorhynchus. The forebrain. Quart. Jour. of Mier. Sc., vol. 39.

1895 The comparative anatomy of the cerebrum of Notoryctes typhlops. Trans. Royal Soe. of South Australia, p. 167.

1896 The fascia dentata. Anat. Anz., Bd. 12.

1897 a The origin of the corpus callosum. Trans. Linnean Soc. of London, 2 series, vol. 7, pp. 47-69.

$1897 \mathrm{~b}$ Further observations upon the fornix, with special reference to the brain of Nyctophilus. Jour. of Anat. and Phys., vol. 32, pp. 231-246.

$1897 \mathrm{c}$ The relation of the fornix to the margin of the cerebral cortex. Jour. Anat. Phys., vol. 32, pp. 23-58.

$1897 \mathrm{~d}$ The morphology of the indusium and striae Lancisii. Anat. Anz., vol. 13, pp. 23-27.

1899 Further observations on the anatomy of the brain in the Monotremata. Jour. Anat. Phys., vol. 33, p. 309.

1903 Note on the so-called 'transitory fissures' of the human brain, with special reference to Bischoff's 'Fissura perpendicularis externa.' Anat. Anz., Bd. 24, S. 216-220.

1910 Some problems relating to the evolution of the brain. The Lancet, Jan. 1, 15, 22.

Symingron, J. 1901 Report of the British Ass. for the Advancement of Science. Glasgow, p. 798.

Timdemann, F. 1816 Anatomie und Bildungsgeschichte des Gehirns die Foetus des Menschen. Nürnberg.

1823 Anatomie du cerveau contenant d'histoires de son developpement dans le foetus avec une exposition comparative de la structure dans les animaux. Trans. par. A. L. Jurdain, Paris, 1823.

WARREN, J. 1917 The development of the paraphysis and pineal region in Mammalia. Jour. Comp. Neur., vol. 28, pp.75-136.

ZuCKerkandL, E. 1901 Zür Entwicklung des Balkens und des Gewölbes. Sitzungsber. d. K. Ak. d. Wissenseh. in Wien. Mathem. nat. Klasse, Bd. 110, Abt. III, S.57. 